دراسة إقتصادية لمحصول الذرة الرفيعة الصيفية بمحافظة أسيوط

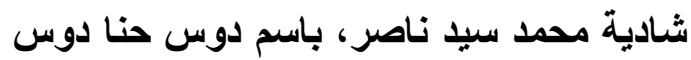

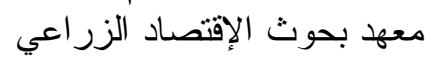

Received on: $31 / 10 / 2016$

Accepted for publication on: 13/11/2016

مقدمة:

يعتبر محصول الذرة الرفيعة من محاصبل الحبوب الغذائية الهامة في مصر ، حيث يعتبــر

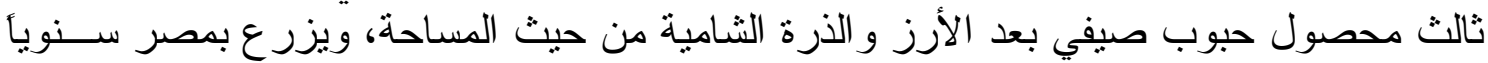

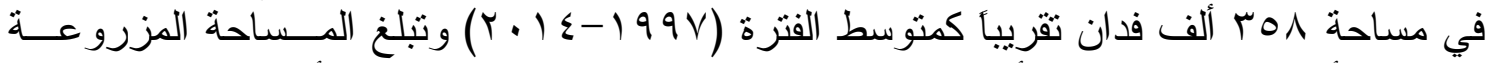

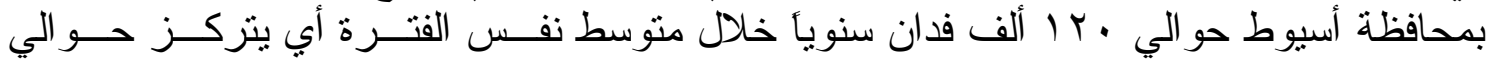

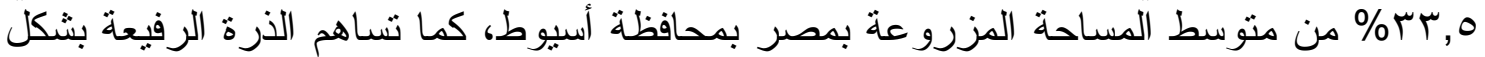

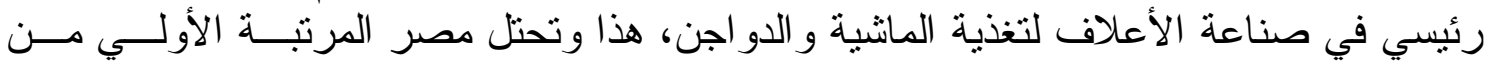
حيث الغلة الفدانية بين دول العالم المنتجة لهذا المحصول.

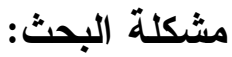

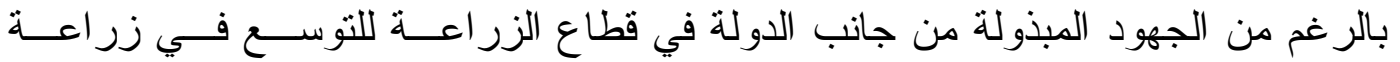

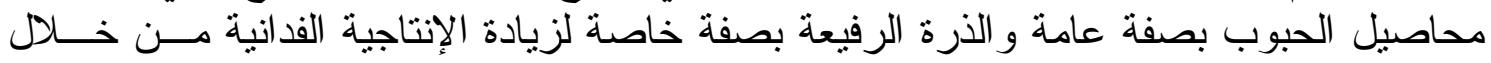

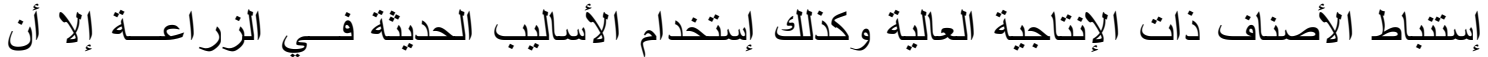

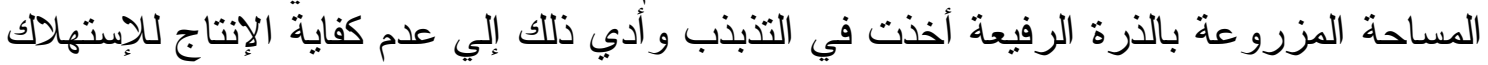

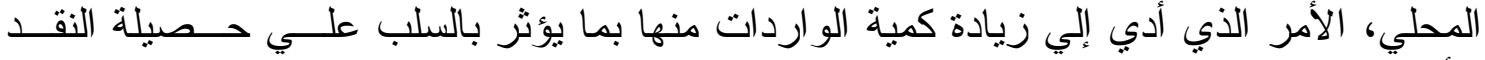

يستهدف البحث التعرف علي الإمكانيات الإنتاجية لمحــصول الــذرة الرفيعــة الــصيفية

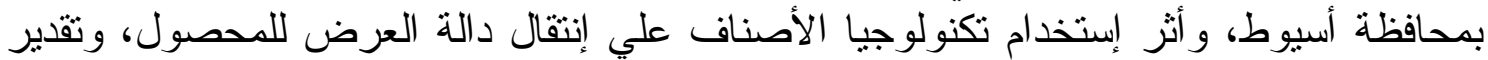

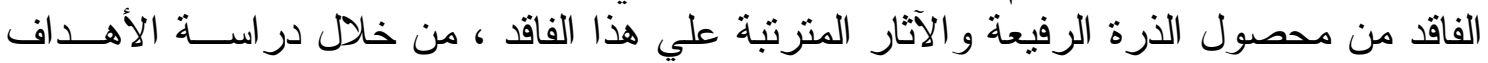

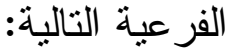

أو لاً: تطور الطاقة الإنتاجية لمحصول الذرة الرفيعة الصيفية في مصر ومحافظة أســـيوط

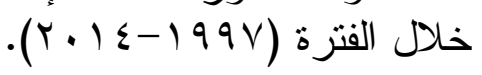

ثانياً: التقدير الإحصائي لدو ال الإنتاج الفيزيقية الفية لمحصول الذرة الرفيعة الــصيفية بالعينــة البحثية بمحافظة أسيوط.

ثالثنا: التقدير الإحصائي لدو ال التكاليف الإنتاجية لمحصول الذرة الرفيعة الصيفية بالعينــة البحثية بمحافظة أسيوط.

رابعاً: در اسة بعض مؤشر ات الكفاعة الإنتاجية و الإقتصادية في الفئــات الحيازيــة بعينــة

خامسأ: در اسة أثر إستخدام تكنولوجيا الأصناف علي إنتقال دالة العرض لمحصول الــذرة الرفيعة بمحافظة أسيوط. سادسأ: تقدير الفاقد من محصول الذرة الرفيعة بعينة البحث بمحافظة أسبوط.

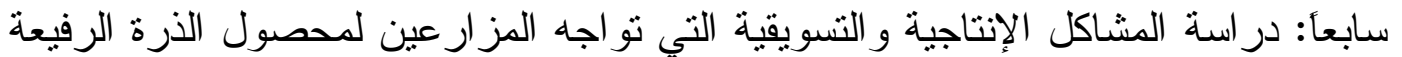

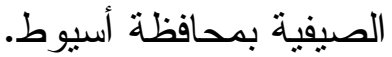
مصادر البيانات و أسلوب البحث: إعتمد البحث في الحصول علي البيانات اللازمة له له علي مصدرين رئيسيين: 
أولهما بيانات ثانوية منشورة وغير منشورة من نشر ات الإقتصاد الزر اعي، وسجلات قسم

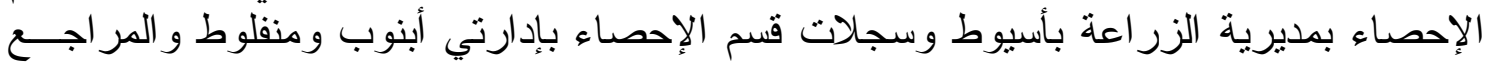

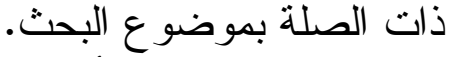

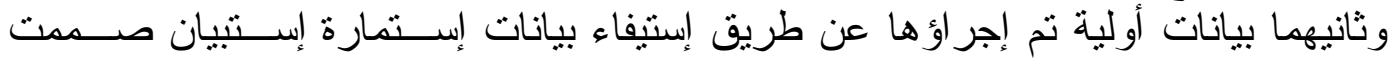

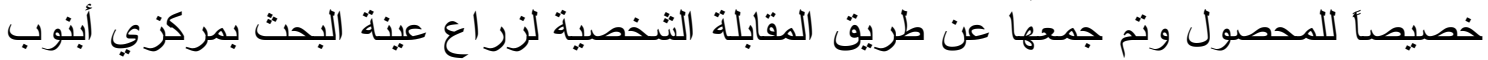

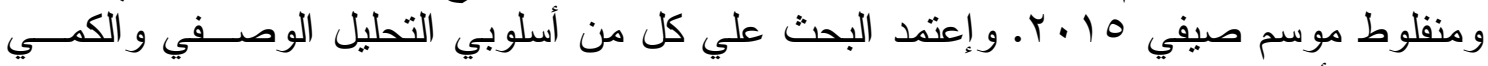
و إستخدام أسلوب الإنحدار البسيط في تقدير الإتجاه الزمني العام وكذلك تم الإســتعانة بإســتخدام

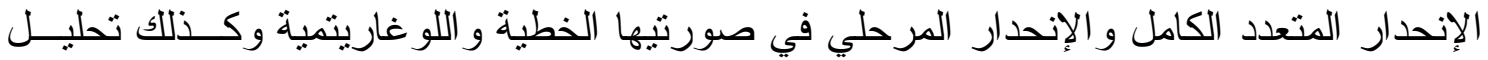

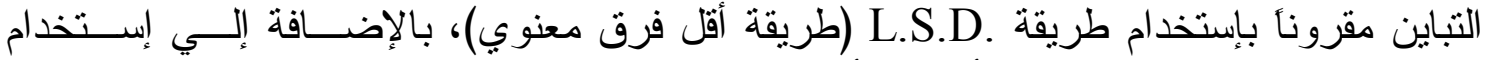

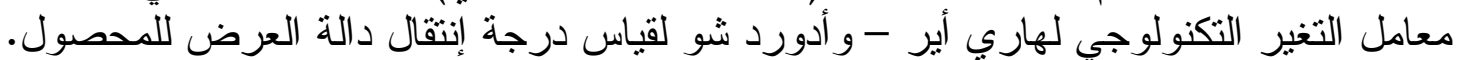
وصف عينة البحث:

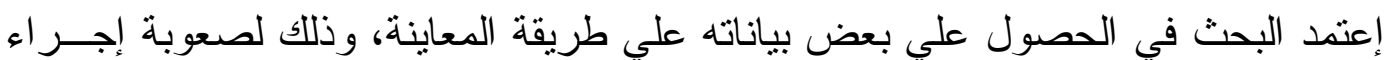

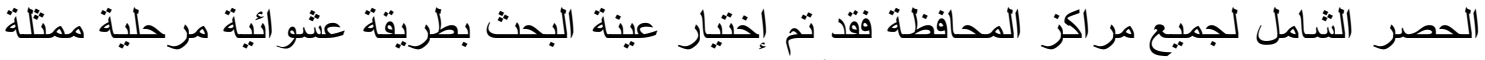

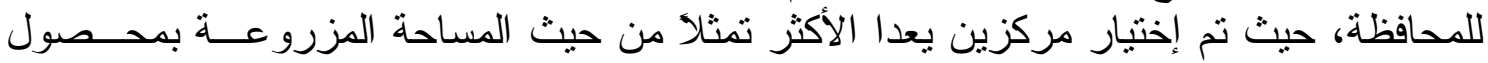

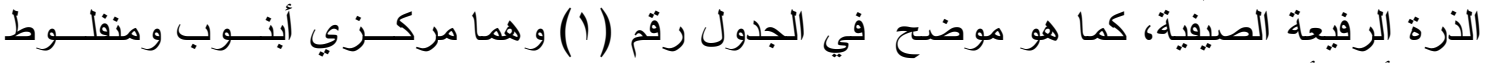

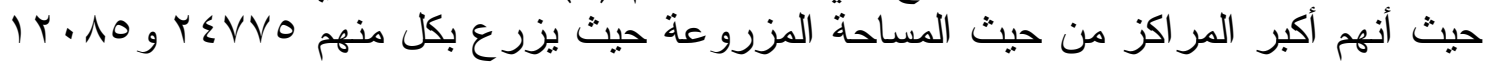

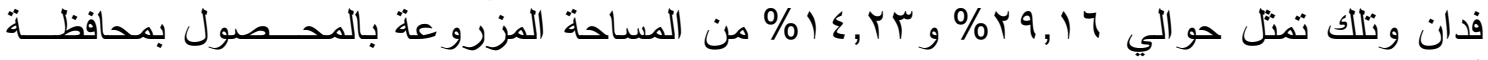

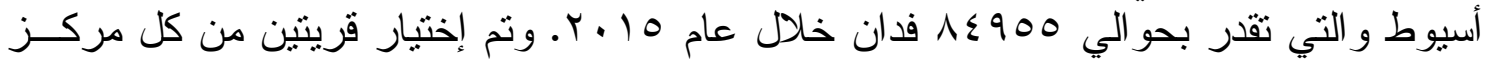

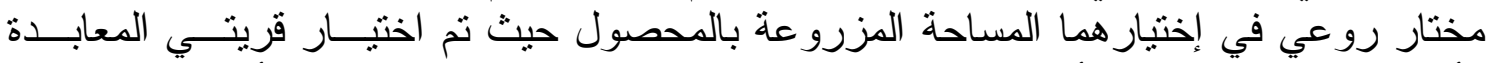

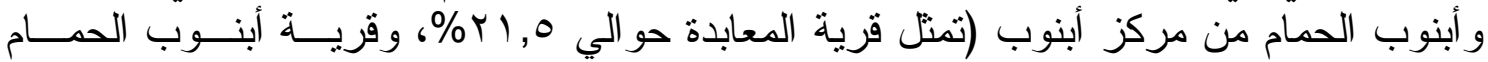

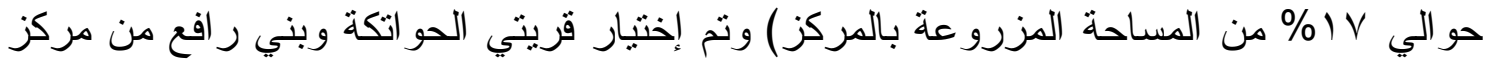

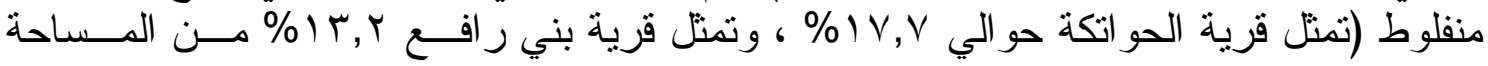

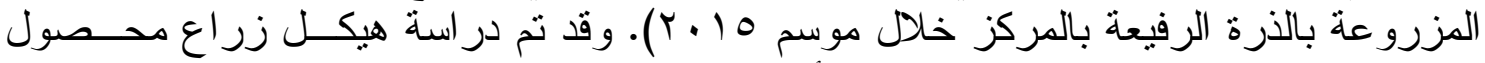

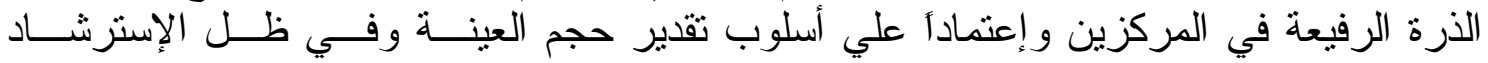

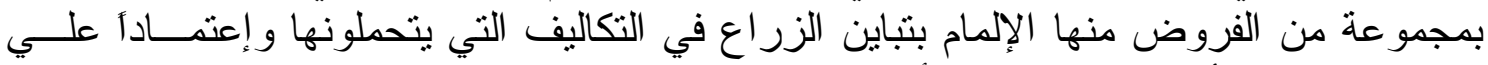

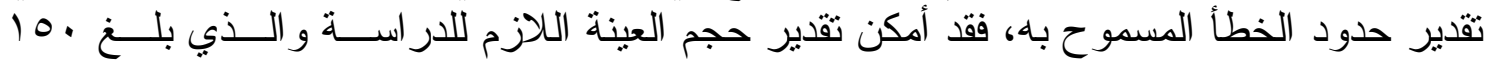

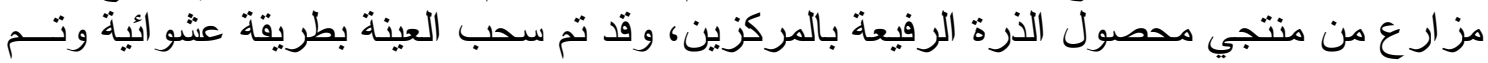

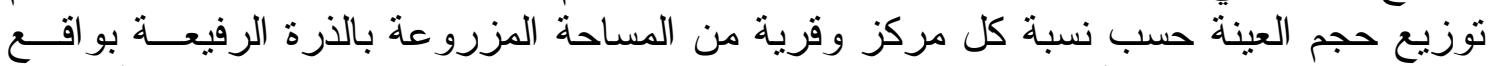

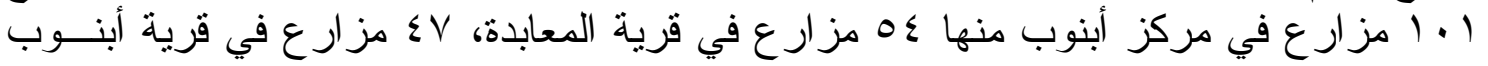

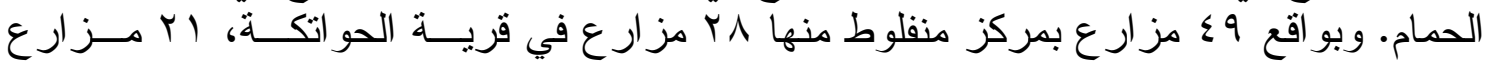

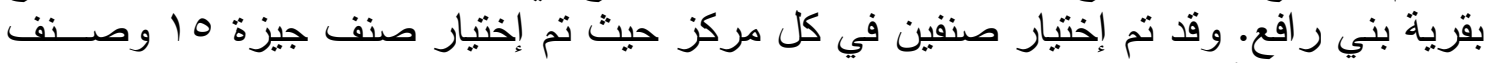

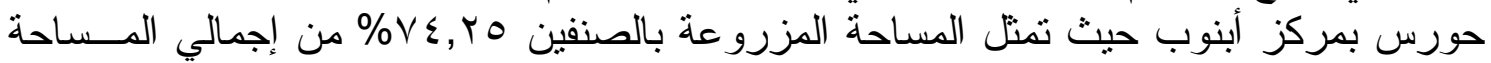

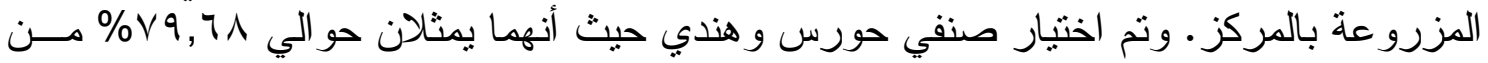

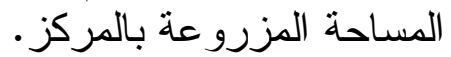
وقد تم تقسيم المزار ع عة إلي ثناث فئات حيازية علي النحو التالي:

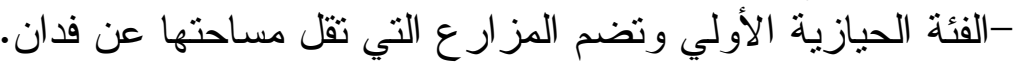
-الفئة الحيازية الثانية وتضم المز الثية وتهارع التي تنز اوح مساحتها من فدان لأقل من ثلاثنة أفدنة. -الفئة الحيازية الثالثة وتضم المز ارية ونضية التي تبلغ مساحتها ثلاثة أفدنة فأكثر . 
جدول رقق 1 ـ مساحة محصول الذرة الرفيعة الصيفية بمر اكز محافظة أسيوط موسم ه 1 ـ r.

\begin{tabular}{|c|c|c|c|}
\hline الترتيب & $\%$ & المساحة (فدان) & المركز \\
\hline 7 & $V, Y \leq$ & $710 \leqslant$ & ديروط \\
\hline$r$ & $M, \Lambda$ & $1.0 \mathrm{~V} 1$ & القوصية \\
\hline T & $T \varepsilon, Y T$ & $1 T \cdot 10$ & منفلوط \\
\hline$\varepsilon$ & $9, \cdot 1$ & VVII & أسيوط \\
\hline 0 & $V, O r$ & (49 & أبوتيج \\
\hline 11 & $1, \cdot r$ & AVq & صدفا \\
\hline 9 & $1, r v$ & 1171 & الغناير \\
\hline 1 & Y9,17 & $r \leqslant V \vee 0$ & أبنوب \\
\hline $\mathrm{V}$ & 0,94 & $0 . \mu$. & الفتح \\
\hline 1. & $1,1 \varepsilon$ & $9 \vee Y$ & ساحل سليم \\
\hline$\Lambda$ & $1, \Sigma V$ & ITOY & البداري \\
\hline- & $9, \cdot r$ & VTVY & أر اضي جديدة \\
\hline- & $1 \ldots$ & $\Lambda \leqslant 900$ & الجملة \\
\hline
\end{tabular}

المصدر : وز ارة الزر اعة و إستصلاح الأر اضي، مديرية الزر اعة بأسيوط، سجلات قسم الإحصاء، بيانات غيـر

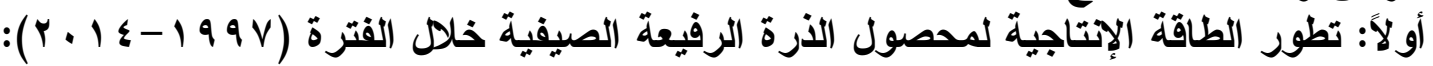

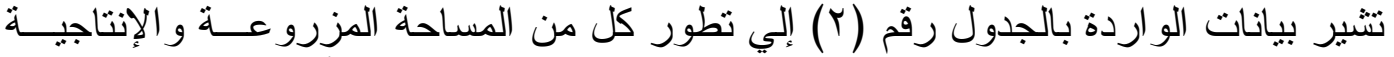

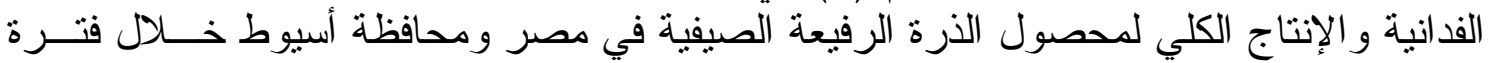

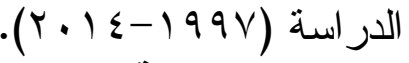
- تطور المساحة المزروعة والإتتاجية الفدانية والإتتاج الكلي لمحصول الأرة الرفيعة الصيفية

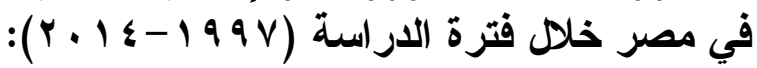

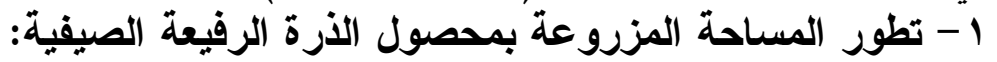

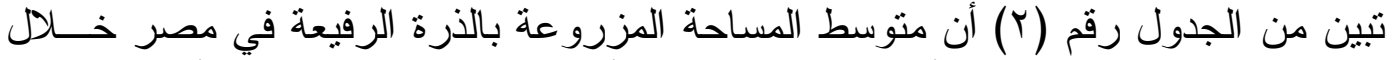

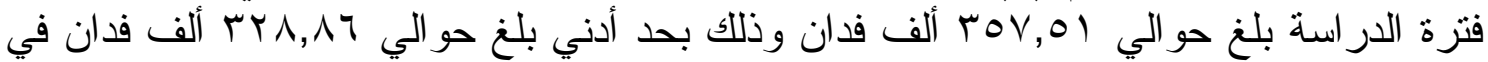

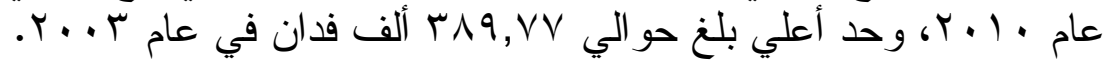

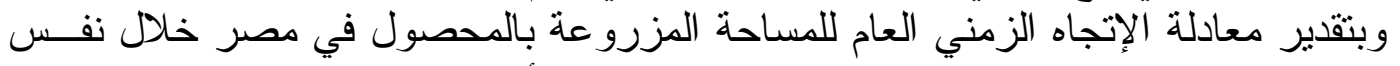

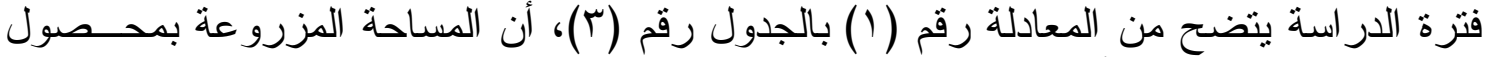

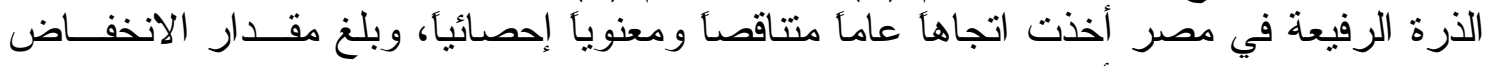

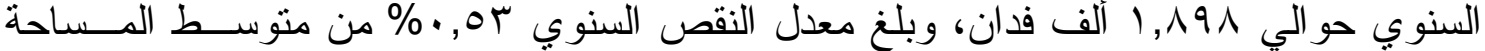

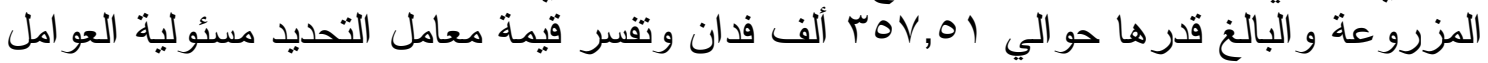

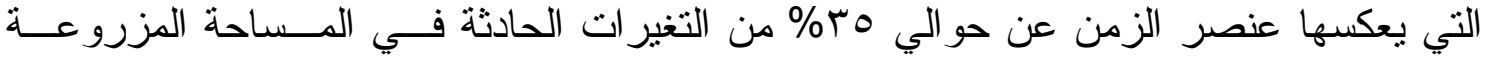

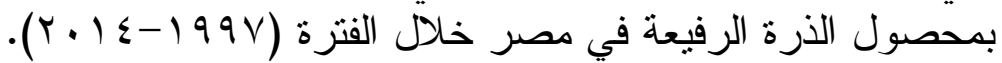
r - تطور الإتتاجية الفدانية لمحصول الأرة الرفيعة الصيفية:

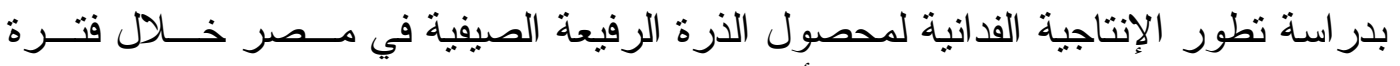

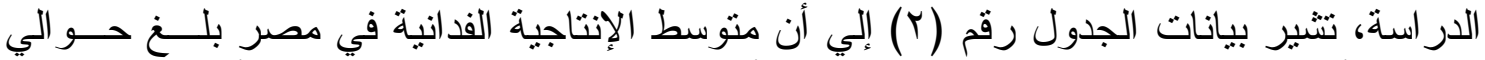

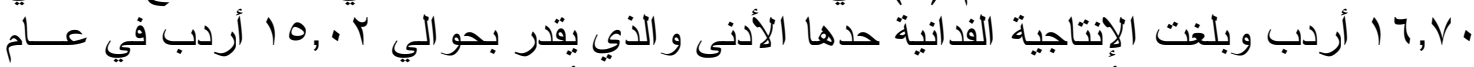

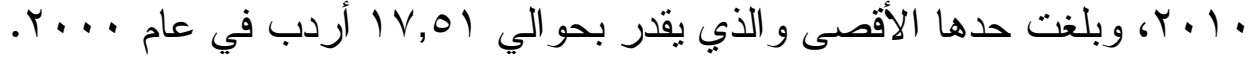


شادية محمد سبي ناصر، باسم دوس حنا دوس، 7 ب 1 r

جدول رقم r ـ تطور المساحة المزروعة والإتتاجية الفدانية والإنتاج الكلي لمحصول الــذرة الرفيعـة

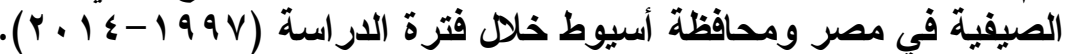

\begin{tabular}{|c|c|c|c|c|c|c|}
\hline \multicolumn{3}{|c|}{ محافظة أسيوط } & \multicolumn{3}{|c|}{ مصر } & \multirow[b]{2}{*}{ السنة } \\
\hline (ألفت أردب) الكلي & 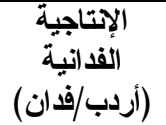 & المساحة المزروعة & (ألفت أردب) الكلي & (الأردباجية الفداندانية & المساحة المزروعة فدان) & \\
\hline 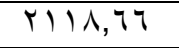 & $10, V Y$ & IrE,VA & $0 \leqslant V \leqslant, 0 r$ & $10, Y 1$ & $r \circ 9,9 r$ & $199 V$ \\
\hline$T E \cdot T, T Y$ & I^, $\varepsilon$. & $1 T \cdot, 07$ & $7 T \leq \cdot, 99$ & $I V, \cdot \Lambda$ & rצo,r) & 1991 \\
\hline r799,7. & $19, Y T$ & $1 \leq \cdot, V \cdot$ & 7790,19 & $I V, \varepsilon 0$ & 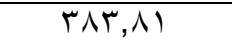 & 1999 \\
\hline YフI $\leqslant, \leqslant \wedge$ & 19,00 & MT,VT & $70 V 7,10$ & $|V, 0|$ & rVo,Tt & $r \ldots$ \\
\hline rrrq, ro & $19,1$. & $M Y, \Sigma V$ & 7109,10 & $1 v, r q$ & ros, IT & $r \ldots l$ \\
\hline$r \leq 1 \cdot, 1 \leq$ & $1 \Lambda, \cdot r$ & Ir,vo & $\pi r \varepsilon \cdot, \varepsilon r$ & IV,rV & rาะ,q1 & $r \ldots r$ \\
\hline YO $\leqslant 7, Y_{0}$ & IV,Or & $1 \leq 0, r_{0}$ & TVKร, 1ᄉ & $I V, Y \wedge$ & 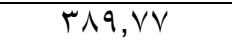 & $r \ldots r$ \\
\hline Y) $1,0$. & IV,rY & $1 Y 0,9 V$ & $7 \cdot \vee 9,11$ & $I V, I Y$ & $r 00, \cdot r$ & $r \ldots \varepsilon$ \\
\hline Y10 $0,7$. & IV,TV & $1 Y 1,94$ & $090 \wedge, \varepsilon \leq$ & 17,97 & rol,r. & $Y . .0$ \\
\hline rMTr,Tr & $1 \vee, 91$ & $\mid T 1, \Sigma 7$ & TYO0, हr & $I V, \cdot r$ & MTV,O & $r \ldots T$ \\
\hline$Y \backslash \vee 0,97$ & $1 \Lambda, 1 T$ & $M \cdot, \cdot r$ & $09 \cdot \varepsilon, 7$. & $I V, \ldots$ & $r \leqslant V, r \leqslant$ & $r \ldots V$ \\
\hline$Y 117,00$ & $1 V, 01$ & $M T_{\cdot}, \lambda T$ & TITr,I & $17, \wedge 7$ & אוז, & $r \ldots \Lambda$ \\
\hline $1 \wedge 09, Y \leq$ & IV,Tr & $1 \cdot 0, \leqslant 7$ & $00 Y 0, Y_{0}$ & 17,01 & rru, Iq & $r \ldots q$ \\
\hline $17 \wedge \wedge, 9 \vee$ & 10,97 & $1 \cdot 0, \lambda r$ & $\varepsilon q \mu q, r V$ & $10, \cdot r$ & 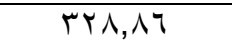 & $r \cdot 1$. \\
\hline$r \cdot T \wedge, r \wedge$ & $1 V, .0$ & $|r|, r \mid$ & OQMT,NI & $17, \cdot r$ & $r v \cdot, \cdot \Lambda$ & $r .11$ \\
\hline $100 \wedge, \varepsilon 9$ & $17, V \varepsilon$ & $94,1 \cdot$ & Ortr,or & $10,9$. & TrV,rr & $r .1 T$ \\
\hline $1 \leq V 0,7 Y$ & $I V, V V$ & $\Delta r, \cdot r$ & $0 \leqslant 19, \wedge Y$ & $17,1 V$ & rro,11 & $T \cdot I T$ \\
\hline $1 \leq \wedge 0,7 T$ & $1 \Lambda, Y V$ & NI,H & $\Delta \vee \backslash \wedge, \cdot r$ & $17, Y \leq$ & ror, . V & $r \cdot 1 \varepsilon$ \\
\hline 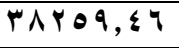 & - & $Y 101, Y 1$ & $1 \cdot v \leq 01$ & - & $7 \leq r 0, \cdot 9$ & الإجمالي \\
\hline YIYO,Or & $I V, V \wedge$ & 119,01 & $0979,0$. & $17, V$. & rov,01 & المتوسط \\
\hline
\end{tabular}

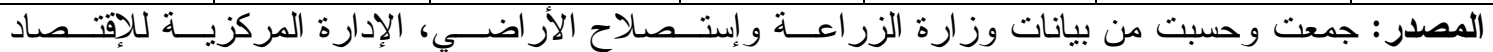

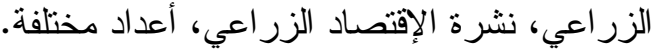

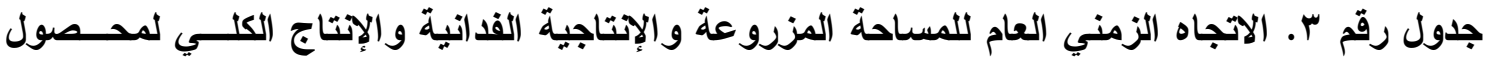

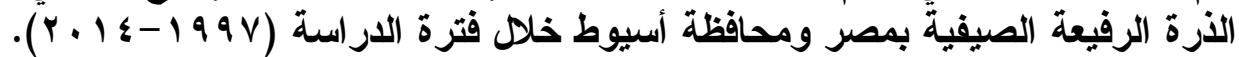

\begin{tabular}{|c|c|c|c|c|c|c|c|c|}
\hline السنوي التغير & التغنير & متوسط الظاهرة & ف & זנ & المعادلة & المتغير التابع & b & \\
\hline •, Or & $1, \wedge 9 \wedge-$ & rov,01 & $* * \wedge, \uparrow$. & •, ro. & 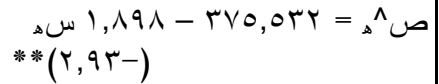 & (ألف فدانة) & 1 & \multirow{3}{*}{$\xi$} \\
\hline- & $\cdot, \cdot 7 \leqslant-$ & $17, V$ & $\varepsilon, \cdot 1$ & $\cdot, r \cdot r$ & 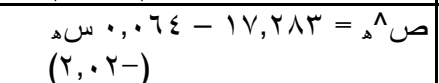 & ألإنتاجية & r & \\
\hline$\cdot, 91$ & $\varepsilon, 177-$ & 0979,0 & $* * \wedge$, or & $\cdot r \leqslant \Lambda$ & 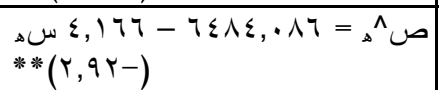 & (ألفت أردب) الكلي & $r$ & \\
\hline$r, \leqslant \uparrow$ & $r, q \leq r-$ & 119,01 & $* * \Gamma \wedge, 0 \wedge$ & $\cdot, V \cdot V$ & $\begin{array}{l}\Delta س r, q \leqslant r-1 \leqslant V, \leqslant 7 q={ }_{\Delta}^{\wedge} ص \\
* *(T, r)-)\end{array}$ & (ألف فدانة) & $\varepsilon$ & \multirow{3}{*}{$\overline{3}$} \\
\hline- & $\cdot, 07-$ & $\mid \vee, \vee \wedge$ & $1,0 \leqslant$ & $\cdot, \cdot \wedge \wedge$ & 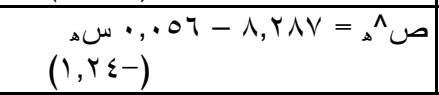 & أإإدتاجية & 0 & \\
\hline$r, Y \wedge$ & $09, \ldots r-$ & rITO,or & *** & $\cdot, 79 \leq$ & 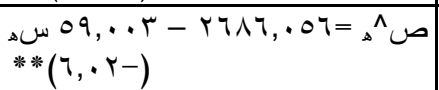 & (الإلفتاج أردب) & 7 & \\
\hline
\end{tabular}

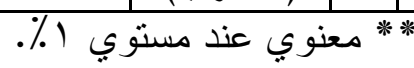

المصدر : جمعت وحسبت من بيانات الجدول رقم (ץ). 


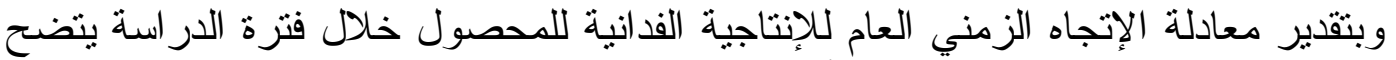

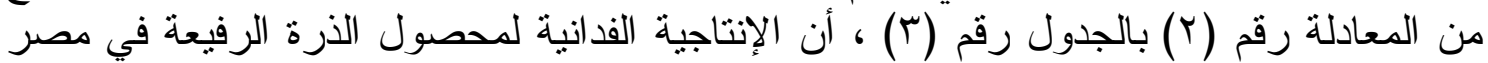

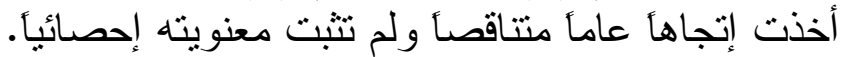

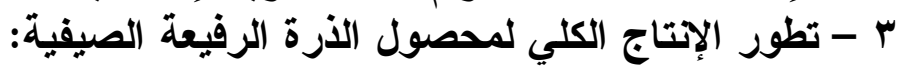

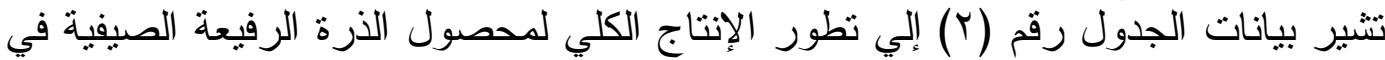

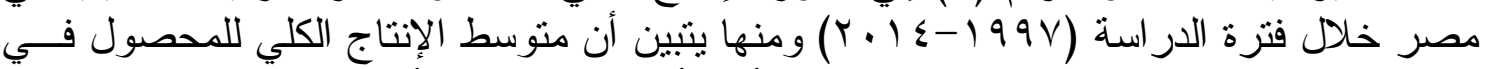

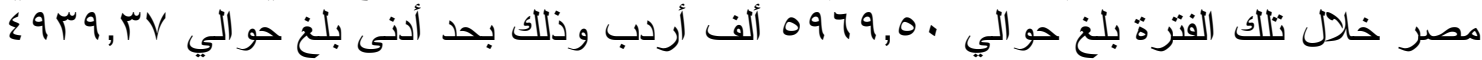

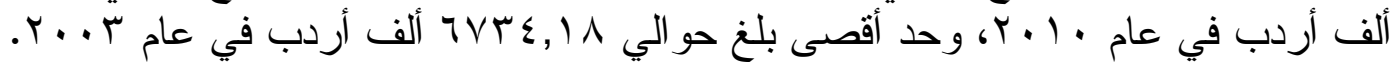

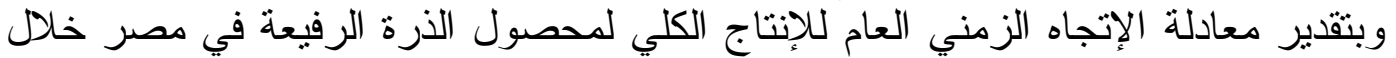

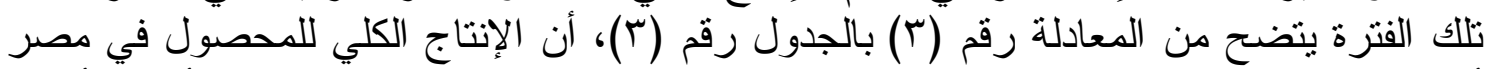

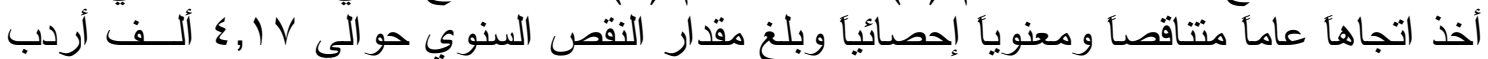

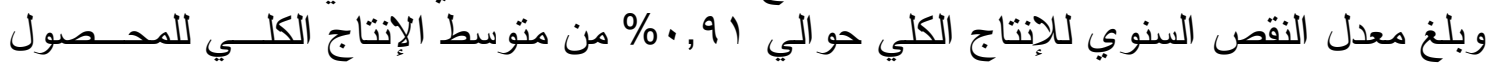

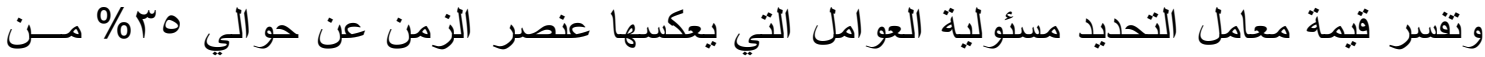

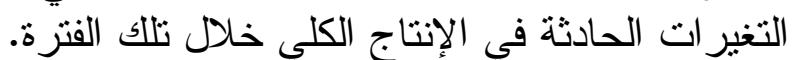

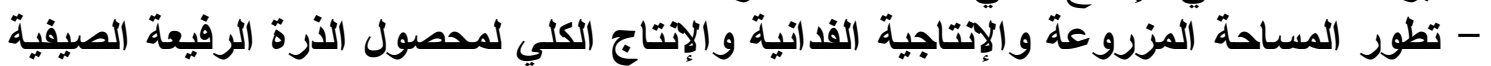

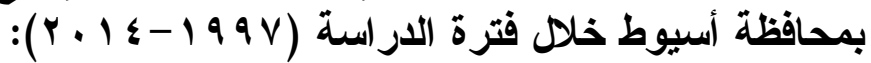

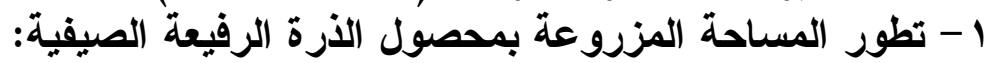

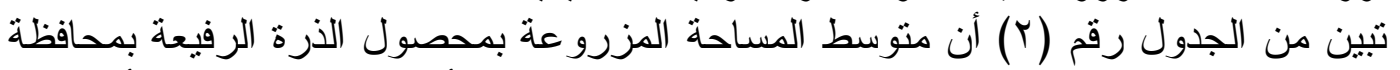

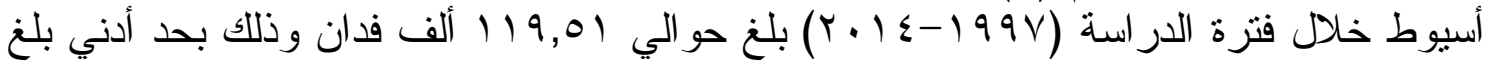

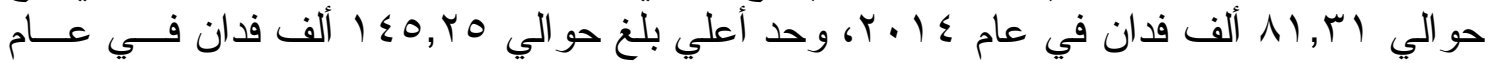
r..r وبتقدير معادلة الإتجاه الزمني العام للمساحة المزروعة بمحافظة أسيوط خلال تلك الفترة،

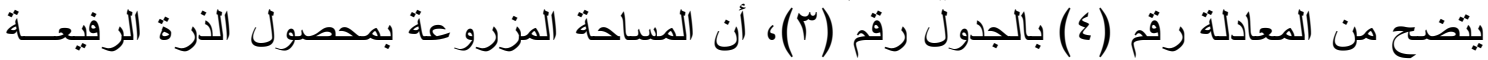

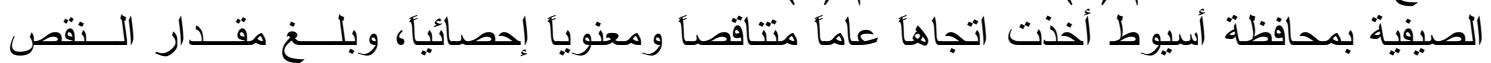

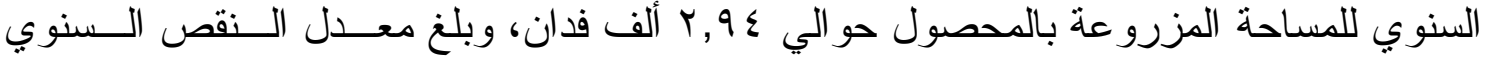

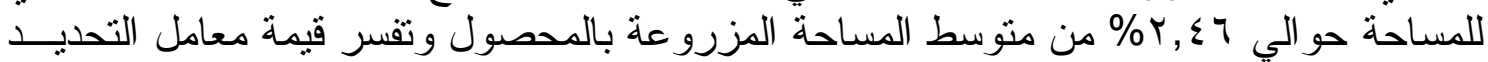

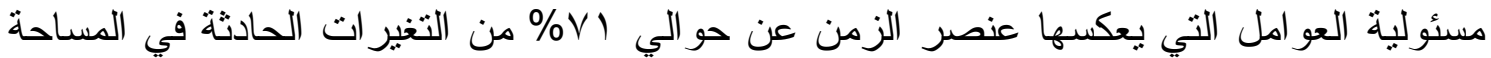
المزرو عة بالمحصول بالفترة المشار المكار إليها سابقأ.

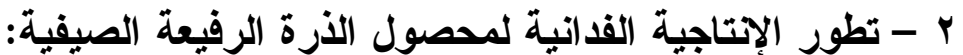

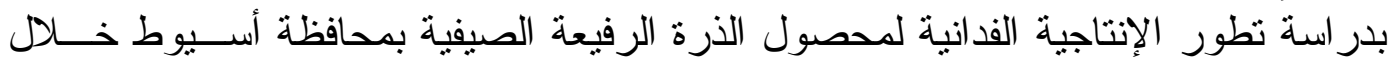

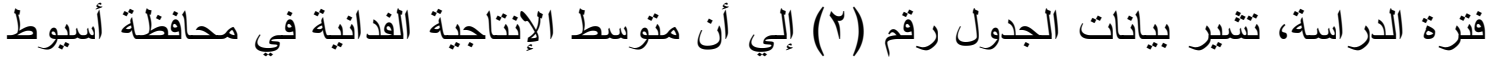

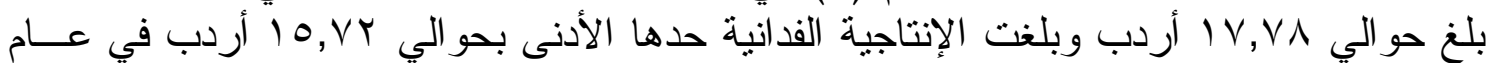

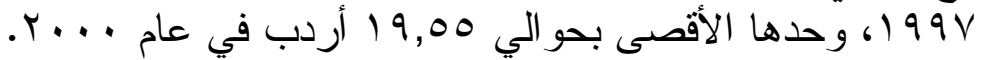

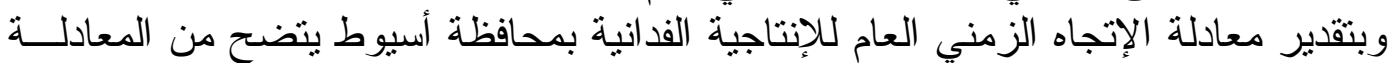

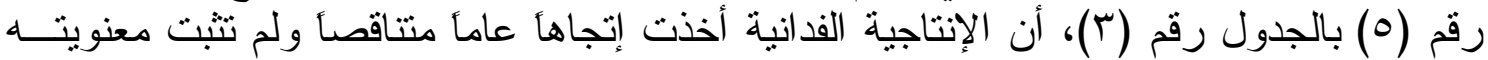
إحصائياً. بُ - تطور الإتتاج الكلي لمحصول الذرة الرفيعة الصيفية:

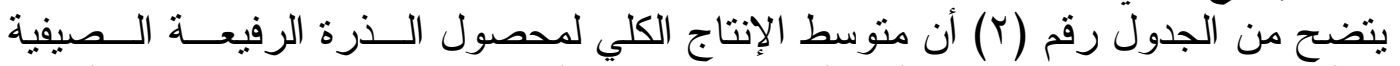

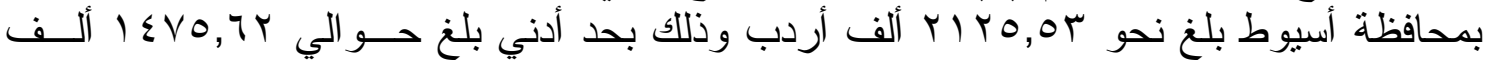

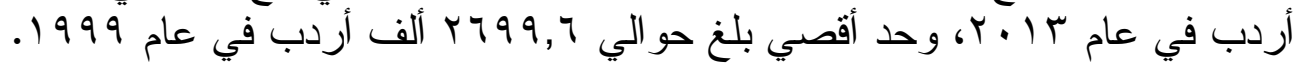




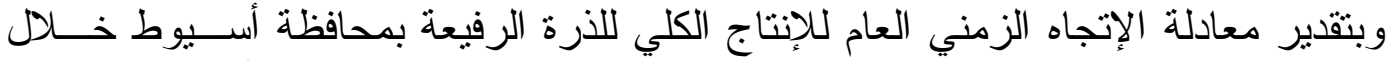

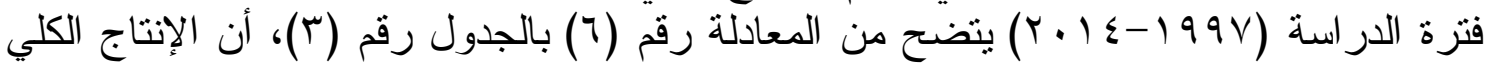

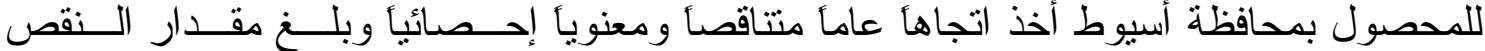

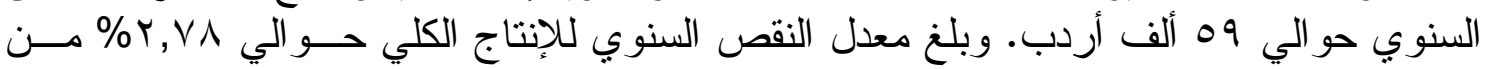

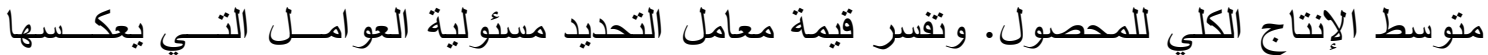

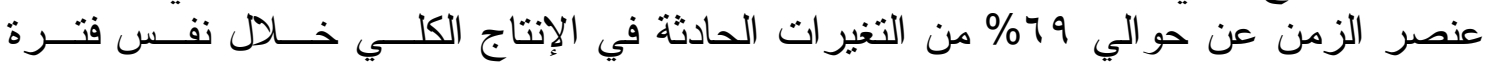

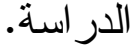

ثاتياً: التقدير الإحصائي لاوال الإنتاج الفيزيقية لمحصول الأرة الرفيعة الصيفية بعينة البحث:

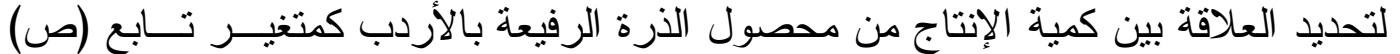

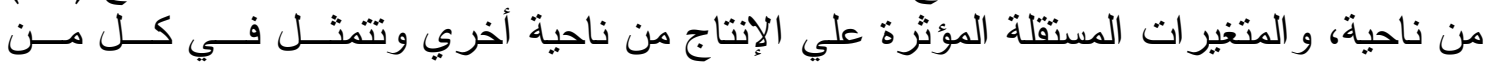

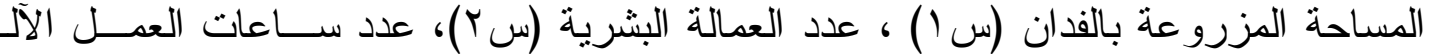

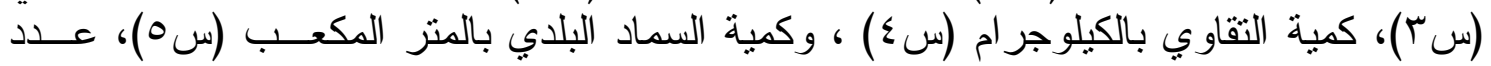
وحدات المادة الفعالة للسماد الآزوتي (س7)، كمية المبيدات بــاللتز (س V) كمتغيـر ات مـستقلة

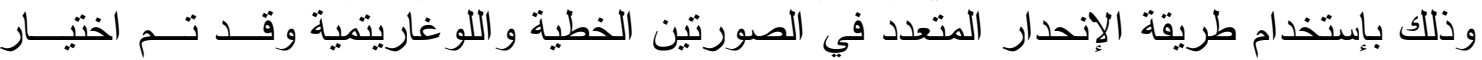
أفضل صور التقدير التي تتمشي مع المنطق الإقتصادي و الإحصائي.

جدول رقم ع. متغيرات إنتاج وتكاليف محصول الأرة الرفيعة بعينة البحث بمحافظة أســيوط موســم

.10

\begin{tabular}{|c|c|}
\hline 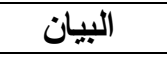 & المتغير ات \\
\hline 10. & عدد المشاهدات \\
\hline YOV,VO & إجمالي مساحة الذرة الرفيعة بالفدان بالعينة \\
\hline $1, V Y$ & متوسط مساحة المشاهدة بالفدان \\
\hline$\Sigma \vee \mu$. & الإنتاج الكلي بالعينة بالأردب \\
\hline $1 \wedge, T_{0}$ & متوسط إنتاج الفدان بالأردب \\
\hline 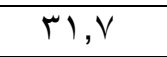 & متوسط عدد العمل البشري للفدان \\
\hline$r Y, q l$ & متوسط عدد ساعات العمل الآليذ للفذان \\
\hline$\wedge, 11$ & متوسط كمية التقاوي (كجم/فدان) \\
\hline $11, r$ & متوسط كمية السماد البلدي (مج/فدان) \\
\hline $97, \cdot 7$ & متوسط عدد الوحدات الفعالة للسماد الآزوتي للفدان \\
\hline $1, \cdot \mathrm{V}$ & متوسط كمية المبيدات باللتز للفدان \\
\hline MVYI, 1 & متوسط إجمالي التكاليف المتغيرة للفدان بالجنيه \\
\hline $0 . \leqslant 0, \wedge \wedge$ & متوسط التكاليف الكلية للفدان بالجنيه \\
\hline
\end{tabular}

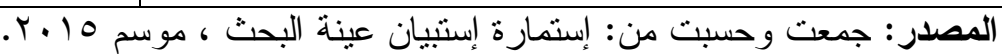

1 - التقدير الإحصائي لاوال الإتتاج بالفئة الحيازية الأولي (أقل من فدان):

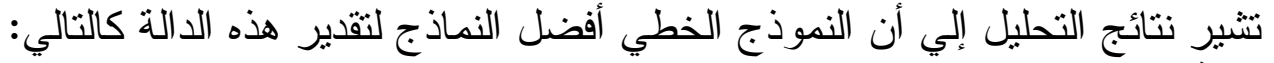
- في حالة النموذج الخطي الكامل: ص=

$*(r, 10) \quad *(r, \Sigma)) \quad * *(r, q \leq) \quad(\cdot, \vee q)$

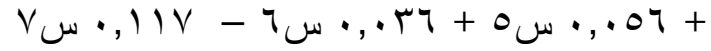

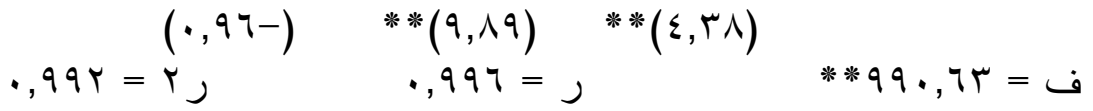




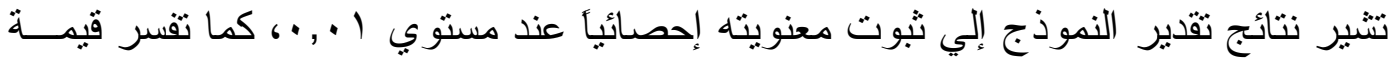

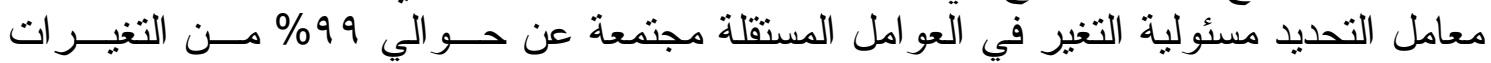
الحادثة في كمية الإنتاج لمحصول اللزية الفير الرفيعة الصيفية بالفئة الحيازية الأولي

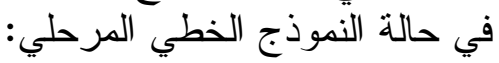

$$
\begin{aligned}
& \text { ص= صن }
\end{aligned}
$$

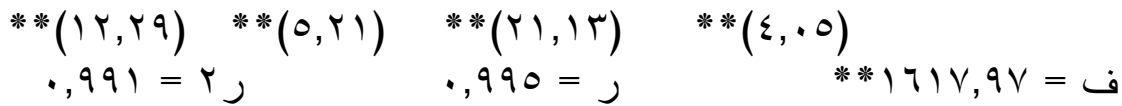

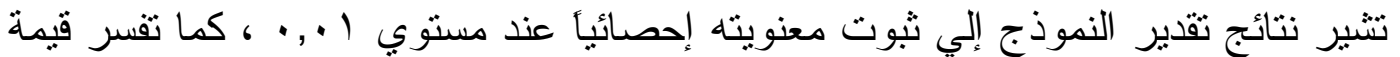

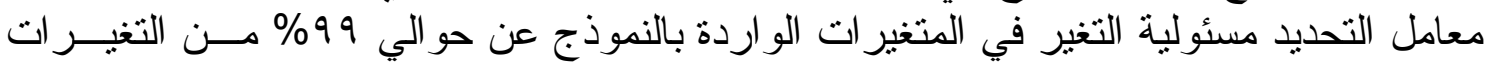

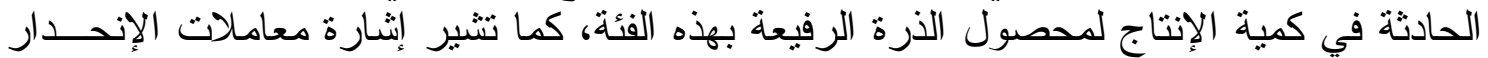

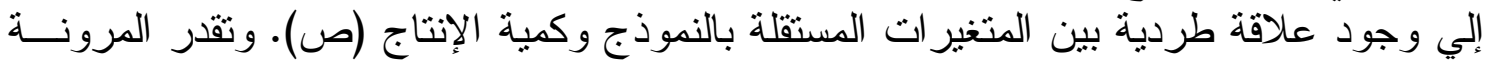

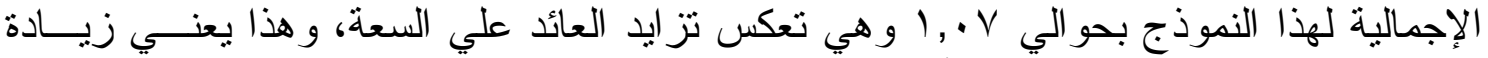

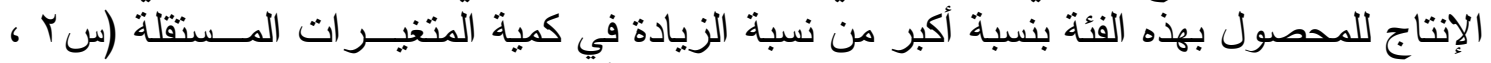

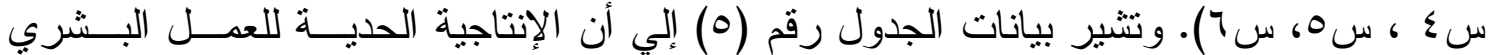

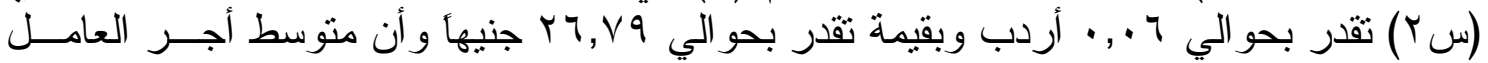

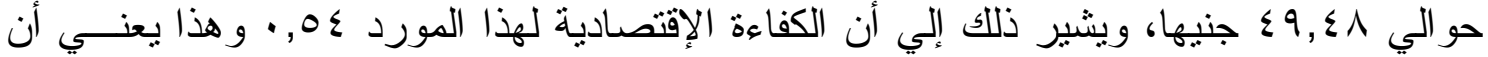

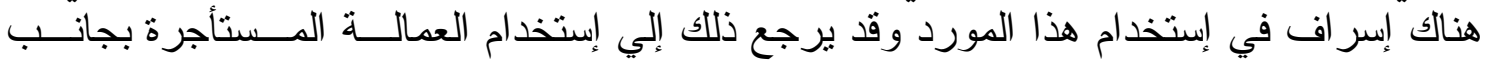
العمل العائلي ويجب في تقليل العمالة البشرية بهذه الفئة.

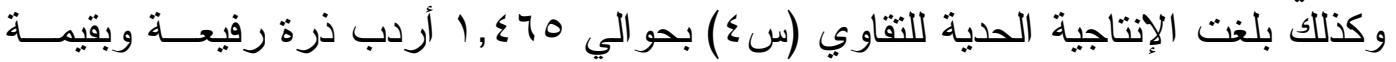

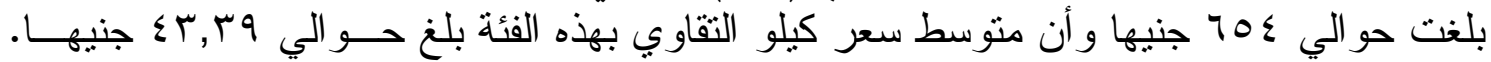

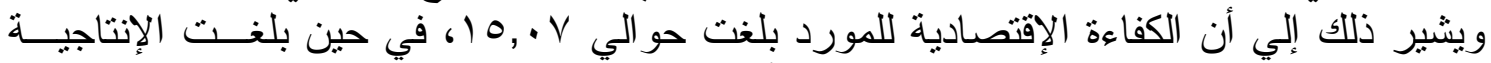

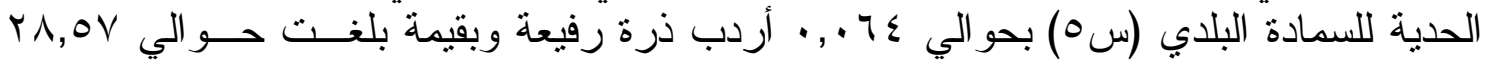

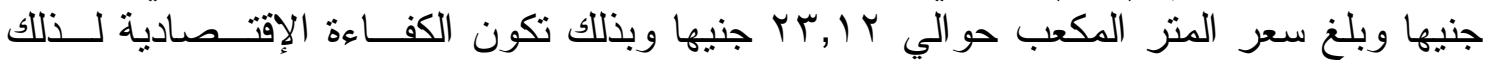

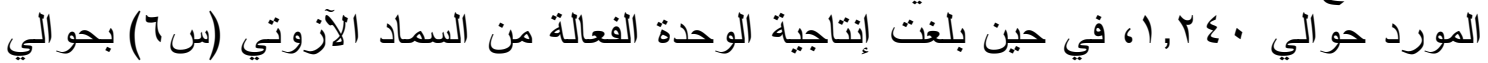

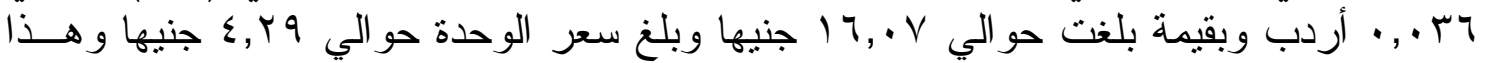

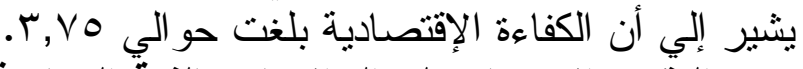

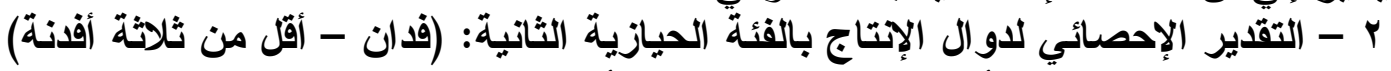

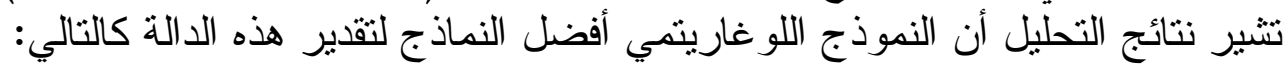
لوص= لو

$$
\begin{aligned}
& *(r, r \uparrow) \quad * *(r, 01) \quad(1, \varepsilon \wedge) \quad * *(r, r q) \\
& \text { + } \\
& (1, \Sigma \tau) \quad * *(r, \cdot \cdot) *(r, 19)
\end{aligned}
$$

$$
\text { ف }
$$

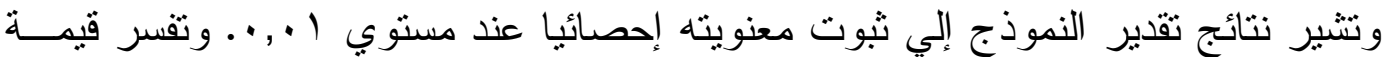

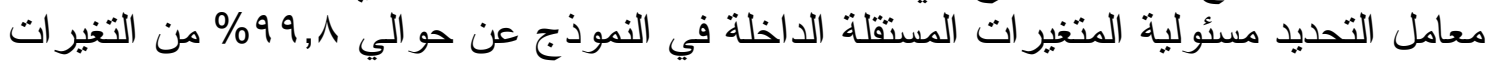
الحادثة في إنتاج الذرة الرفيعة في الفئة الحيازية الثانية.

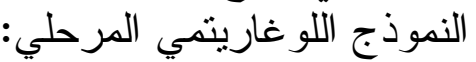

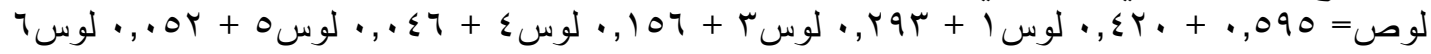

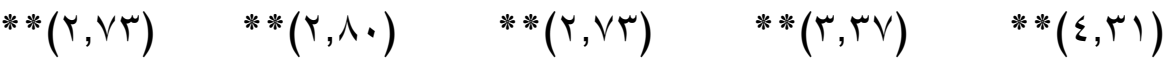
•

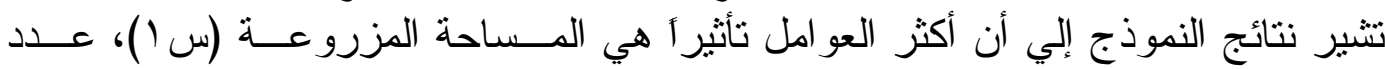

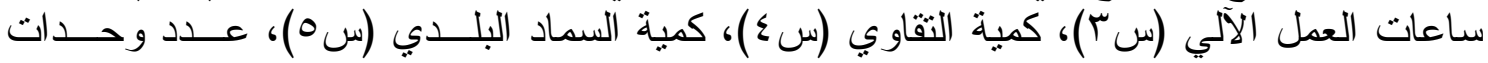


المادة الفعالة للسماد الآزوتي (س)، وتعكس المرونة الإنتاجية الإجمالية في النــــوذج و المقــدرة

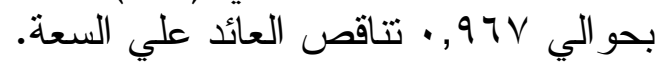

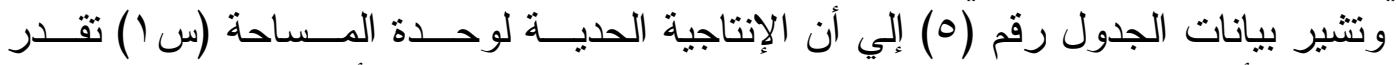

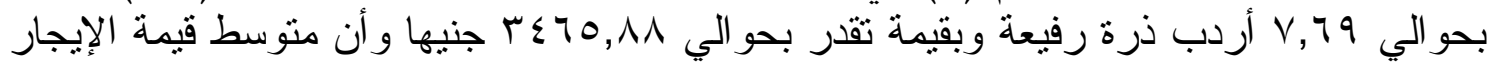

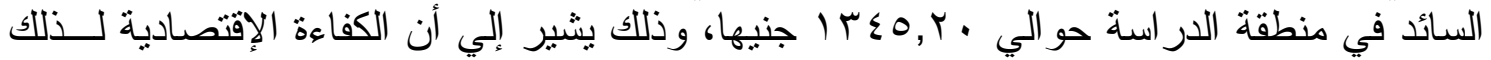

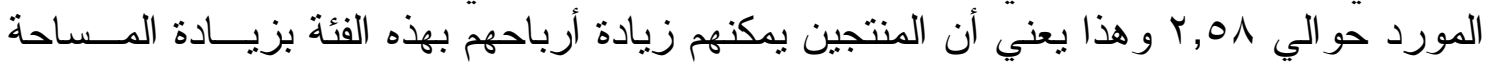

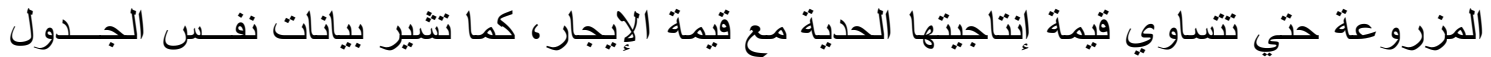

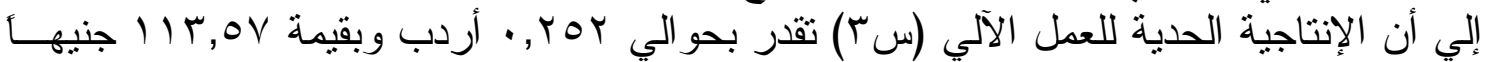

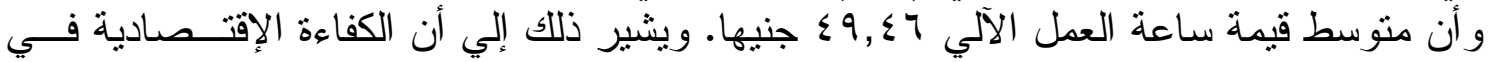

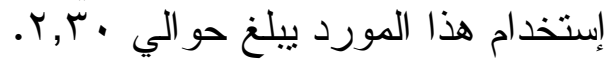

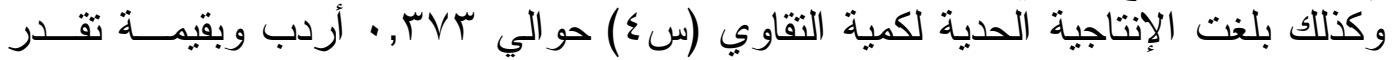

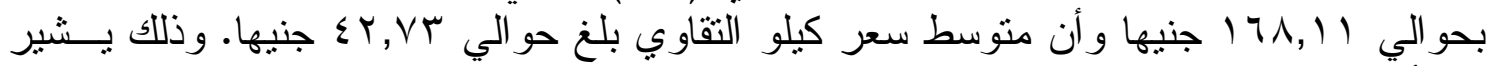

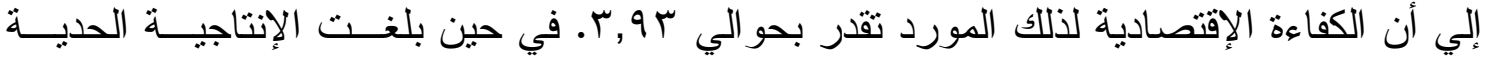

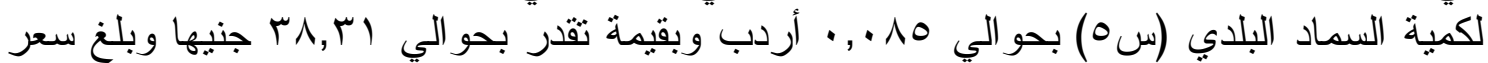

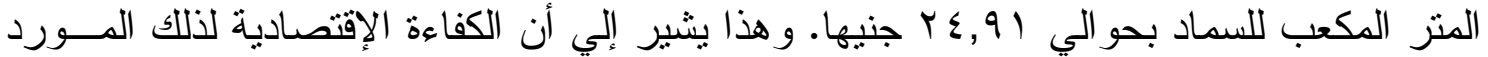

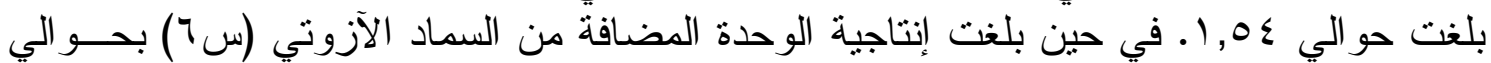

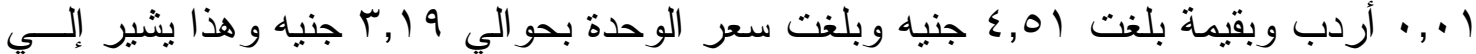

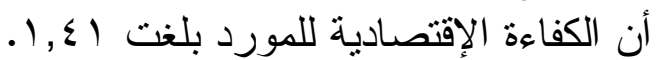

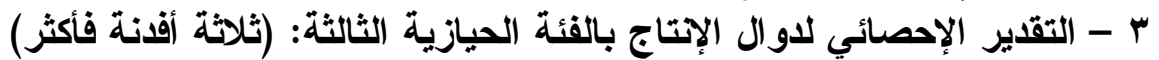

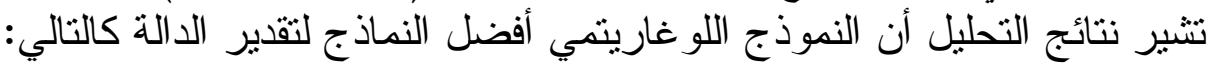
لوص= §

$$
\begin{aligned}
& * *(r, 0 \leqslant) \quad * *(\varepsilon, \Sigma \wedge) \quad * *(9,0 \uparrow)
\end{aligned}
$$

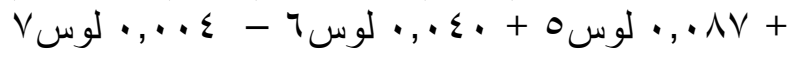

$$
\begin{aligned}
& \text {.,9人r=r, }
\end{aligned}
$$

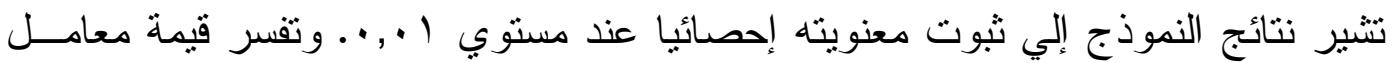

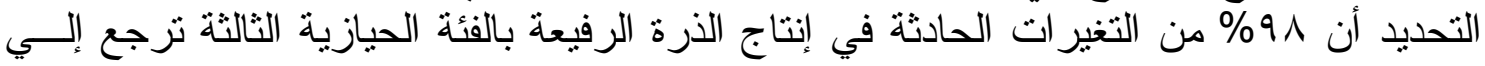

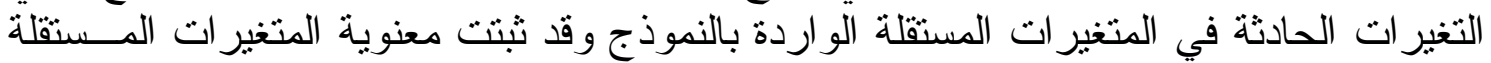

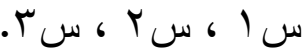

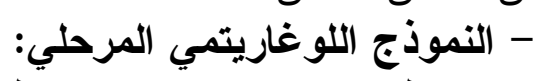

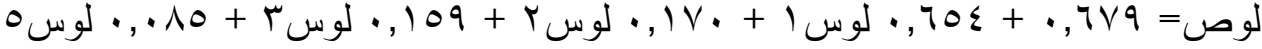

$$
\begin{array}{lcc}
* *(\varepsilon, \cdot r) & * *(r, \varepsilon \cdot) \quad * *(r, \wedge r) & * *(1 r, q \varepsilon) \\
\cdot, 9 \vee \vee=r, & \cdot, 9 \wedge \wedge=, & * * r, r, 1 r=0
\end{array}
$$

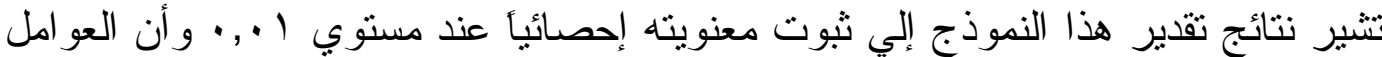

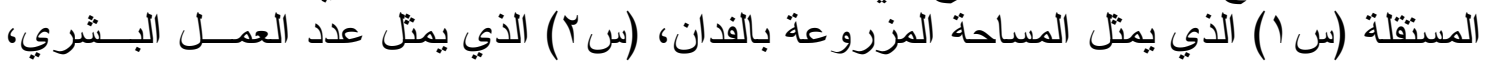

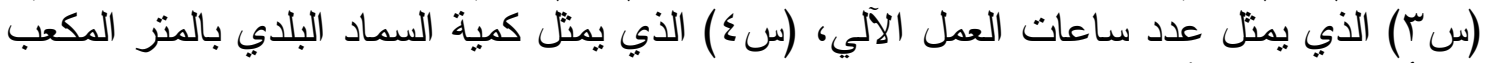

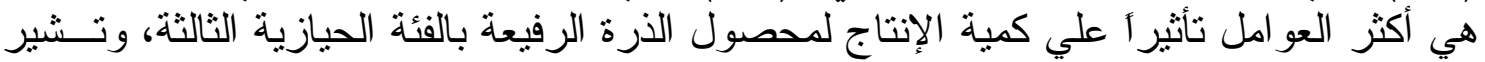
معاملات الإنحدار إلي وجود علاقة طردية بين جميع المتغير ات المستقلة بالنموذجة بله 
جدول رقم هـ كفاءة إستخدام الموارد الإنتاجية في إنتاج محصول الذرة الرفيعة الصيفية في الفئـات

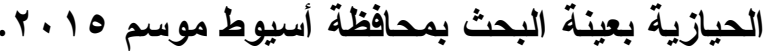

\begin{tabular}{|c|c|c|c|c|c|c|c|}
\hline الإقتصادية & سن المورد الوحدة & قيمة الناتج & 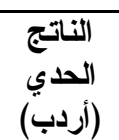 & $\begin{array}{c}\text { (المتوسط) } \\
\text { (الناتج) }\end{array}$ & الإنتاجية & الموارد الإتتاجية & الحيازية \\
\hline$\cdot, 0 \leqslant$ & $\varepsilon q, \varepsilon \wedge$ & rq, vq & $\cdot, .7$ & $\cdot, \varepsilon T Y$ & $\cdot, 149$ & عدد العمالة البشرية (سr) & \multirow{5}{*}{ 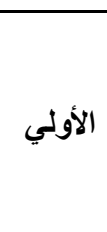 } \\
\hline $10, \cdot \mathrm{V}$ & $\varepsilon r, r q$ & $70 \varepsilon, \ldots$ & $1, \leqslant 70$ & T,IRT & $\cdot, 7 \wedge \mathrm{V}$ & كمية التقاوي (سء) & \\
\hline $1, Y \leq$ & $T r, I Y$ & YA,OV & $\cdot, \cdot 7 \varepsilon$ & $\overline{l, A Y r}$ & $\cdot, \cdot r_{0}$ & كمية السماد البلدي (سه) & \\
\hline \multirow[t]{2}{*}{ r,vo } & $\varepsilon, r_{q}$ & $17, \cdot V$ & $\overline{., .} M_{4}$ & $\cdot, I V Y$ & $\cdot, r \cdot 9$ & عدد وحدات السماد الآزوتي (س،) & \\
\hline & & & & & $1, \cdot V \cdot$ & المرونة الإجمالية & \\
\hline$r, 01$ & $T \Gamma \leqslant 0, r$. & $r \leqslant 70, \wedge \wedge$ & $V, 79$ & $|\Lambda, r| V$ & $\cdot, \varepsilon Y \cdot$ & المساحة المزرو عة (س)) & \multirow{6}{*}{ الثانية } \\
\hline$r, r$. & $\varepsilon 9, \leqslant 7$ & $11 r, 0 \mathrm{~V}$ & $\cdot$, YOY & $\cdot, \wedge T r$ & - , Y & عدد ساعات العمل الآلي (سب) & \\
\hline$r, q 4$ & $\varepsilon r, V T$ & 171,11 & $\cdot, \Gamma V \mu$ & $r, r \wedge q$ &., 107 & كمية التقاوي (س؛) & \\
\hline $1,0 \leqslant$ & $r \varepsilon, 91$ & $r \Lambda, r \mid$ & $\cdot, \cdot 10$ & $1, \wedge \sum 9$ & $\cdot, \cdot, \leqslant 7$ & كمية السماد البلدي (سه) & \\
\hline \multirow[t]{2}{*}{$1, \varepsilon 1$} & $r, 19$ & $\varepsilon, 01$ & $\cdot, \cdot 1$ & $\cdot, 1 \wedge \wedge$ &., $.0 Y$ & عدد وحدات السماد الآزوتي (س؟) & \\
\hline & & & & & $\cdot, 97 \mathrm{~V}$ & المرونة الإجمالية & \\
\hline$\varepsilon, 1 \varepsilon$ & $1 \Gamma \leqslant 0, \cdot$. & $00 V \varepsilon, Y q$ & IY,Y09 & $\backslash \wedge, V \leqslant \varepsilon$ & $\cdot, 70 \leqslant$ & المساحة المزروعة (س) & \multirow{5}{*}{ 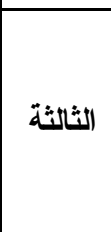 } \\
\hline $1, .1$ & $\varepsilon q, Y Y$ & Or,Vo & $\cdot, 117$ & $\cdot, 7 \wedge 0$ & $\cdot, I \vee$. & عدد العمالة البشرية (سr) & \\
\hline 1,17 & $\varepsilon q, r v$ & ov,rq & $\cdot, 1 Y 4$ & $\cdot, \vee \vee$ & $\cdot, 109$ & عدد ساعات العمل الآلى (سب) & \\
\hline \multirow[t]{2}{*}{$r, \leqslant 7$} & $r r, \wedge V$ & $0 \wedge, 74$ & $\cdot, 1 Y q$ & $1,01 \mathrm{~V}$ & $\cdot, \cdot 10$ & كمية السماد البلدي (سه) & \\
\hline & & & & & $1, .71$ & المرونة الإجمالية & \\
\hline$r, \Lambda V$ & $T r \varepsilon \varepsilon, \Gamma q$ & $O Y \cdot \sum, \Lambda T$ & $11,0.0$ & $1 \Lambda, r_{0}$ & $\cdot, T Y V$ & المساحة المزروعة (س،) & \multirow{5}{*}{ الجعمالي } \\
\hline$\cdot, \wedge$. & $\varepsilon \Lambda, Y \vee$ & $r \wedge, \varepsilon 0$ & $\cdot, \cdot 10$ &., $0 \vee 9$ & $\cdot, 1 \leqslant 7$ & عدد العمالة البشرية (سr) & \\
\hline$\varepsilon$, YO $_{0}$ & $\sum 1,97$ & $I V \wedge, Y_{O}$ & $\cdot, r q \leqslant$ & T,YTr & $\cdot, \mid \vee \varepsilon$ & كمية الثقاوي (س ؛) & \\
\hline \multirow[t]{2}{*}{$r, 0 \leqslant$} & $r, \leqslant 0$ & $|Y, Y|$ & $\cdot, \cdot T V$ &., 191 &., $1 \Gamma 9$ & عدد وحدات السماد الآزوتي (س؟) & \\
\hline & & & & & $1, \cdot 14$ & المرونة الإجمالية & \\
\hline
\end{tabular}

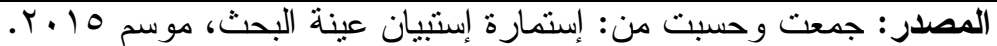

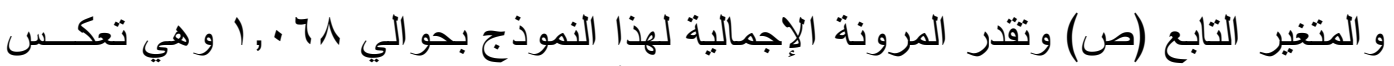

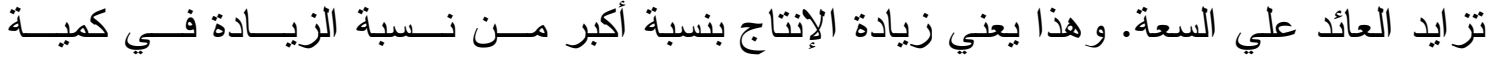

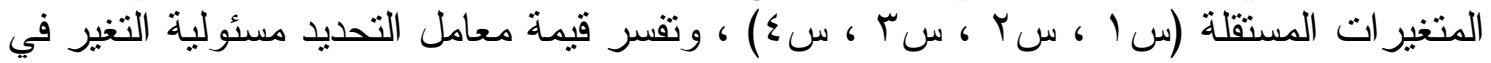

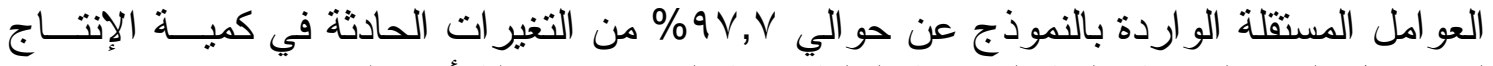

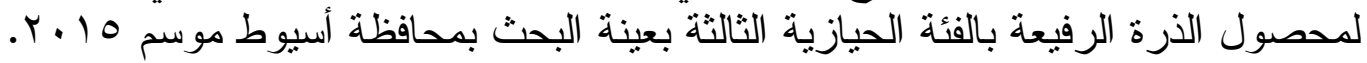

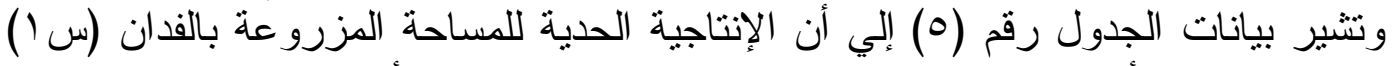

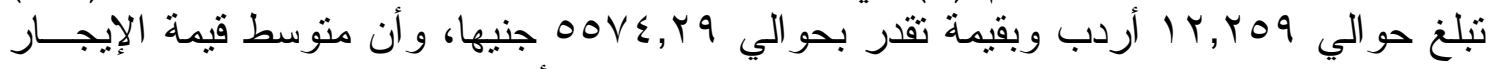

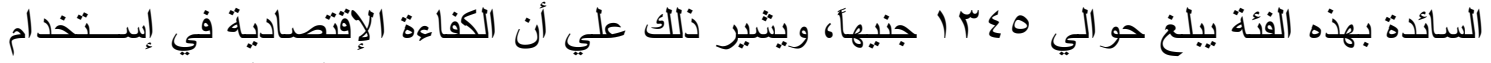

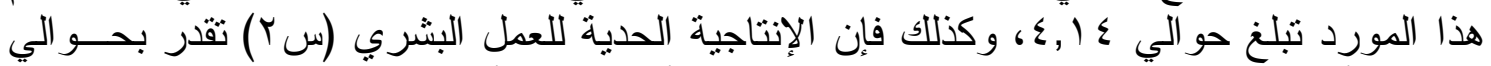

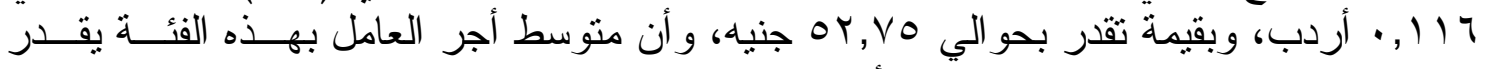

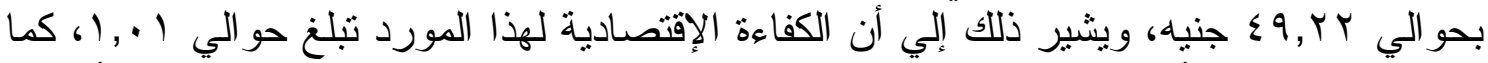

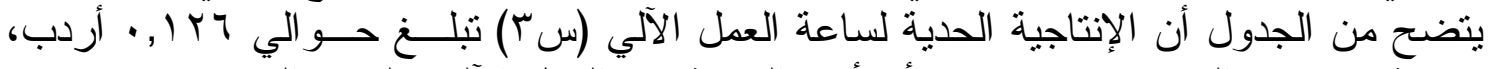

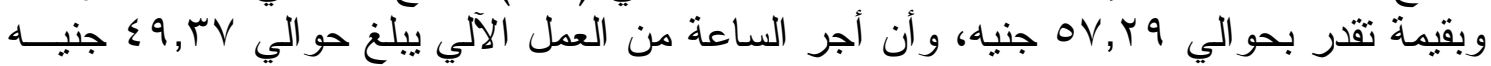

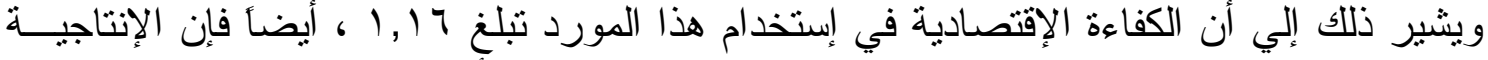

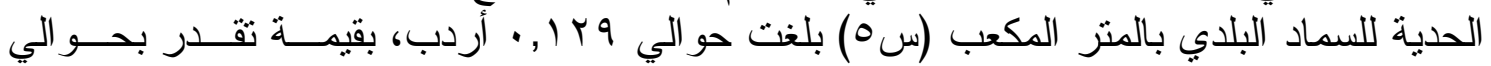

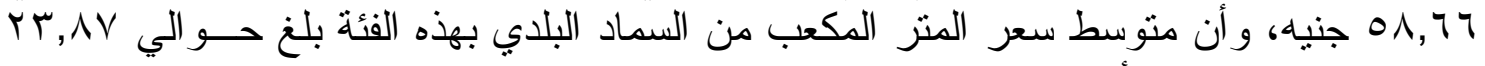

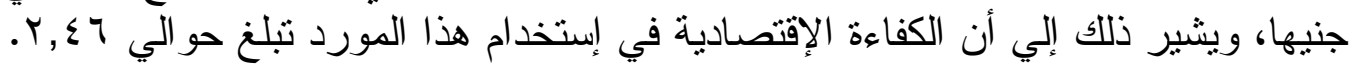


؛ - التقدير الإحصائي لاو ال الإتتاج بإجمالي العينة:

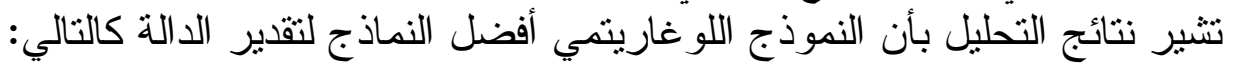

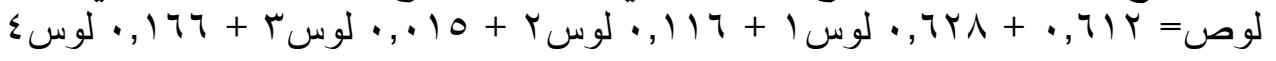

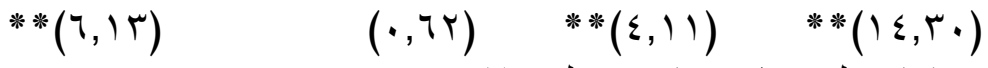

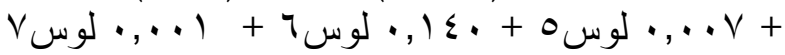

$(\cdot, 0 \varepsilon) \quad * *(\wedge, \wedge \Lambda) \quad(1,79)$

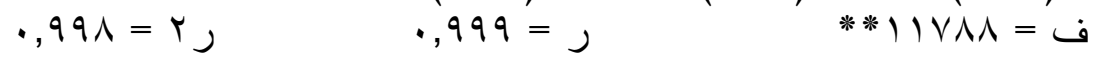

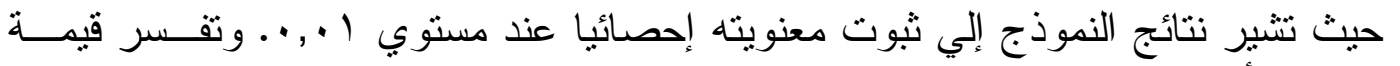

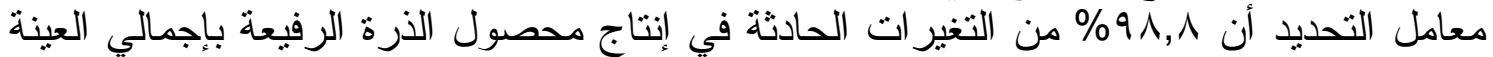

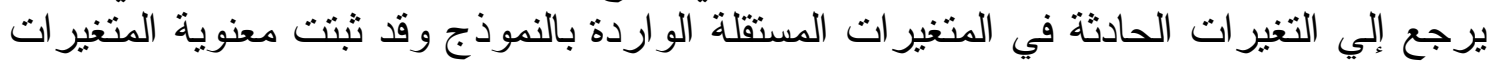

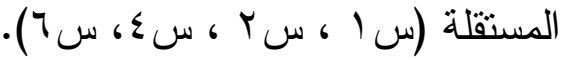

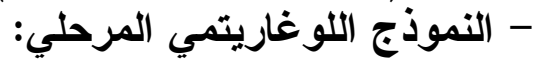

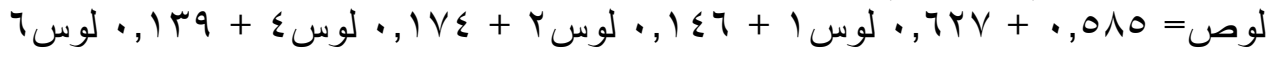

$$
\begin{array}{ccc}
* *(\wedge, 0 \vee) & * *(7,71) \quad * *(0, r) & * *(1 \leqslant, \Lambda 1) \\
., 99 \wedge=r, 999=, & * * 179.0=0
\end{array}
$$

تشير نتائج تقدير هذا النموذج إلي ثبوت معنويته إحصائياً عند مستوي ا +., • وأن العو امل

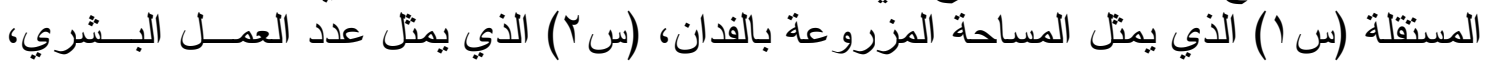

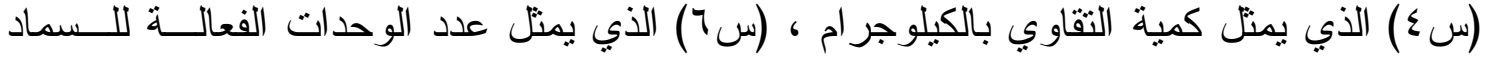

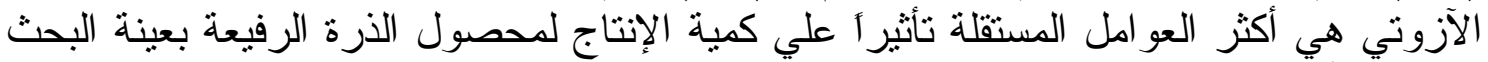

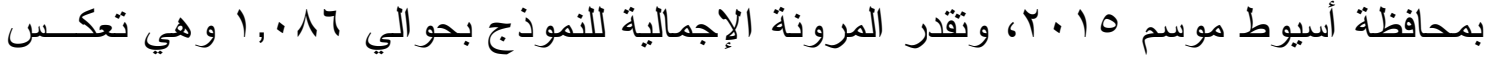

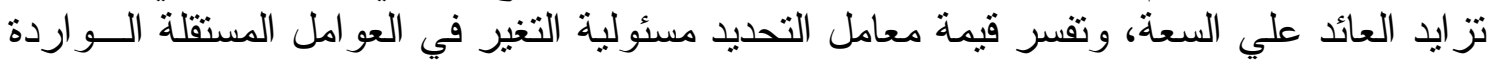
بالنموذج عن حوالي ^,99\% من التغير ات الحادثة في كمية الإنتاج بعينة البحث.

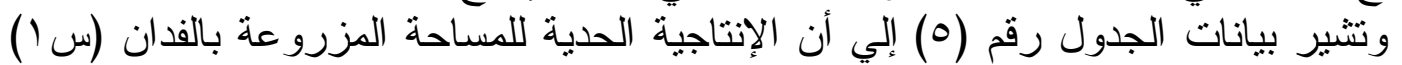

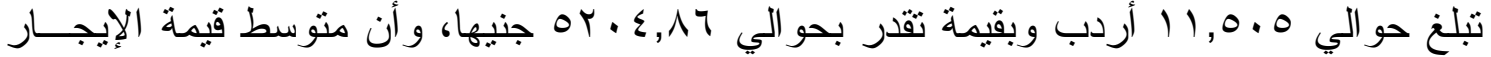

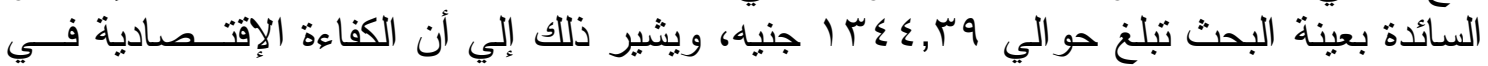

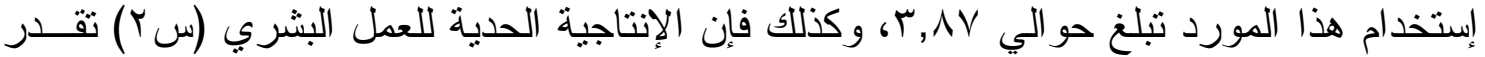

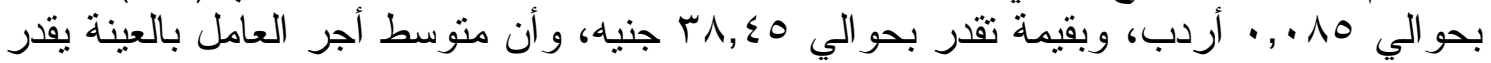

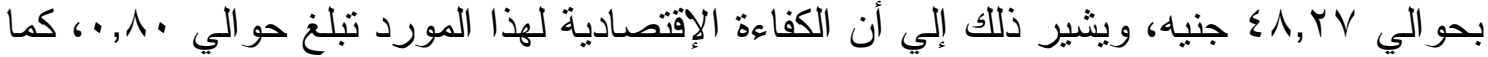

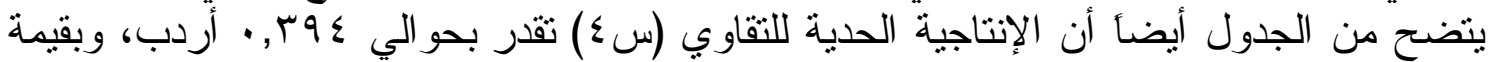

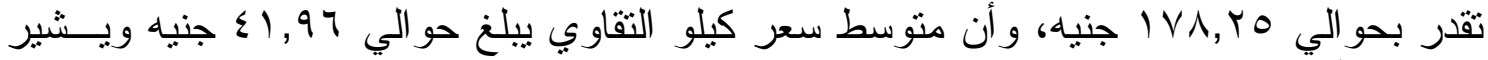

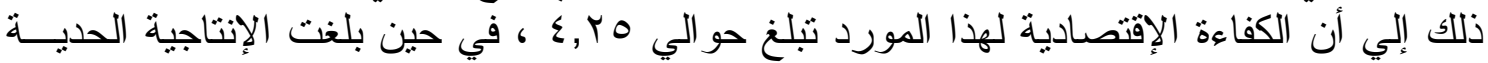

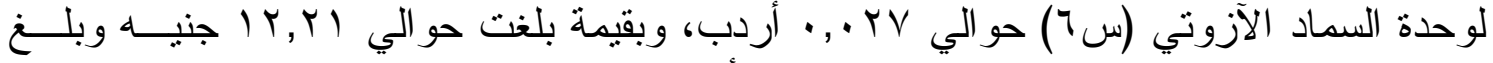

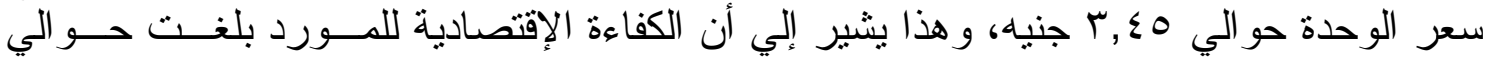
.

ثالثاً: التقدير الإحصائي لاوال التكاليف الإنتاجية لمحصول الذرة الرفيعة الصيفية بعينة البحث:

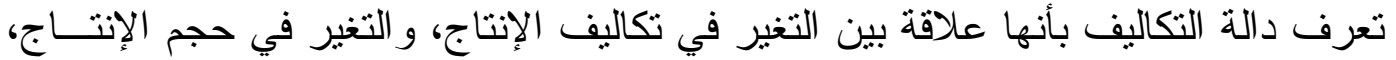

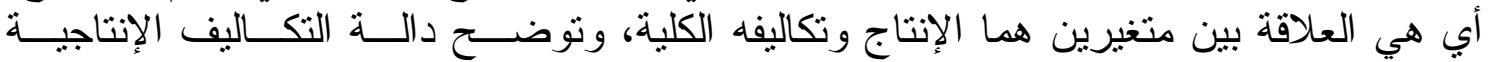

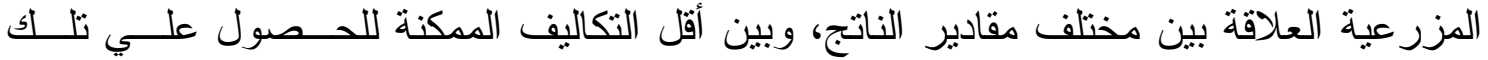

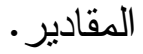

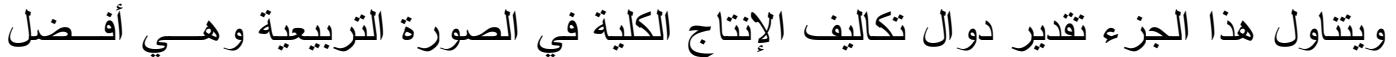

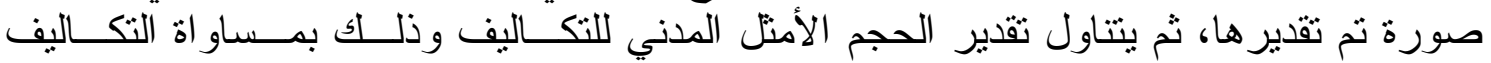

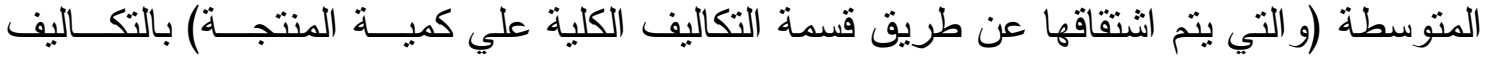


الحدية (و التي يتم انتقاقها بإجر اء التفاضل الأول لدالة التكاليف الكلية) وكذللك يتم تقـدير حجـــ

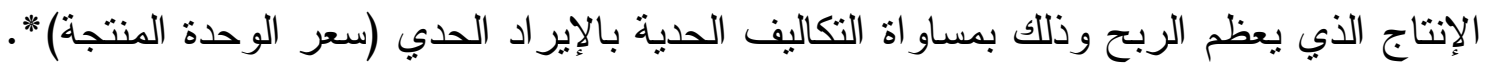

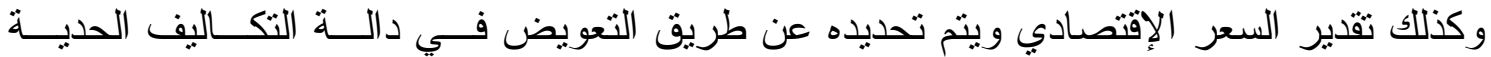

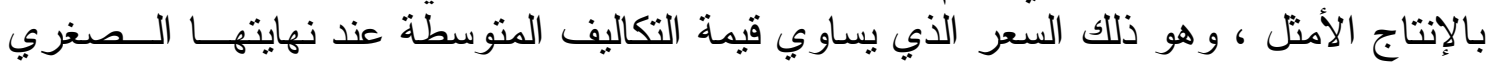

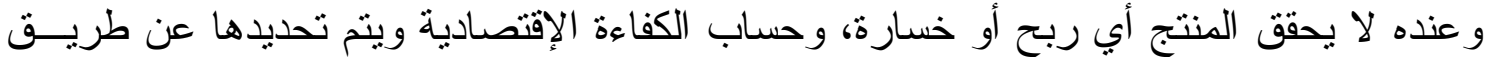

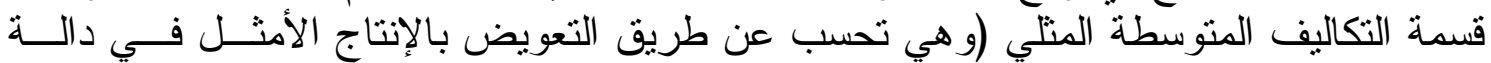

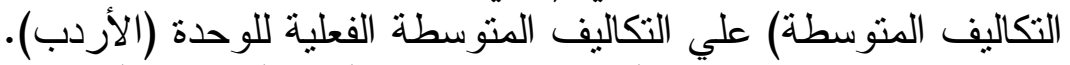

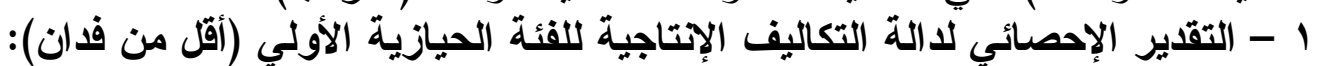

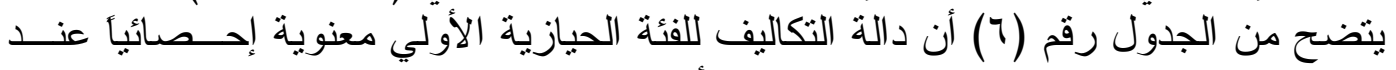

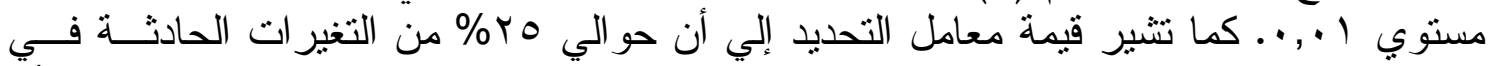

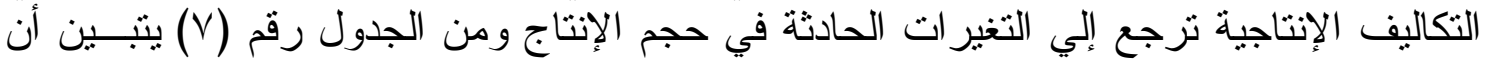

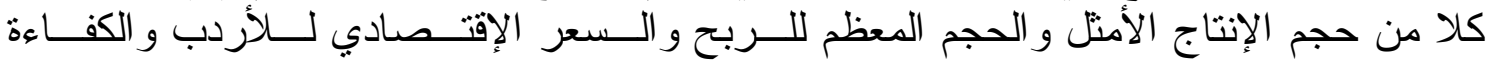

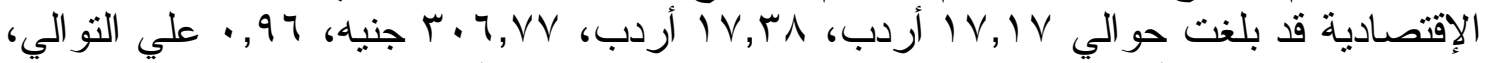

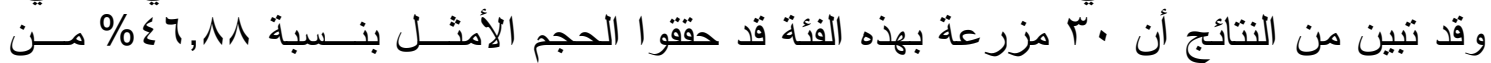

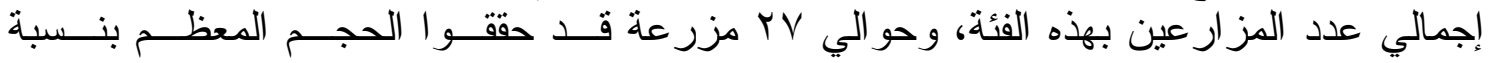

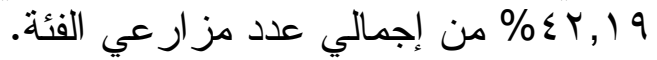
r - التقدير الإحصائي لدالة التكاليف الإتتاجية للفئة الحيازية الثانية (فدان - أقل مـن ثلاثــة أفدنة):

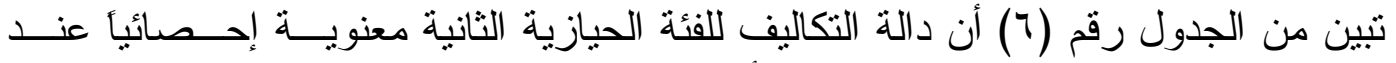

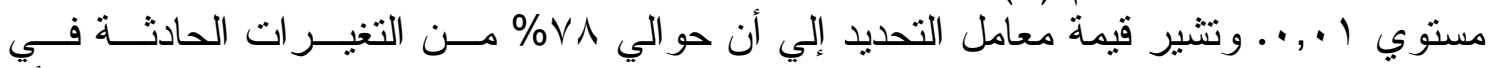

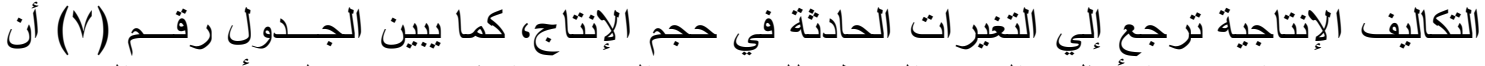

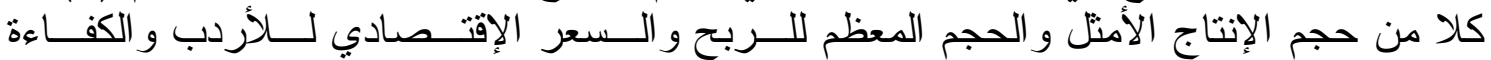

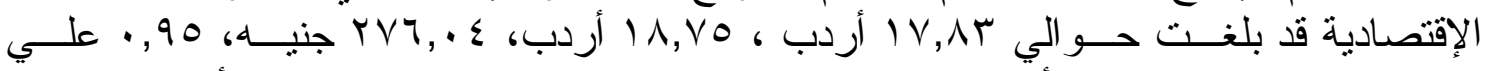

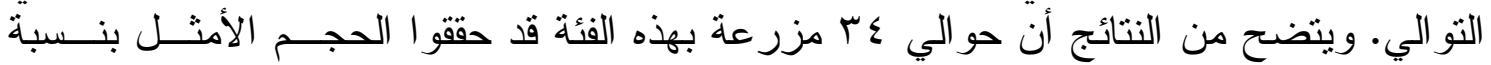

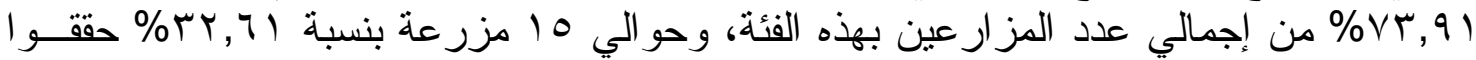

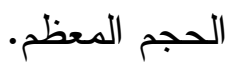

r - التقدير الإحصائي لد الة التكاليف الإتتاجية للفئة الحيازية الثالثة (ثلاثة أفدنة فأكثر):

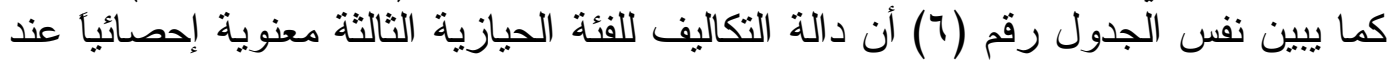

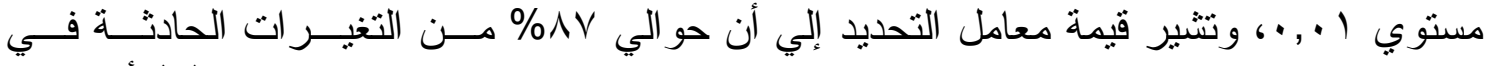

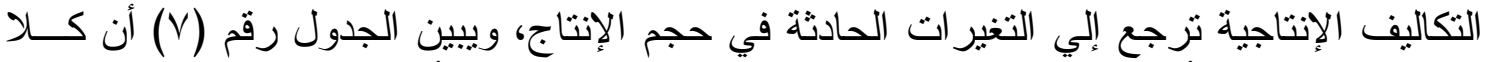

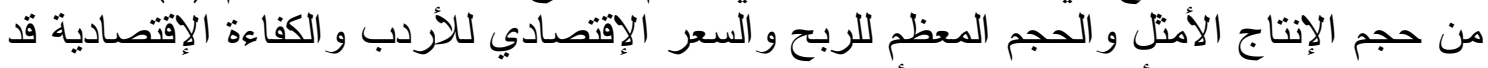

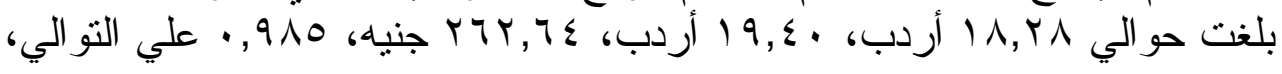

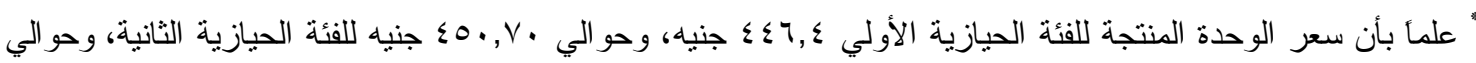

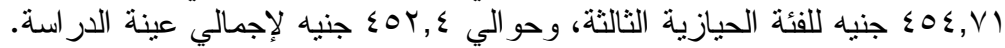


شادية محمد سيل ناصر، باسم دوس حنا دوس، 7 م

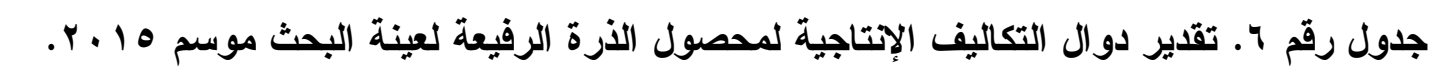

\begin{tabular}{|c|c|c|c|c|}
\hline J & J & ف & المعادلة & الحيازية \\
\hline$\cdot, r \leqslant 9$ & $\cdot, \leqslant 90$ & $* * 1,, 1 \leq$ & 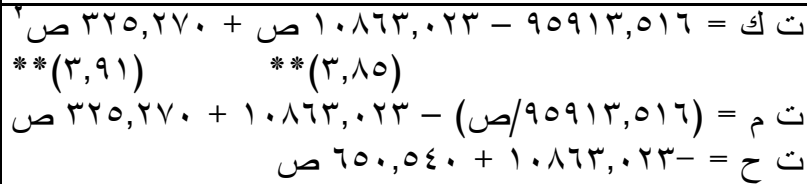 & الأولي \\
\hline$\cdot, \vee \vee \vee \wedge$ & $\cdot, \wedge \wedge r$ & $* * \vee 0,01$ & 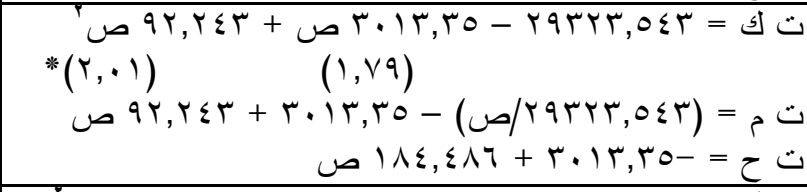 & الثانية \\
\hline$\cdot, \mathrm{AVY}$ & $\cdot, 9 \leq r$ & $* * \mid r 0,0$ r & 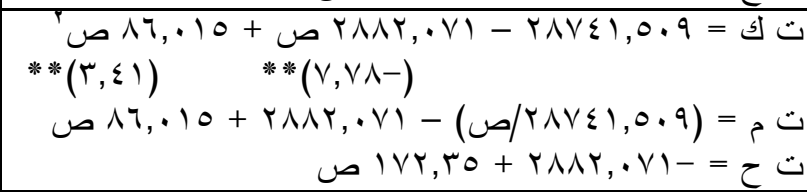 & الثالثة \\
\hline$\cdot, .7$ & $\cdot, r \leqslant T$ & $* * \varepsilon, V \Gamma$ & 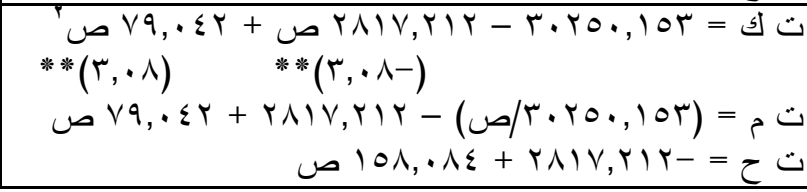 & إجمالي عينة \\
\hline
\end{tabular}

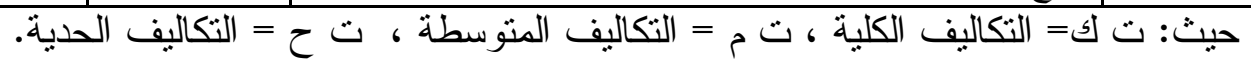

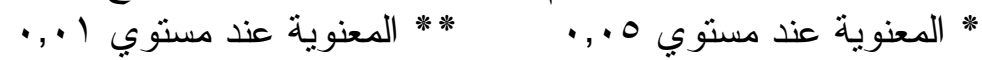

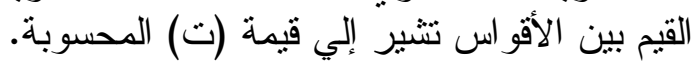

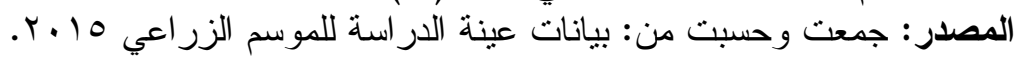

جدول رقم V. المشتقات الإقتصادية لدوال تكاليف إنتاج محصول الذرة الرفيعة بعينة الاراسة موســم

.r. 10

\begin{tabular}{|c|c|c|c|c|}
\hline إجمالي العينة & الفئة الحيازية & الفئة الحيازية & الفئة الحيازية & المؤشر \\
\hline 19,07 & $1 \wedge, Y \wedge$ & $I V, \wedge r$ & $I V, I V$ & حجم الإنتاج الأمنل (أردب) \\
\hline$r \cdot, 7 \Lambda$ & $19, \varepsilon$. & $11, \vee 0$ & $I \vee, r \Lambda$ & الحجم المعظم للربح (أردب) \\
\hline$T V \varepsilon, \lambda r$ & TTY,TE & $Y \vee \neg, \cdot \varepsilon$ & $r \cdot 7, V V$ & السعر الإقتصادي للأردب (جنيه) \\
\hline$\cdot, 997$ & $\cdot, 9 \wedge 0$ & $\cdot, 90$ & $\cdot, 97$ & الكفاءة الإقتصادية \\
\hline
\end{tabular}

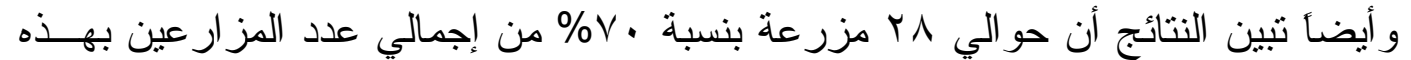

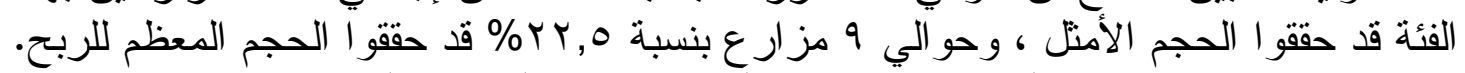

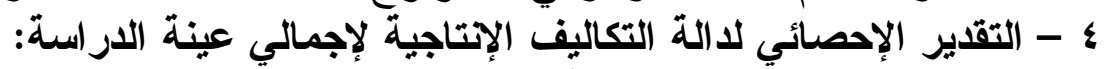

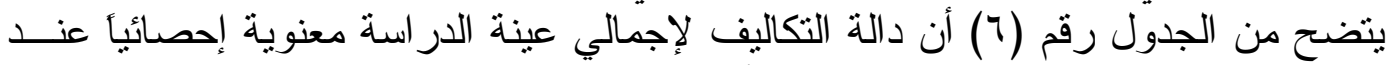

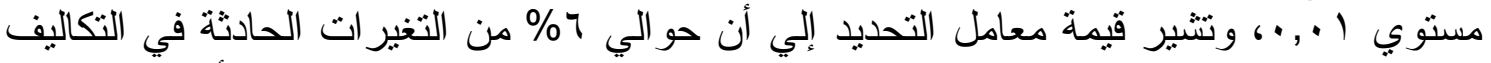

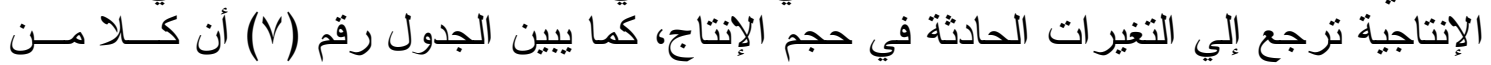

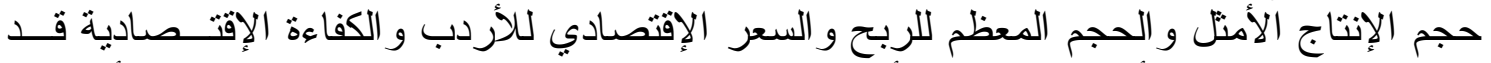

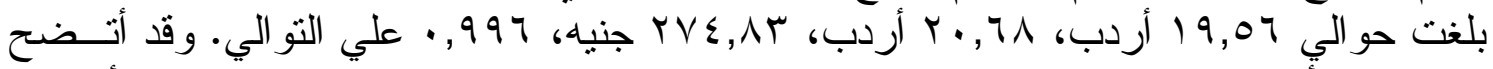

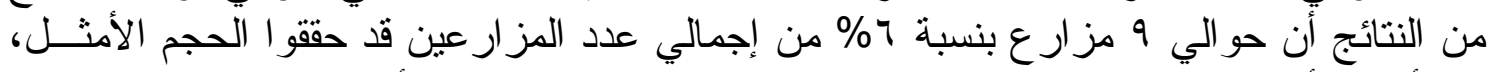

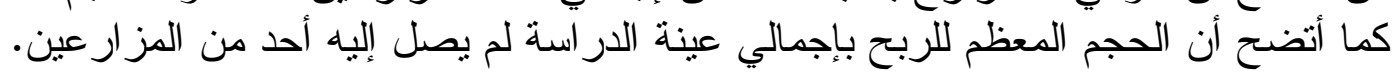


رابعاً: دراسة بعض مؤشرات الكفاءة الإتاجية والإقتصادية في الفئات الحيازية بعينة الدراسة:

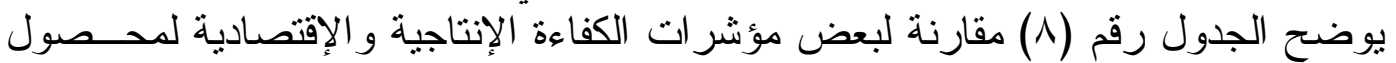

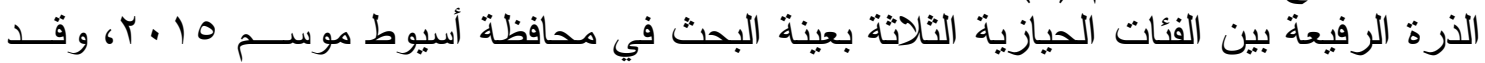

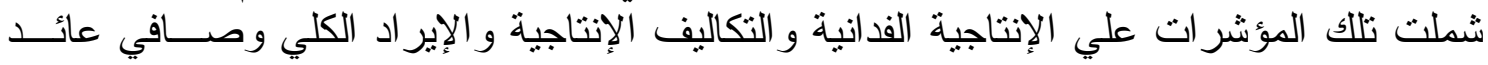
الفدان وصافي العائد علي الجنيه المستثر . الإني ا 1 - الإنتاجية الفدانية:

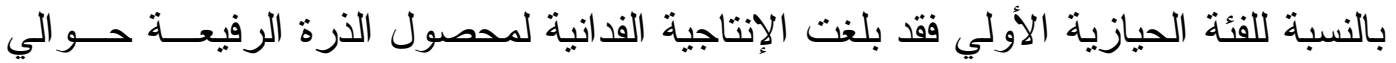

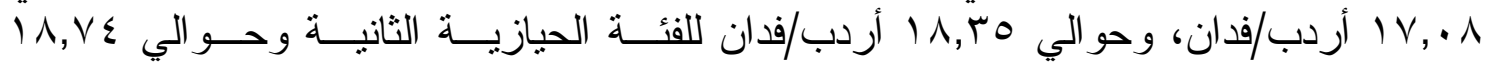

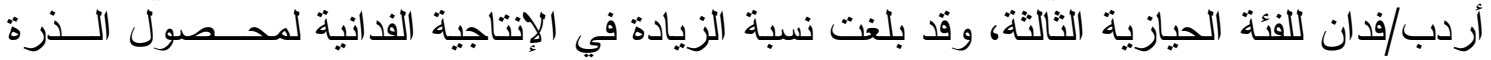

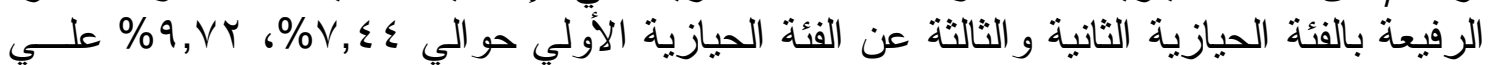

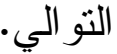
r - ألتكاليف الإتتاجية الكلية للفدان:

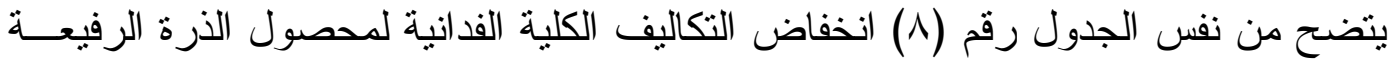

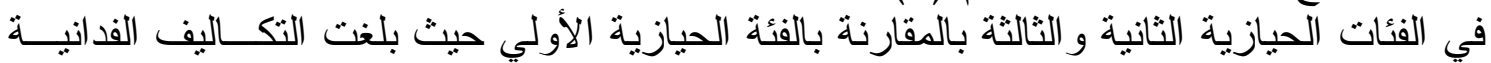

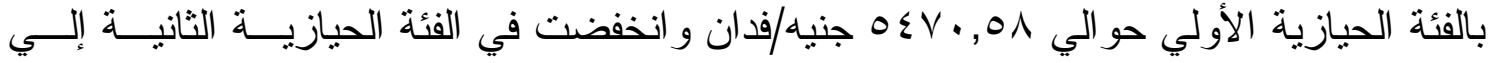

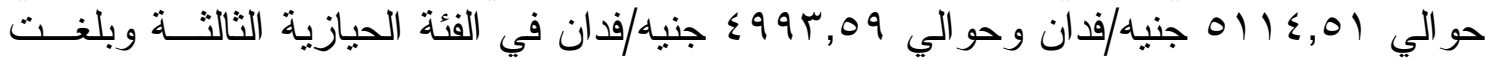
نسبة الانخفاض في التكاليف الكلية الفدانية للفئة الحيازية الثانية والثانية الثالثة عن الفئة الحيازية الأولي الثيا

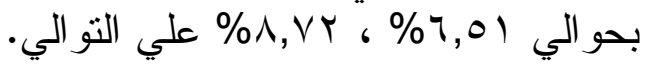
ب - ب الإير اد الكلي للفدان:

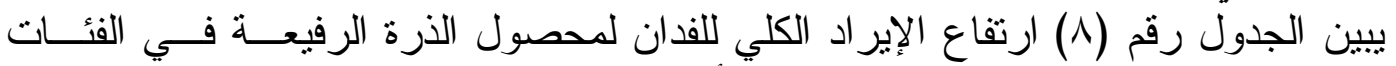

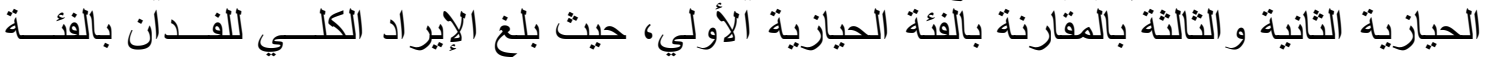

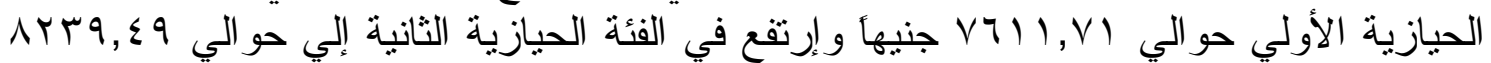

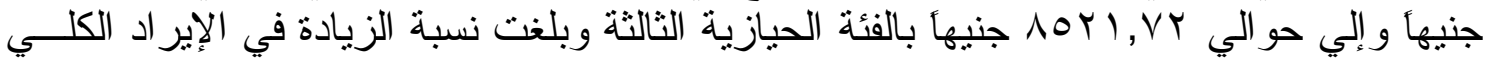

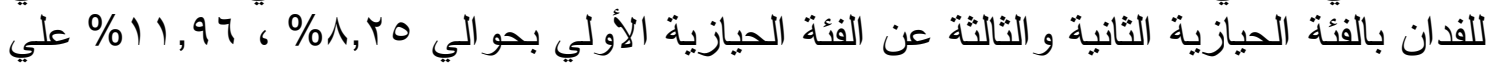
التو الي. يتضح من الجدول رقم (^) ارتفاع صافي العائد الفداني لمحصول الذرة الرفيعة في الفئات

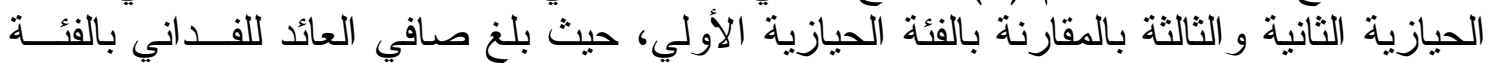

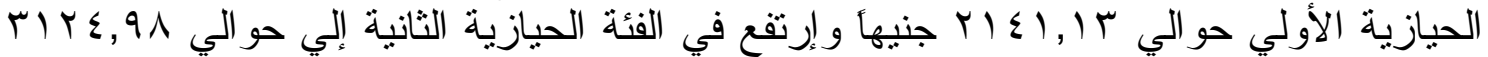

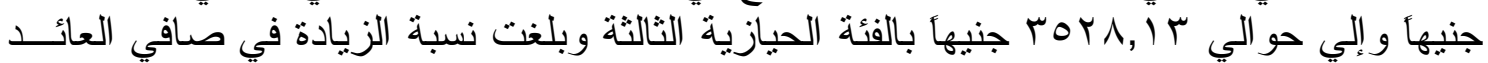

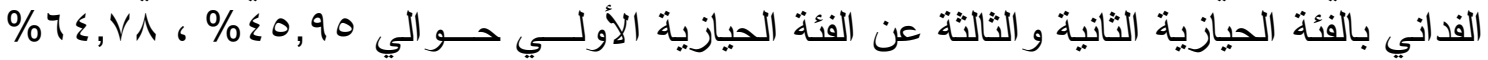

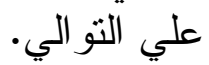

جدول رقم ^. مقارنة بعض المؤشرات الإتتاجية والإقتصادية لمحصول الذرة الرفيعة بعينة الاراســة

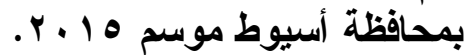

\begin{tabular}{|c|c|c|c|}
\hline الفئة الحيازية الثالثة & الفئة الحيازية الثانية & الفئة الحيازية الأولي & المؤشرات \\
\hline $1 \wedge, \vee \varepsilon$ & $1 \Lambda, r_{0}$ & $T V, \cdot A$ & متوسط الإنتاجية الفدانية (أردب/فدان) \\
\hline$\varepsilon 994,09$ & $011\{, 01$ & $0 \leqslant \vee \cdot, 0 \Lambda$ & متوسط التكاليف الكلية (جنيه/فدان) \\
\hline AOY I,VY & $\wedge r r q, \varepsilon q$ & $\overline{V 711, V 1}$ & متوسط الإير اد الكلي (جنيه/فدان) \\
\hline TOYA,IT & $M I Y \varepsilon, 9 \Lambda$ & $r(\varepsilon 1,1 r$ & متوسط صافي العائد (جنيه/فدان) \\
\hline$\cdot, \mathrm{VI}$ & $\cdot, 7)$ & $\cdot, r q$ & أربحية الجنيه المستثمر (جنيه) \\
\hline
\end{tabular}


ه - صافي العائد علي الجنيه المستثمر:

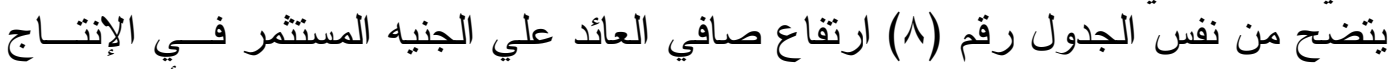

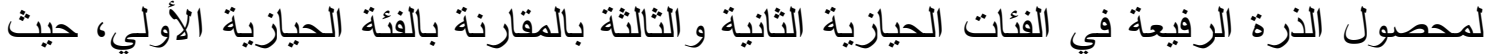

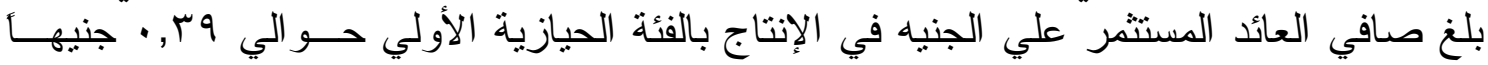

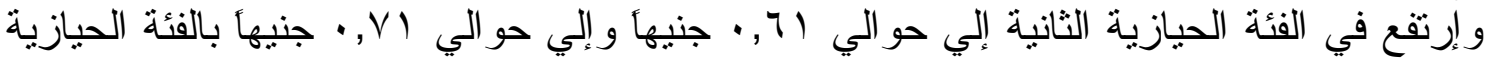

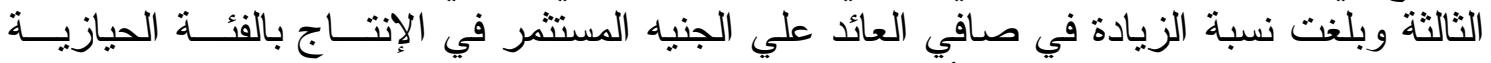

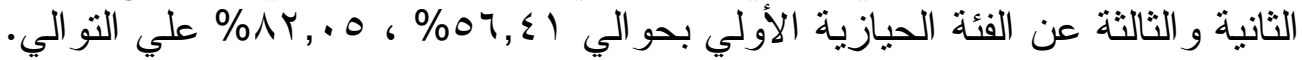

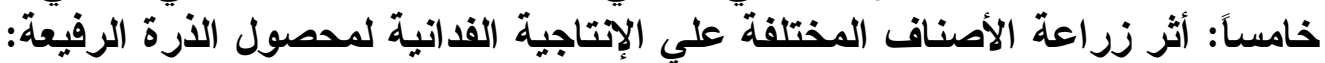

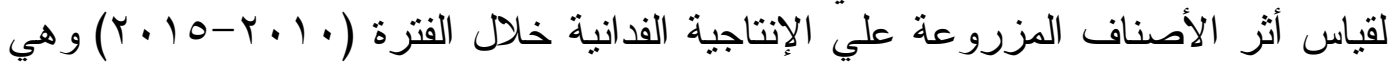

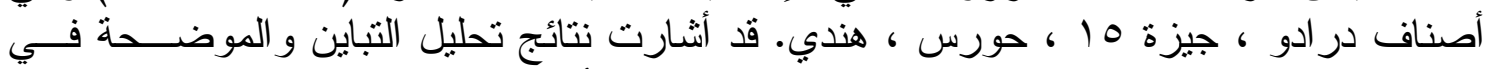
الجدولين رقمي (9 ، • 1) إلي وجود فروق معنوية بين الأصناف في الإنتاجية الفدانية لمحصول

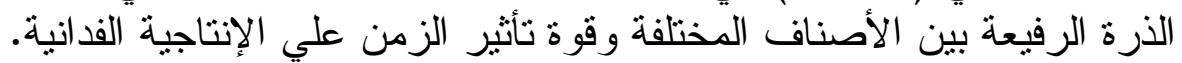

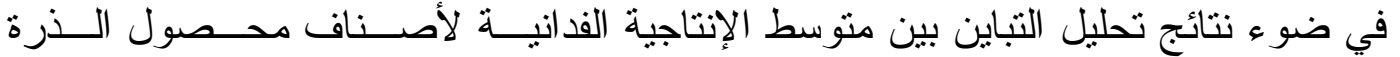

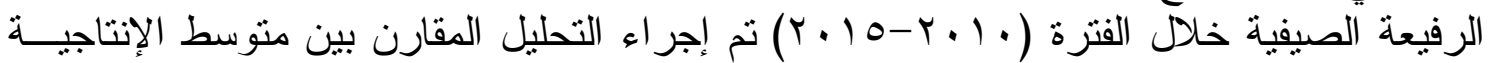

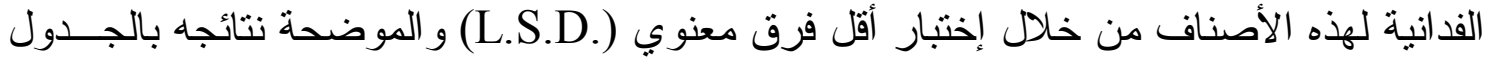

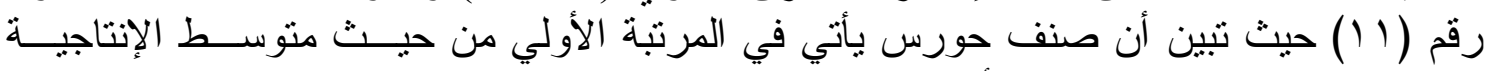

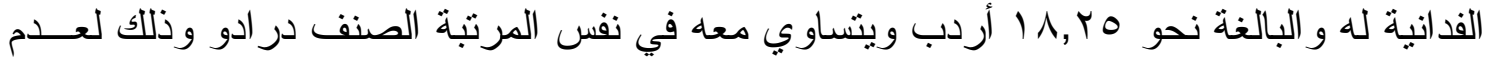

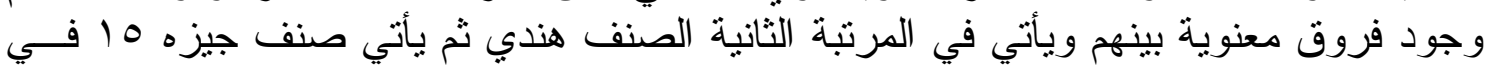

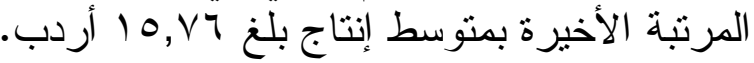

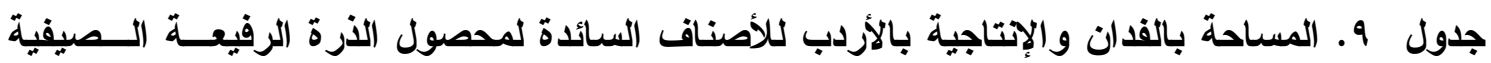

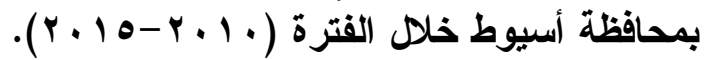

\begin{tabular}{|c|c|c|c|c|c|c|c|c|}
\hline المتوسط & $r .10$ & $r \cdot 1 \leqslant$ & $r \cdot 1 r$ & $r .1 r$ & $r .11$ & $r \cdot 1$. & المتغير & الصنف السنة \\
\hline TATYO & T.OVV & YIA৭V & IVYOY & rAIV. & $E Y V T Y$ & rqRTr & مساحة & در ادو \\
\hline$I V, T V$ & $17,9$. & 17,1 . & $1 \wedge, 0$. & $I V, \wedge$. & 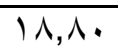 & $I V, q r$ & إنتاجية & \\
\hline TY\^ & rqr & KTVYT & rצף.. & $T_{1100}$ & TYY.I & $\varepsilon 1 \cdot V V$ & مساحة & جيزة 10 \\
\hline 10,17 & $1 \leqslant, 9$ & 10,9 & $17, Y$ & $10, \pi$ & 17,9 & $10, \mu \mu$ & إنتاجية & \\
\hline$r \ldots \leqslant 0$ & $17 \ldots 7$ & IrotV & $1 \leqslant \vee 70$ & $1 \wedge \ldots V$ & r7011 & TYRTV & مساحة & حورس \\
\hline $1 \wedge, Y_{0}$ & IV,. & $1 \wedge, \varepsilon$ & $1 \wedge, 9$ & $I V, r$ & $1 \wedge, 7$ & $19, \mathrm{rV}$ & إنتاجية & \\
\hline$\varepsilon \varepsilon \cdot V$ & $09 \mathrm{VI}$ & rqr. & $19 \leq 7$ & $0 V \cdot \Lambda$ & VVIV & $\| V \mid$ & مساحة & هندي \\
\hline $17, \wedge 9$ & 17,0 & $1 \wedge, 1$ & $I V, Y$ & 10,1 & $1 \wedge, 1$ & 10,70 & إنتاجية & \\
\hline
\end{tabular}

المصدر : جمعت وحسبت من: وزارة الزر اعة و إستصلاح الأر اضي، مديرية الزر اعة بأسيوط، قسم الإحـصاء،

$$
\text { بيانات غير منشورة. }
$$

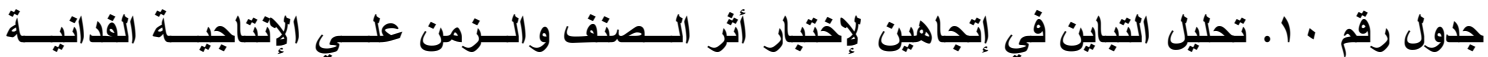

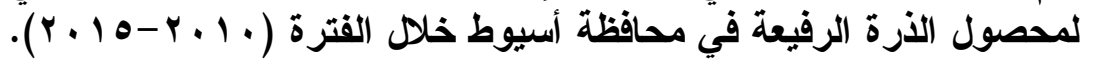

\begin{tabular}{|c|c|c|c|c|}
\hline قيمة ف & متوسط مربع & درجات الحرية & مجموع مربعات الاتحر افات & مصادر الاختلاف \\
\hline$* * \mid r, \cdot 1$ & $7,9 V$ & $r$ & $r \cdot, q$ & بين الأصناف \\
\hline$* r, 11$ & $1, \lambda 1$ & 0 & $9, \cdot r$ & بين السنو ات \\
\hline & $\cdot, 01$ & 10 & $\Lambda, \vee \cdot$ & الخطأ \\
\hline & & $T r$ & 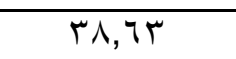 & المجموع \\
\hline
\end{tabular}

المصدر: جمعت وحسبت من: بيانات الجدول رقم (9). 


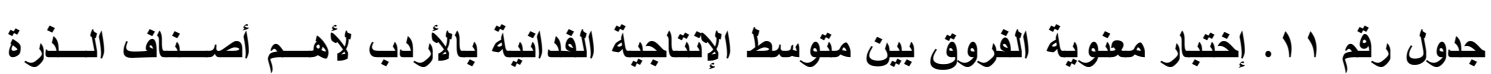

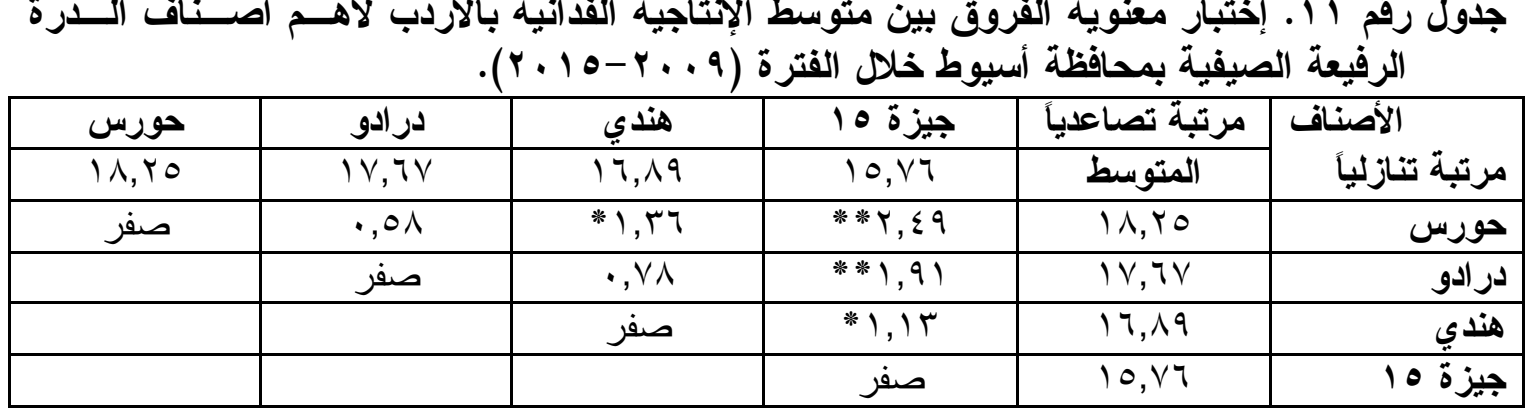

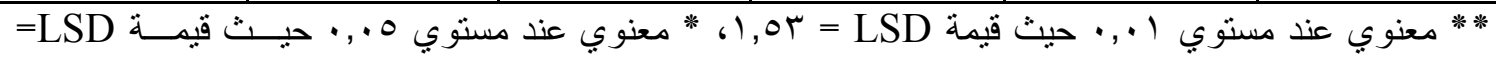

المصدر : جمعت وحسبت من: وزارة الزر اعة و إستصلاح الأر اضي، مديرية الزر اعة بأسيوط، ســجلات قـسم

$$
\text { الإحصاء، بيانات غير منشورة. }
$$

- أثر زراعة الأصناف الحديثة علي إنتقال دالة العرض لمحصول الذرة الرفيعة بمحافظة أسيوط خلا

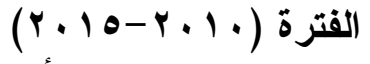

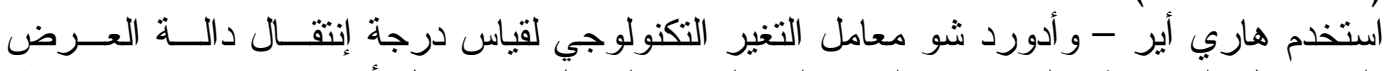

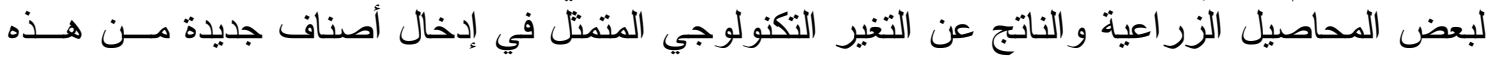
المحاصيل و هذه المعادلة تمنتل كالتالي:

$$
K=\sum\left[\left(1-\frac{Y u \cdot F u}{Y a \cdot F a}\right) \cdot P a\right] \times 100
$$

$$
\begin{aligned}
& \text { حيث: }
\end{aligned}
$$

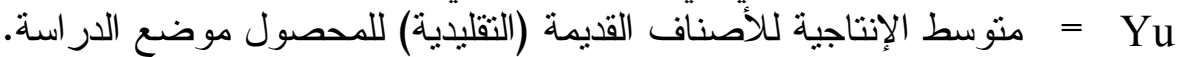

$$
\begin{aligned}
& \text { متوسط الإتتاجية للأصناف المستحدثة للمحصول موضع الدافة استة. }
\end{aligned}
$$

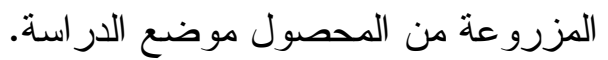

= Fu

= Fa

Pa

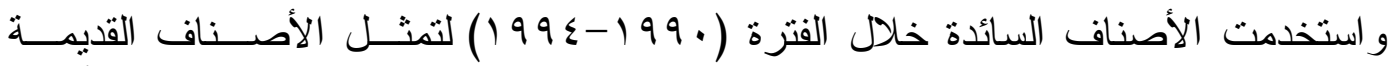

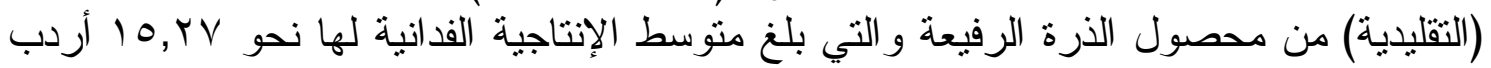

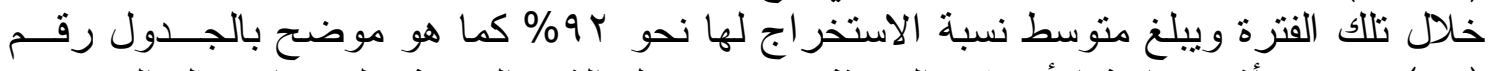

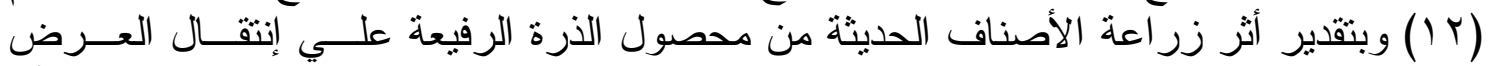

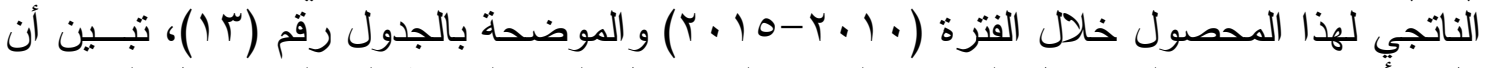

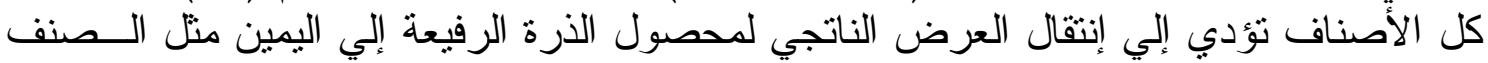

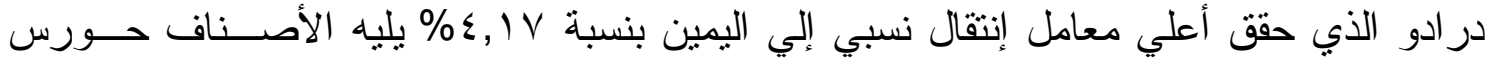

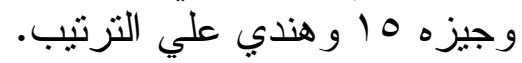


شادية محمد سبي ناصر، باسم دوس حنا دوس، 1 ب مب

جدول رقم r 1. المساحة والإنتاجية لأصناف الأرة الرفيعة السائدة بمحافظة أسـيوط خــلال الفتـرة

\begin{tabular}{|c|c|c|c|c|c|}
\hline \multicolumn{6}{|c|}{.$(199 \leq-199 \cdot)$} \\
\hline Yu.Fu & 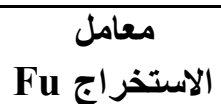 & الإنتاجية & الإتتاج بالأردب & المساحة & الصنف \\
\hline $\begin{array}{c}=(9 r \times 10, r 0) \\
1 \leqslant . \leqslant, \wedge \varepsilon\end{array}$ & $\% 9 r$ & $10, Y V$ & $\leqslant 97 \vee 700$ & TrOTY. & بلدي \\
\hline
\end{tabular}

المصدر: جمعت وحسبت من: وزارة الزر اعة و إستصلاح الأر اضي، مديرية الزر اعة بأسيوط، قسم الإحسـاء، بيانات غير منشورة.

جدول رقم بـ 1 . حساب قيم معادلة التغير التكنولوجي لمحصول الذرة الرفيعة الصيفية بمحافظة أسيوط

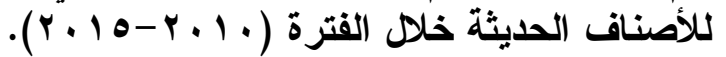

\begin{tabular}{|c|c|c|c|c|c|}
\hline $\mathbf{K}$ & $(\mathbf{Y u . F u}) /($ Ya.Fa $)$ & Ya.Fa & Yu.Fu & $\mathbf{P a}$ & الصنف \\
\hline$\varepsilon, 1 V$ & $\cdot, \wedge \neg$ & $17 r 0,7 \varepsilon$ & $1 \leq \cdot \varepsilon, \wedge \varepsilon$ & $\cdot, r 9 \Lambda$ & در ادو \\
\hline$T, \cdot r$ & $\cdot, 9 \mathrm{~V}$ & $1 \leq \varepsilon 1,7 \leq$ & & व & جيزة 10 \\
\hline r, rᄉ & $\cdot, \wedge \varepsilon$ & $17 \vee 9, \ldots$ & & $\cdot, Y \backslash 1$ & حورس \\
\hline$\cdot, \leqslant 7$ & $\cdot, 9$. & $100 \mathrm{r}, \mathrm{N \Lambda}$ & & $\cdot, \cdot \leq 7$ & هندي \\
\hline
\end{tabular}

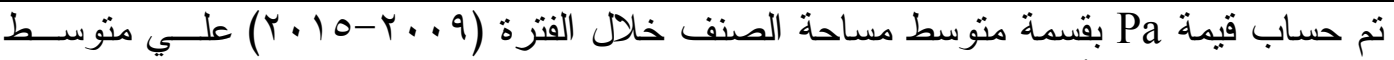

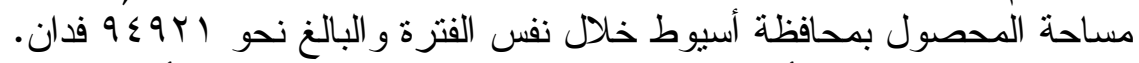

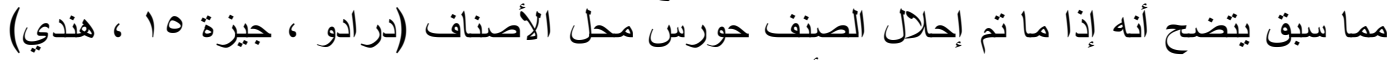

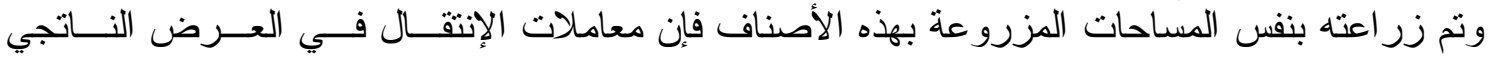

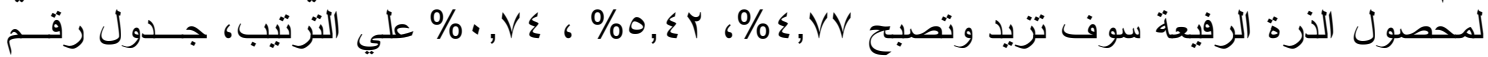

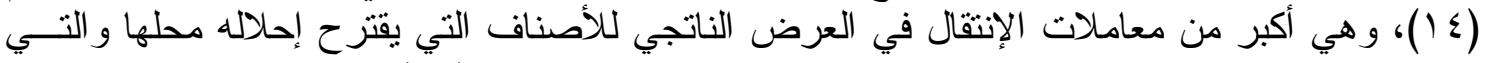

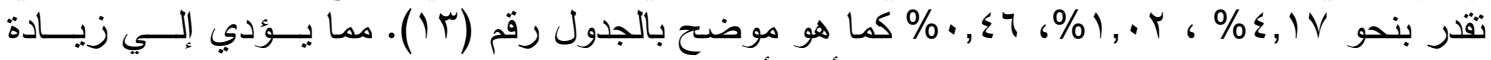

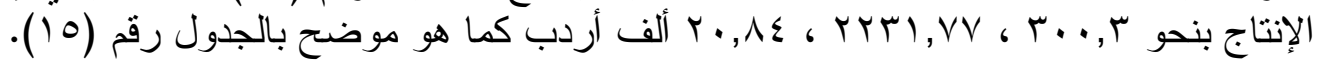

جدول رقم ؟ اـ إحلال الصنف حورس عالي الإتتاجية محل الأصناف منخفضة الإتتاجيـة لمحـصول الأرة الرفيعة بمحافظة أسيوط.

\begin{tabular}{|c|c|c|c|c|c|}
\hline $\mathbf{K}$ & (Yu.Fu)/(Ya.Fa) & Ya.Fa & Yu.Fu & $\mathbf{P a}$ & الصنف \\
\hline$\varepsilon, \vee V$ & $\cdot, \wedge \varepsilon$ & $17 V 9$ & $1 \varepsilon \cdot \varepsilon, \wedge \varepsilon$ & $\cdot, Y q \wedge$ & در ادو \\
\hline $0, \sum Y$ & & & & . & جيزة 10 \\
\hline$\cdot, V \varepsilon$ & & & & $\cdot, \cdot \leq 7$ & هندي \\
\hline
\end{tabular}

المصدر : وز ارة الزر اعة و إستصلاح الأر اضي، مديرية الزر اعة بأسيوط، قسم الإحصاء، بيانات غير منشورة. جدول رقم 10 ـ مقدار الزيادة في الإنتاج لمحصول الأرة الرفيعة بمحافظة أسـيوط لإحسـلال الــصنف

\begin{tabular}{|c|c|c|c|c|}
\hline & & & \multicolumn{2}{|c|}{ حورس محل الأصناف الأخري. } \\
\hline الزيادة في الإنتالفاج) & الفرض بين إنتقال & متوسط الإنتاجية & متوسط المساحة & الصنف \\
\hline$r \cdots, r \cdot$ & $\cdot, 7$ & $1 \mathrm{~V}, 7 \mathrm{~V}$ & rATrO & 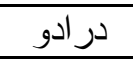 \\
\hline YYTI,VV & $\varepsilon, \varepsilon$. & 10,17 & TYIAE & جيزة 10 \\
\hline$r \cdot, \wedge \Sigma$ & $\cdot, r \wedge$ & $17, \wedge 9$ & $\varepsilon \varepsilon, V$ & هندي \\
\hline
\end{tabular}

المصدر: جمعت وحسبت من: بيانات الجدول رقم (9) و الجدول رقم (rا (1) و الجدول رقم (ع ().

سادساً: تقدير الفاقد من محصول الذرة الرفيعة بعينة البحث بمحافظة أسيوط:

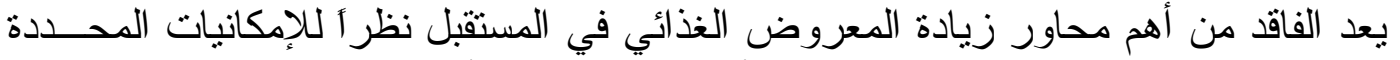
لزيادة الإنتاج الزر اعي عن طريق التوسع في الأر اضي الزر اعية أو عن طريق زيادة الإنتاجيــة 


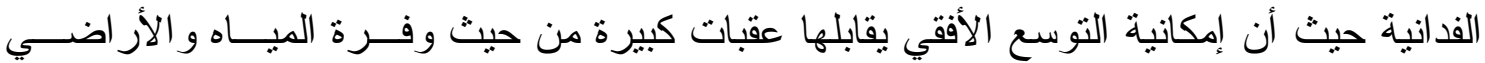

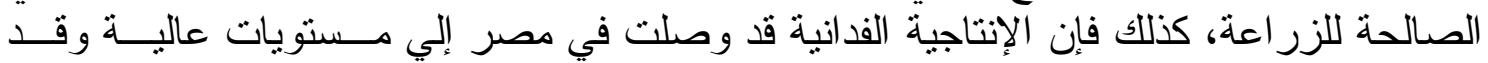

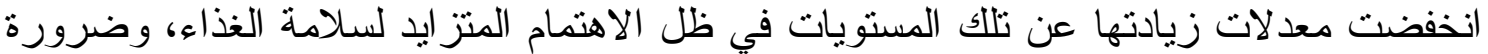
تقليل إستخدام الأسمدة و المبيدات.

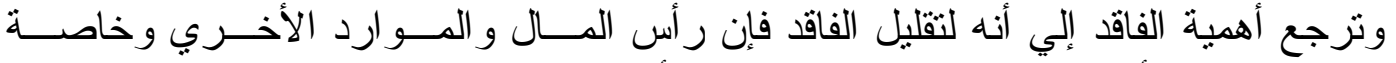

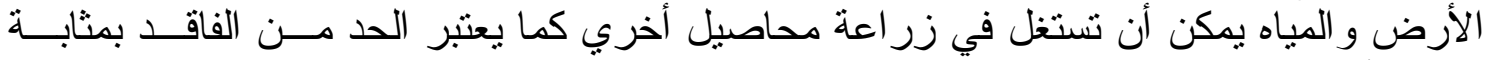
تتمية رأسية بتكاليف محدودة. تقدير الفاقد التسويقي لمحصول الذرة الرفيفة الصيفة الصيفية:

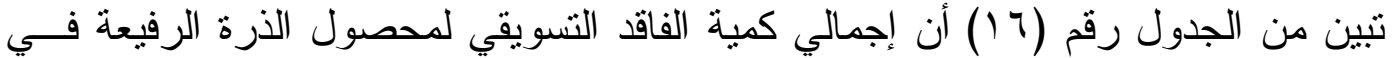

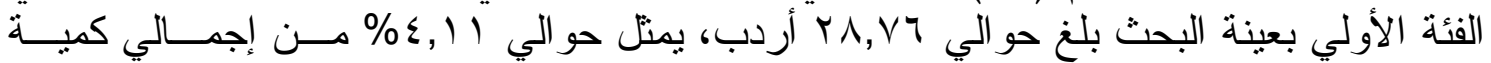

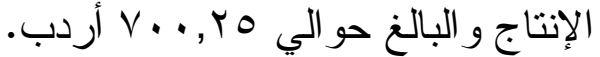

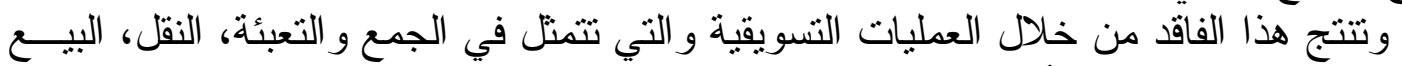

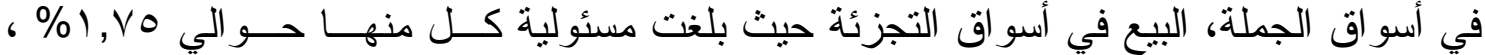

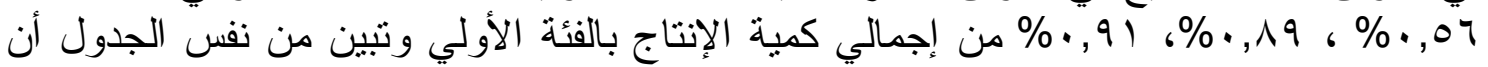

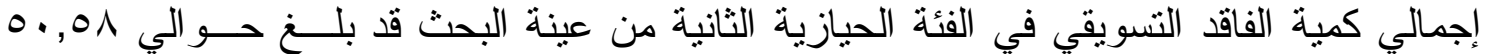

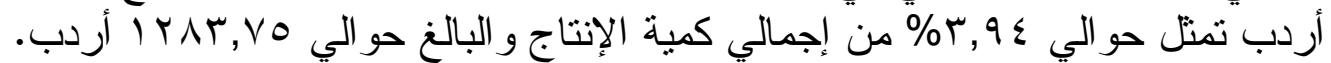

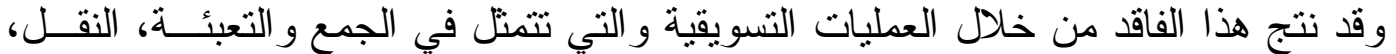

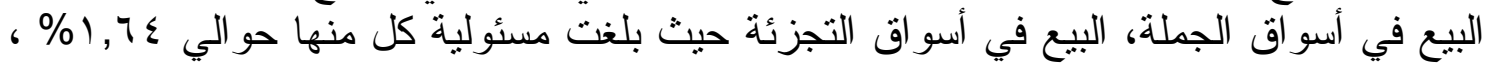

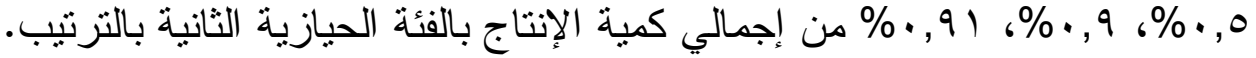

جدول رقم 14 ـ كمية الفاقد التسويقي وأهميته بالنسبة لإجمالي كمية الإنتاج لمحصول الذرة الرفيعـة

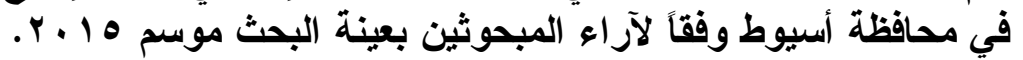

\begin{tabular}{|c|c|c|c|c|c|c|c|c|c|c|c|}
\hline \multirow{2}{*}{\multicolumn{2}{|c|}{ إجمالي كمية الفاقد }} & \multicolumn{8}{|c|}{ الفاقد التسويقي } & \multirow{3}{*}{ (بالإلإتاجية } & \multirow{3}{*}{ الحيازية } \\
\hline & & \multicolumn{2}{|c|}{ البيع في أسواقئة } & \multicolumn{2}{|c|}{ البيع في أسلةواق } & \multicolumn{2}{|c|}{ النقل الن } & \multicolumn{2}{|c|}{ الجمع و التعبئة } & & \\
\hline $\begin{array}{c}\text { \% } \\
\text { (1) }\end{array}$ & أردب & $\begin{array}{l}\text { \% } \\
\text { (1) }\end{array}$ & أردب & $\begin{array}{l}\text { \% } \\
\text { (1) }\end{array}$ & أردب & $\begin{array}{l}\text { \% } \\
\text { (1) }\end{array}$ & أردب & $\begin{array}{c}\text { \% } \\
\text { (1) }\end{array}$ & أردب & & \\
\hline$\varepsilon, 11$ & $Y \Lambda, V 4$ &., 91 & $7, r V$ & $\cdot, 19$ & $7, Y$. &., 07 & $r, q \leqslant$ & 1,10 & TY,YO & $V_{\cdots} \cdot r_{0}$ & الأولى \\
\hline$r, q \leqslant$ & $0 ., 01$ & $\cdot, 91$ & $11,7 \mathrm{~V}$ & $\cdot, 9$ & $11,0$. & $\cdot, 0$. & $7, \S)$ & $1,7 \varepsilon$ & 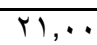 & TKNY,VO & الثَاتِية. \\
\hline$\xi, \cdot \wedge$ & 111,91 & $\cdot, 94$ & $r_{O}, Y_{O}$ & $\cdot, 9$. & $r \varepsilon,\rceil \Lambda$ &., $0 Y$ & $T \varepsilon, r$. & $1, V \varepsilon$ & $\varepsilon \vee, V_{O}$ & 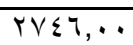 & الثُالثًة \\
\hline$\xi,+\xi$ & $191,1 Y$ & $\cdot, 9 Y$ & $\leqslant r, Y q$ & $\cdot, 9$. & 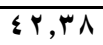 &.,$O Y$ & $r \leqslant, Y 0$ & $1, v 1$ & $11, \ldots$ & $\varepsilon V \Psi \cdot,$. & الإجمالى \\
\hline
\end{tabular}

المصدر: جمعت وحسبت من: بيانات إستمارة الإستيان بعينة البحث بمحافظة أسيوط موسم 10 المب.

من نفس الجدول أيضاً تبين أن كمية الفاقد التسويقي للمحصول بالفئة الحيازية الثالثة بعينة

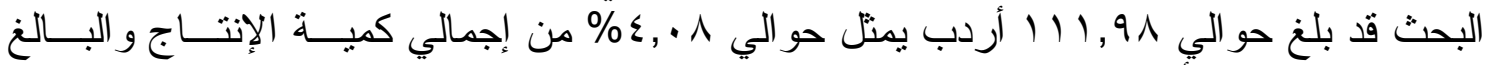

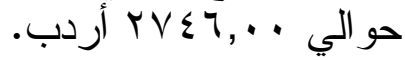

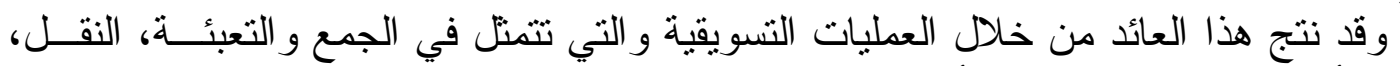

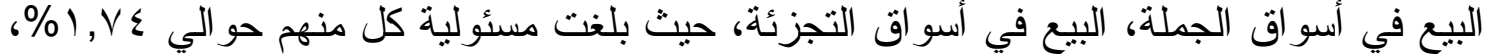


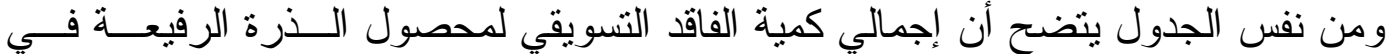

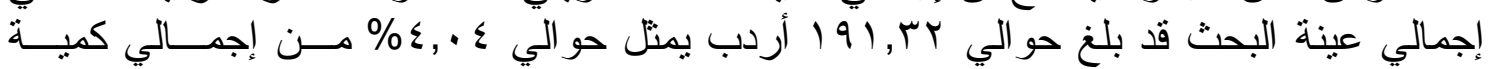

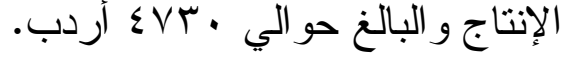




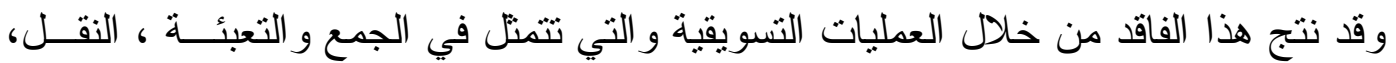

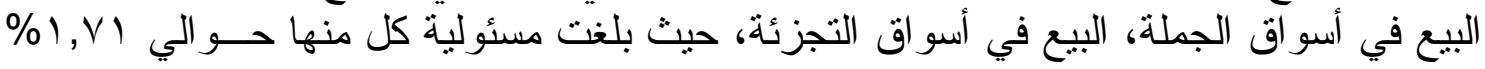

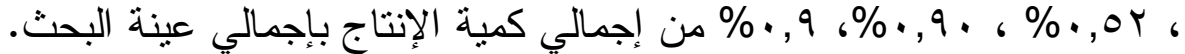
تقدير الآثار الناتجة عن الفاقد:

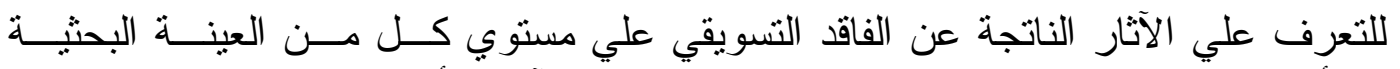

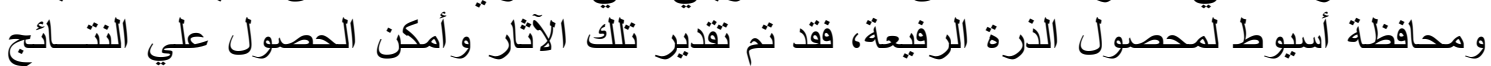

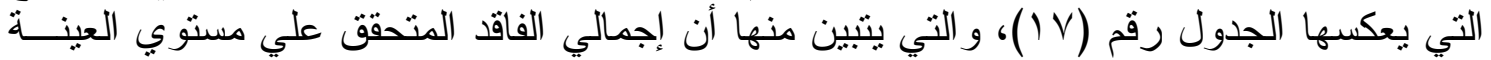

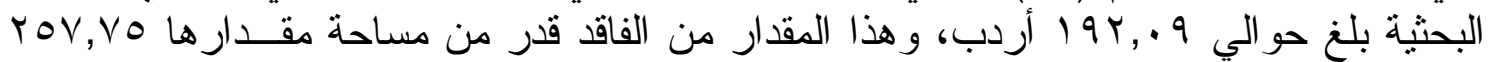

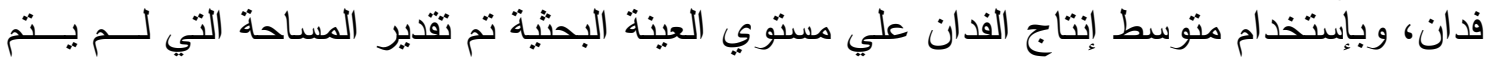

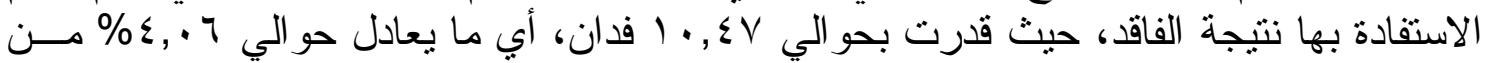

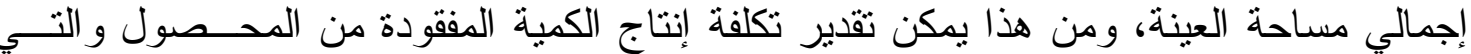

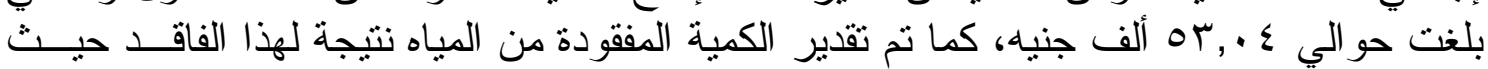
بلغت r •, • مليون متر مكعب.

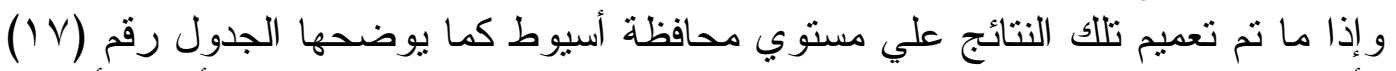

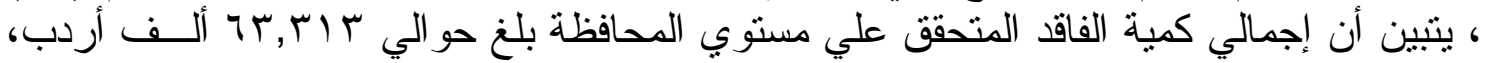
و هذا المقدار من الفاقد قدر من مساحة مقدارها

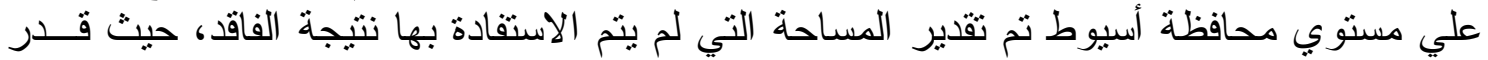

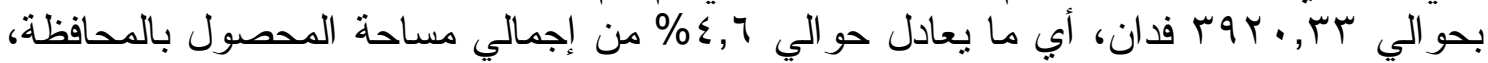

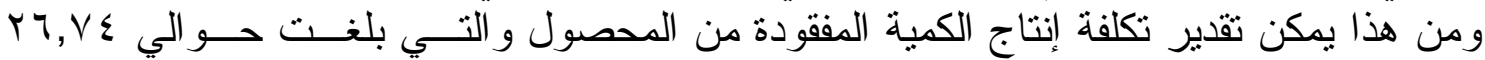

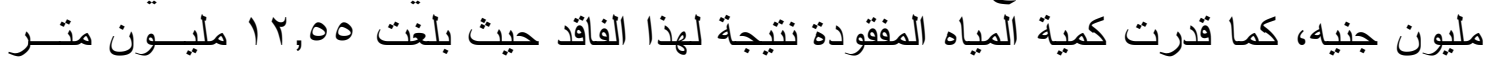
مكعب. 


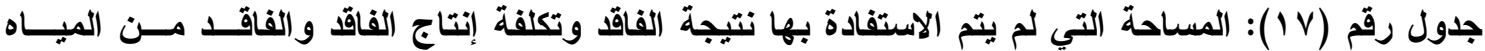

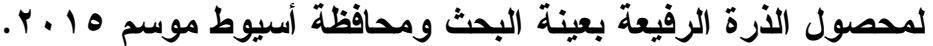

\begin{tabular}{|c|c|c|c|c|c|c|}
\hline فليون مجا المياه & تلفاقدة (أنتاج & 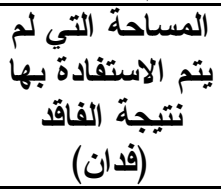 & الفاقدالي كمية (أردب) & إنتاج الفدان) & ألمسالية & المستوي \\
\hline$\cdot, \cdot r$ & $0 \sigma_{,}, \varepsilon$ & $1 \cdot, \leqslant V$ & $19 r, .9$ & $11, r_{0}$ & YOV, VO & العينة البحثية \\
\hline $1 T, 00$ & YTVYד,70 & r & ו & 17,10 & $1 \leqslant 900$ & محافظة \\
\hline
\end{tabular}

المصدر : جمعت وحسبت من بيانات:

1 - إستمارة الإستنيان لعينة البحث.

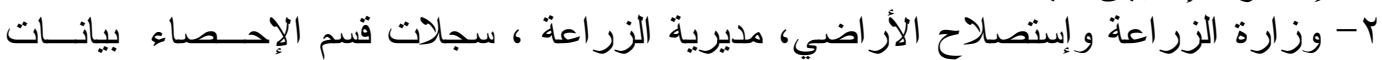

ب- معهد بحوث الأر اضي و المياه، قسم المقنتات المائية، بيانات غير منشورة.

غير منشورة.

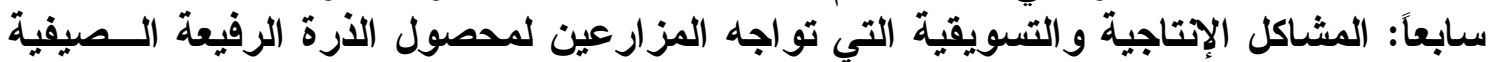

بمحافظة أسيوط:

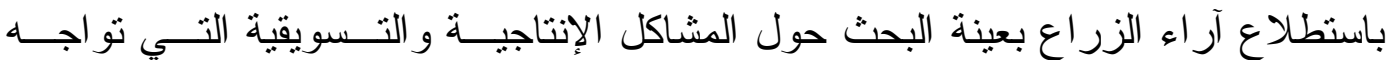

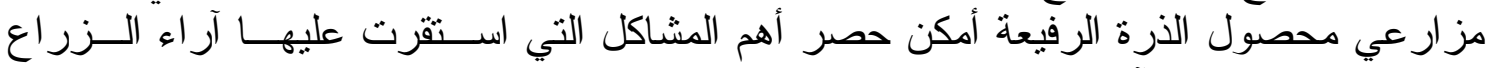

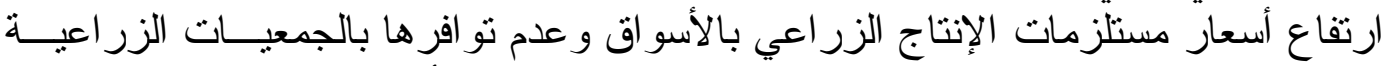

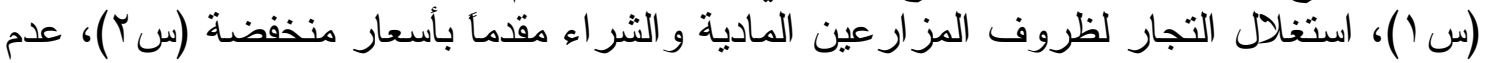

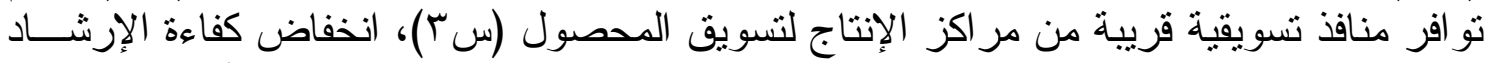

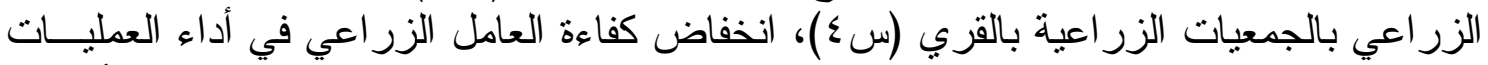

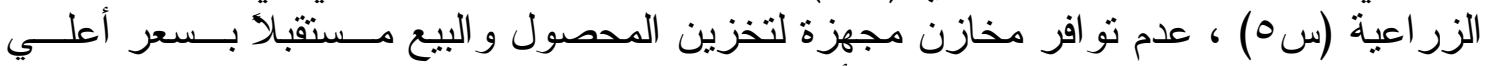

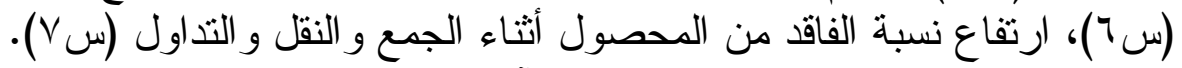

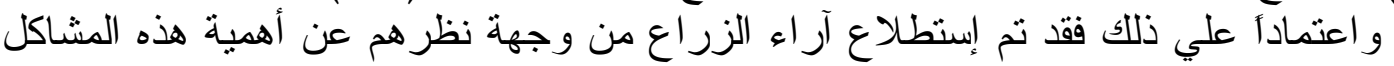

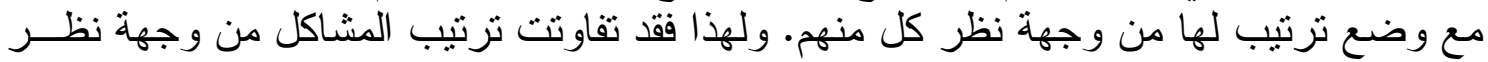

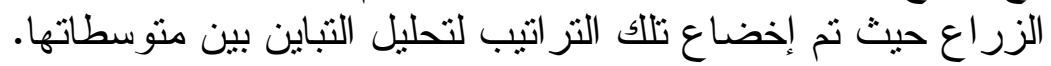

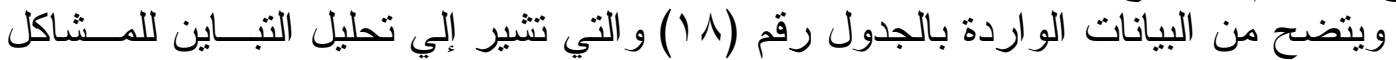

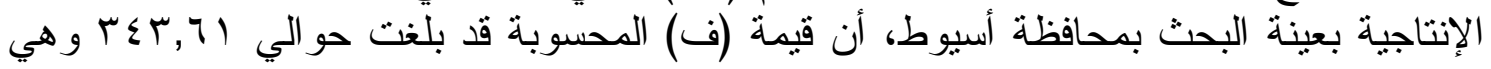

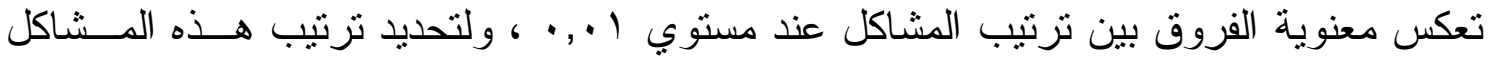

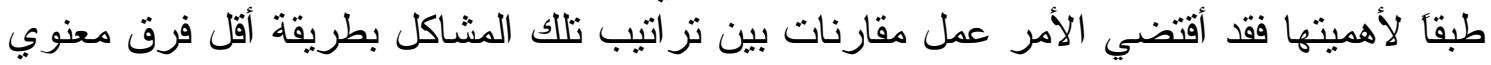
عند مستوي l (+.S.D.)

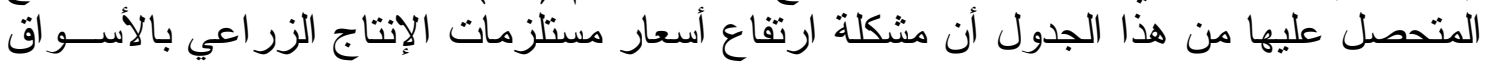

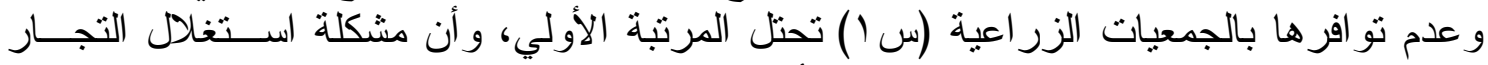

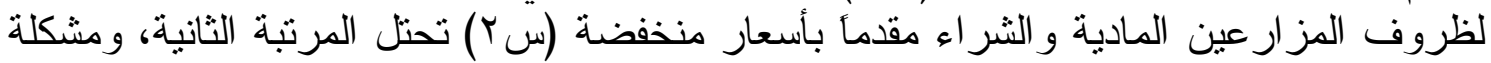

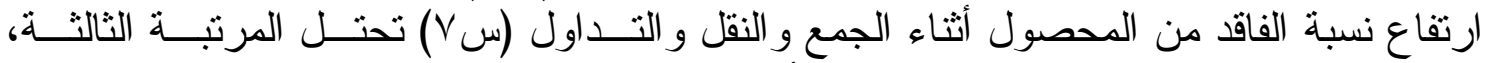

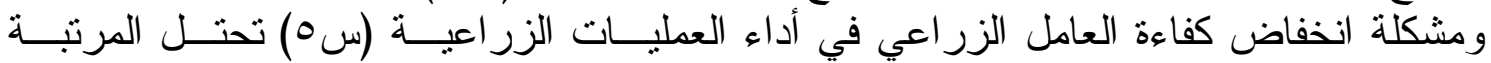

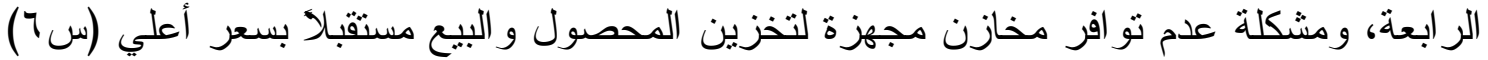

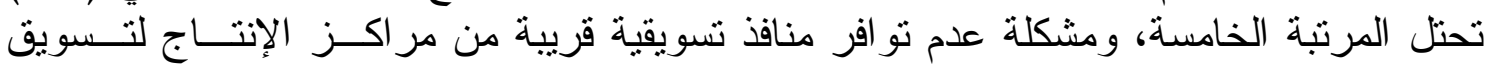

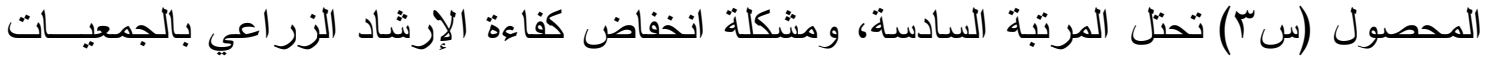
الزر اعية بالقري (سء) تحتل المرتبة السابعة و الأخيرة. 
شادية محمد سيل ناصر، باسم دوس حنا دوس، 7 م

جدول رقم 1^ ا. نتائج تحليل التباين للمشاكل الإنتاجية والتسويقية بعينة البحث بمحافظة أسيوط موسم

.10

\begin{tabular}{|c|c|c|c|c|}
\hline قيمة ف & متوسط مربعات الاحصر افات & درجات الحرية & مجموع المربعات & مصدر الاختلاف \\
\hline \multirow[t]{3}{*}{$* * \Gamma \leq r, T)$} & $\varepsilon 7 \leqslant, 01$ & 7 & TVAV,・r & بين المشاكل \\
\hline & $1, r_{0}$ & $1 \cdot \varepsilon r$ & $1 \leq .9,9 V$ & داخل المشاكل \\
\hline & & $1 \cdot 1 \leqslant 9$ & $\varepsilon 19 \vee, \ldots$ & المجموع \\
\hline
\end{tabular}

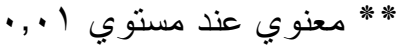

المصدر : جمعت وحسبت من: استمار ات إستبيان عينة البحث موسم 10 ـ ؟.

جدول رقم 9 1. إختبار معنوية الفروق بين المشاكل الإنتاجية والتسويقية بعينة البحث بمحافظة أسيوط موسم

.10

\begin{tabular}{|c|c|c|c|c|c|c|c|c|}
\hline س؛ & سי & سי & س. & س v & سץ & سا & تصاعدياً & المرتبة \\
\hline 7,19 & $0,0 \mathrm{~V}$ & $\varepsilon, \wedge \vee$ & $\varepsilon, \Gamma q$ & $r, 10$ & $r, 17$ & 1,01 & المتوسط & تنازلياً \\
\hline \multirow[t]{7}{*}{ صفر } & $* *{ }^{*}, V Y$ & $* * 1, \leqslant Y$ & $* * 1,9$. & $* * \Psi, 1 \varepsilon$ & $* * \varepsilon, 1 \Gamma$ & $* * \varepsilon, V)$ & $7, Y q$ & س ؛ \\
\hline & صفر & $* *, V \cdot$ & $* * 1,1 \wedge$ & $* * Y, \Sigma Y$ & $* * r, \Sigma)$ & $* * r, q 9$ & $0,0 \mathrm{~V}$ & سب \\
\hline & & صفر & $* *, \_\wedge$ & $* * 1, V Y$ & $* * Y, \vee \backslash$ & $* * r, r q$ & $\varepsilon, \wedge \vee$ & سי \\
\hline & & & صفر & $* * Y, Y \xi$ & $* * Y, Y Y$ & $* * Y, \wedge)$ & $\varepsilon, \Gamma q$ & س.. \\
\hline & & & & صفر & $* *, 99$ & $* * 1,0 \mathrm{~V}$ & $r, 10$ & سلv \\
\hline & & & & & صفر & $* *, 01$ & $r, 17$ & سن \\
\hline & & & & & & صفر & 1,01 & سا \\
\hline
\end{tabular}

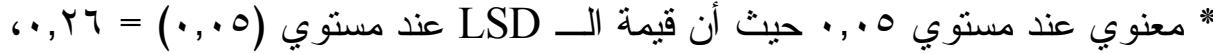

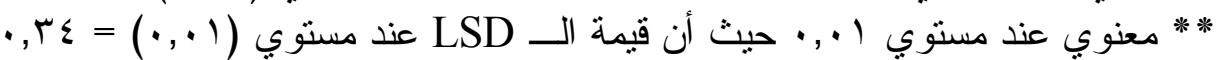

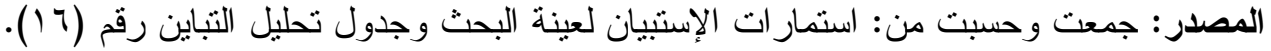

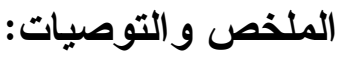

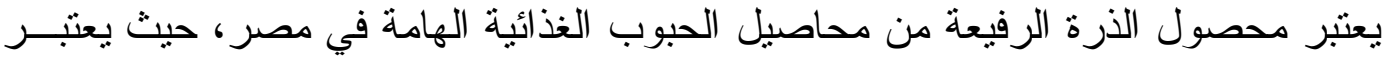

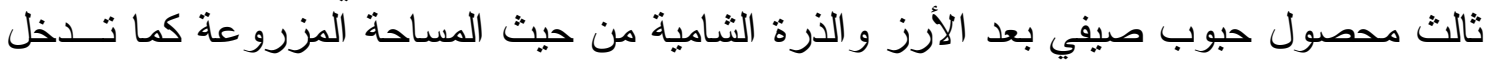
الذرة الرفيعة في صناعة الخبز البلدي وصناعة الأعلاف لتغذية الماثية و الدو اجن.

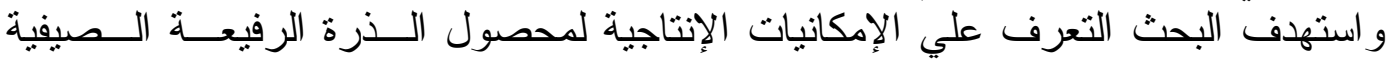

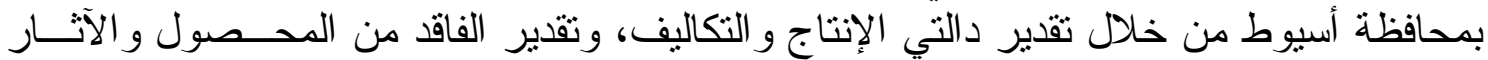

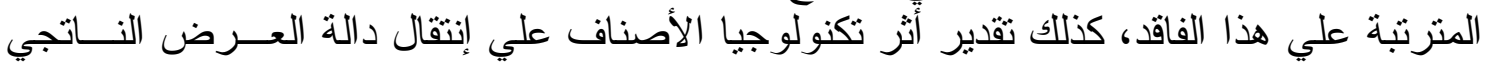
للمحصول. وبتقدير دو ال إنتاج محصول الذرة الرفيعة الصيفية للفئات الإنتاجية الثالاثة و إجمالي العينة

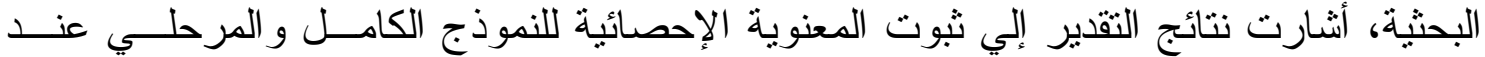

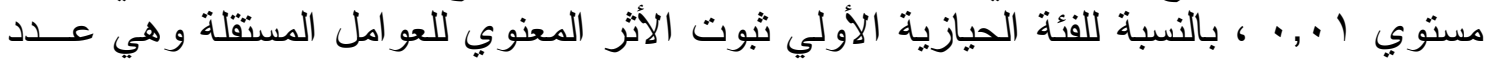

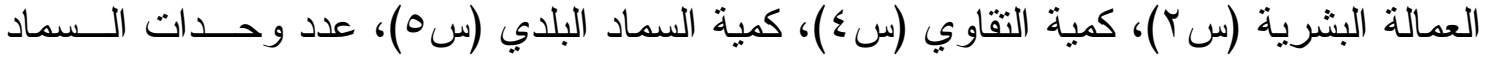

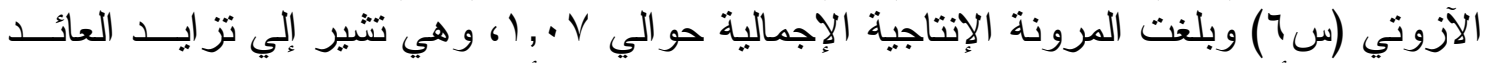

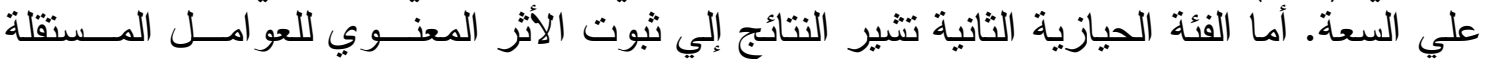

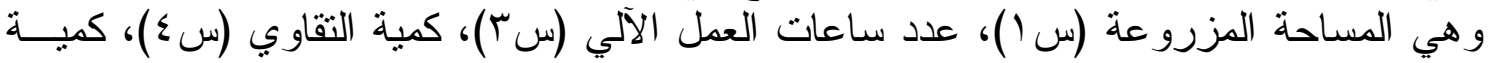

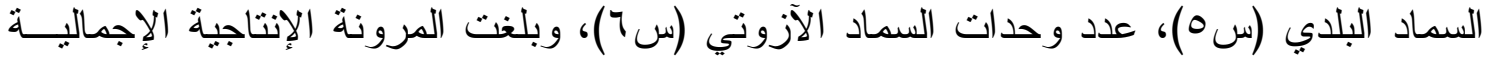

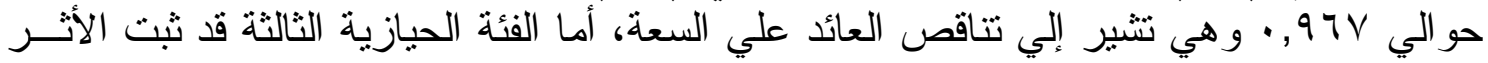

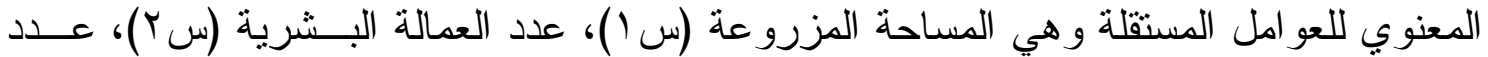

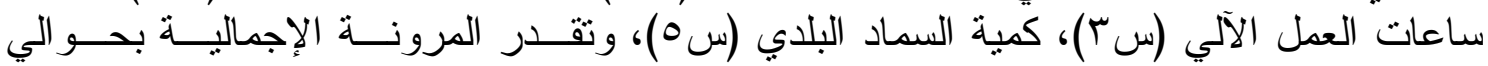




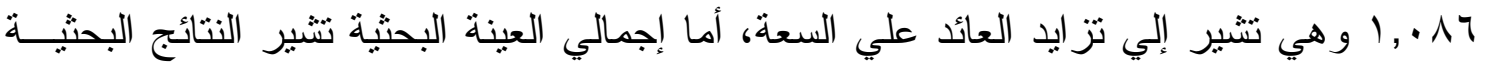

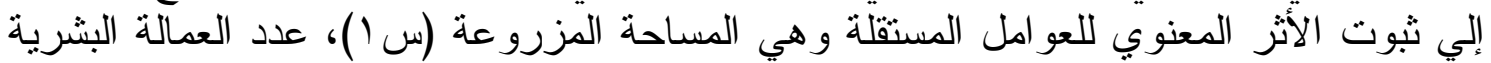

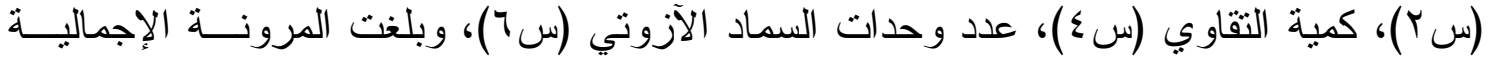

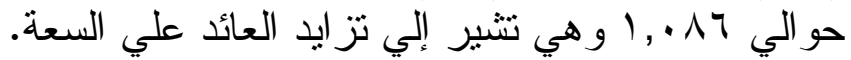

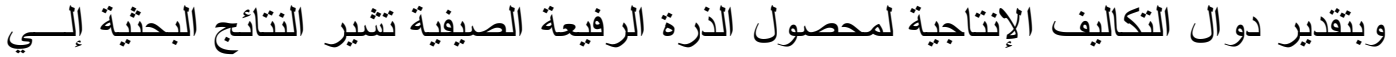

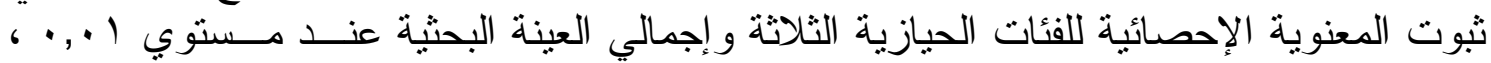

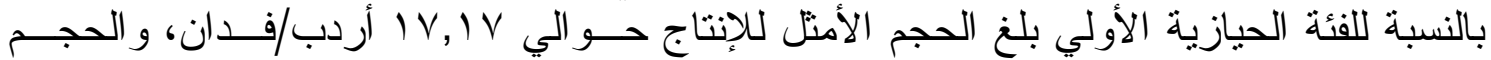

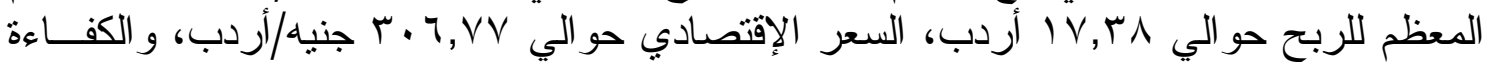

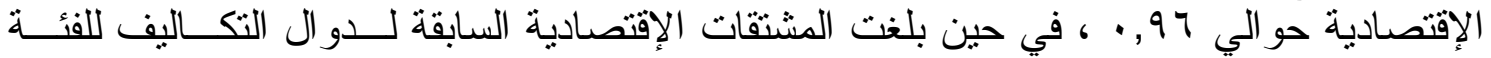

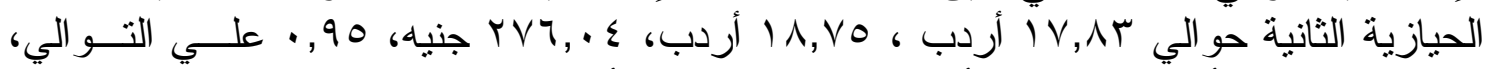

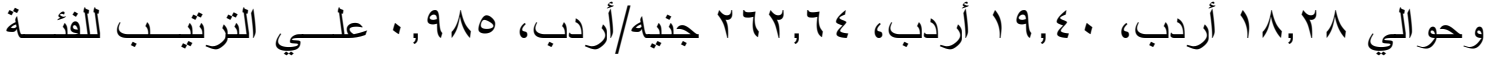

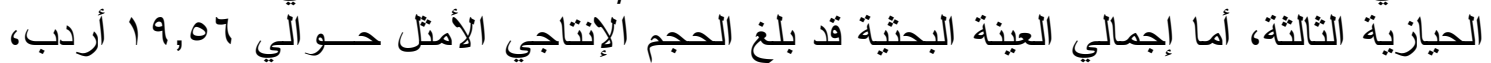

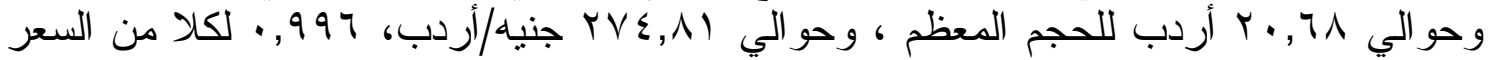
الإقتصادي و الكفاءة الإقتصادية. وبدر اسة أثز زر اعة الأصناف المختلفة لمحصول الذرة الرفيعة تم إجر اء تحليل التباين في

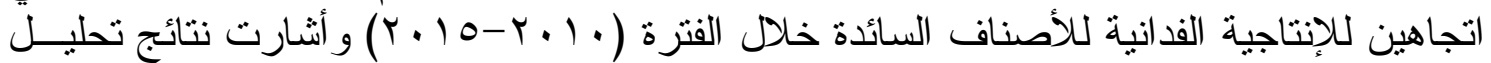

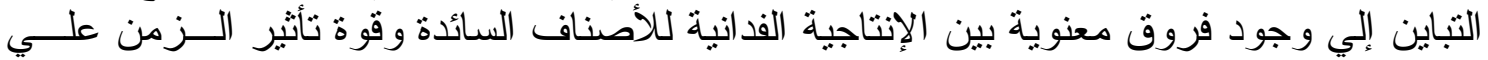

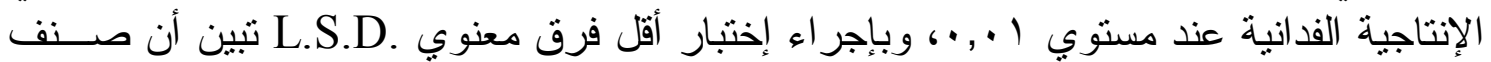

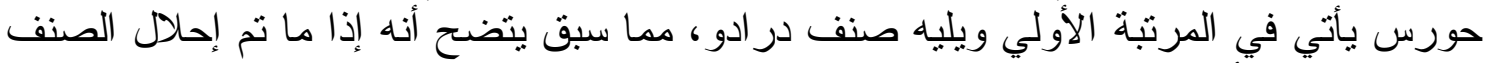

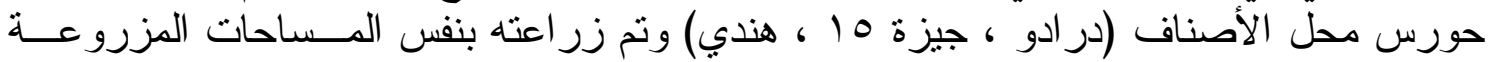

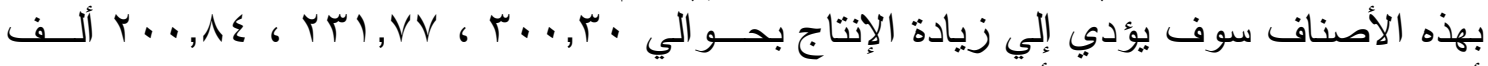
أردب علي مستوي محافظة أسيوط.

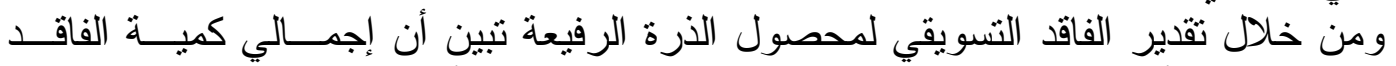

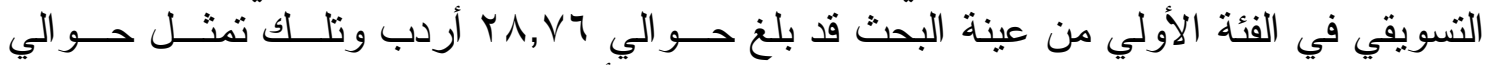

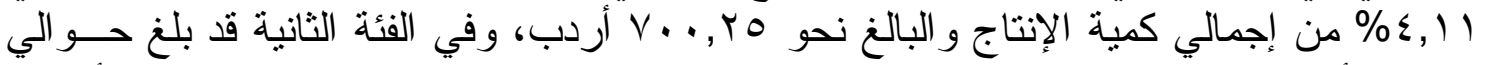

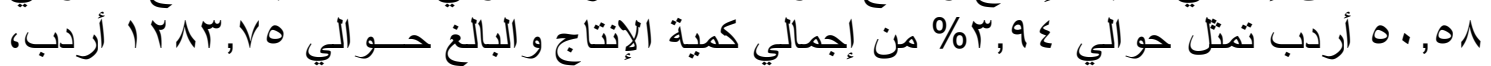

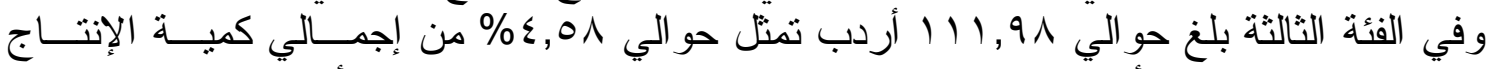

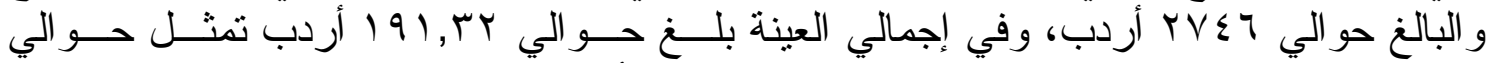

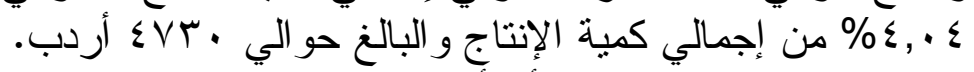

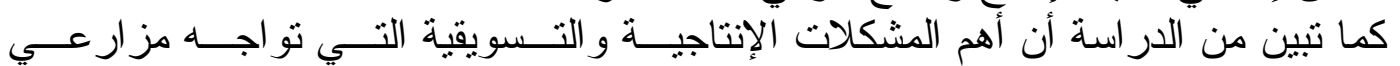

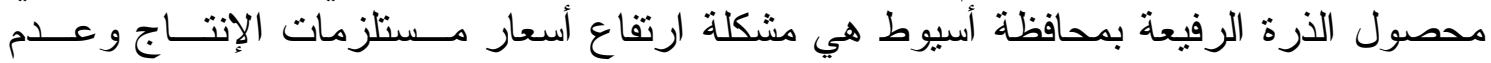

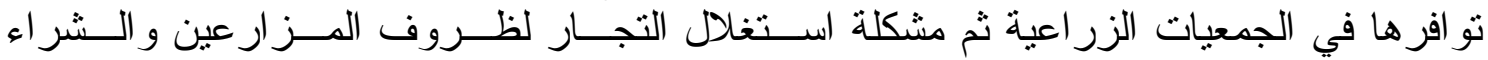

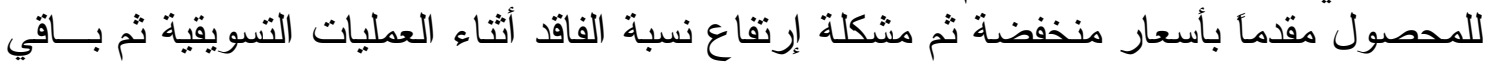

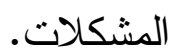
وفي ضو ء ما سبق توصي الدر اسة بالآتي: - - الإهتمام باستتباط أصناف عالية الإنتاجية و الجودة. - ضرورة إحلال الصنف حورس محل الأصناف الأخري وتعميمه علي مستوي المحافظة.

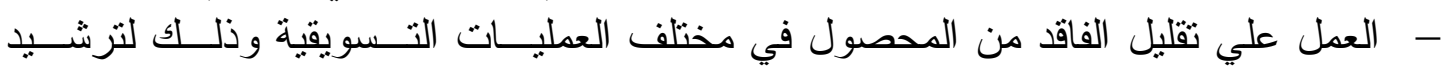
إستهلاك المياه وتقليل التكاليف. 


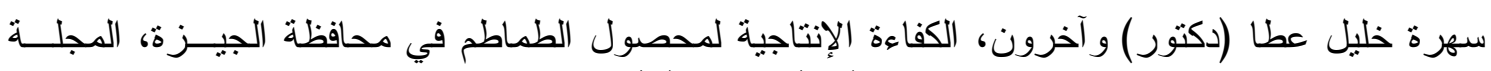

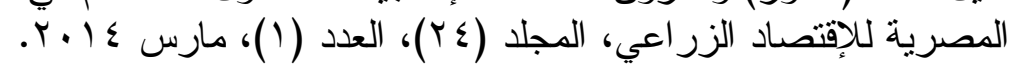

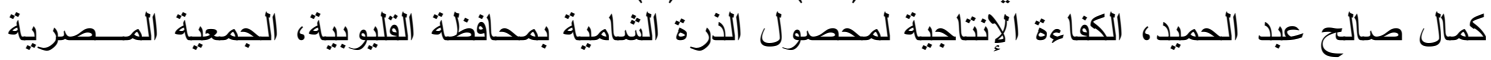

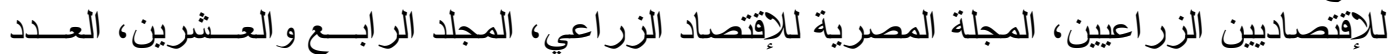

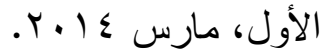

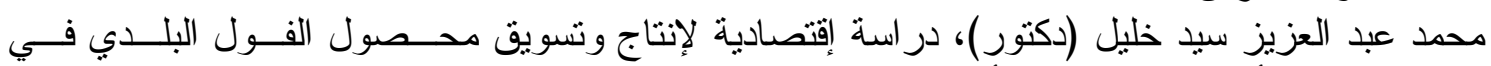

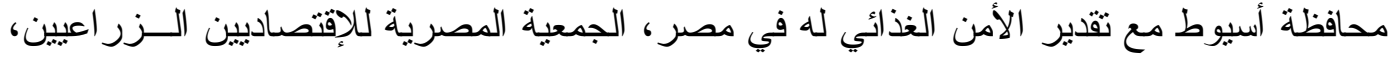

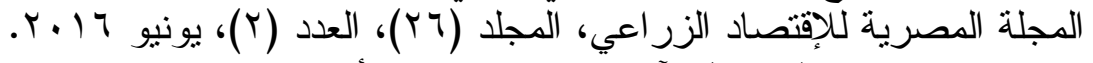

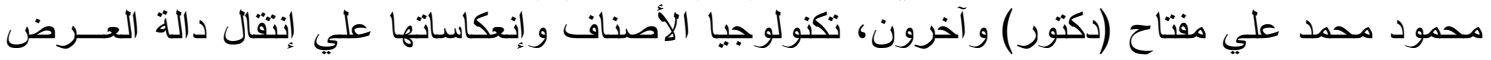

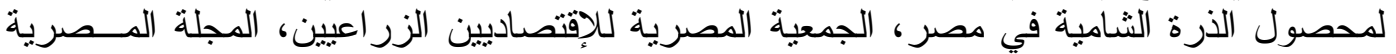

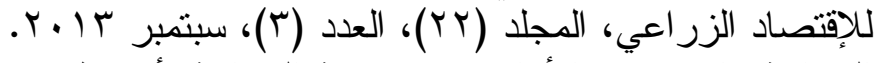

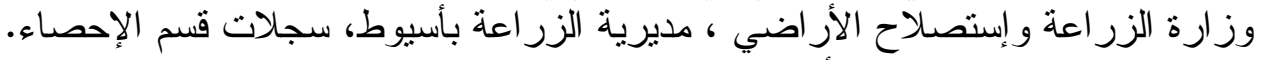

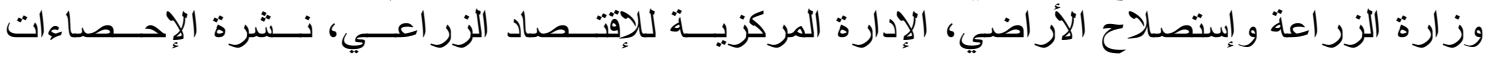

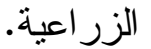

وزارة الزر اعة وإستصلاح الأر اضي، معهد بحوث الأر اضي و المباه، قسم المقننات المائية.

Harry Ayer \& G Edward Schu, Social Rates of Return and other Aspects of Agricultural Research the Case of Cotton Research In Sao Paulo, Brazil. American Journal of Agricultural Economic, Vol. 54, No. 4, Part 1, November 1972. 


\title{
An Economic Study of the Summer Sorghum Crop- Assiut Governorate
}

\author{
Shadia Mohamed Said Nasser and Bassem Doos Hanna Doss
}

Senior Researcher - Agricultural Economy Research Institute

\begin{abstract}
Sorghum is considered one of the most important crops in Egypt, it is considered the third grain summer crop, after rice and corn according to the space of the cultivated area. It is also used in making bread and fodder for animals and poultry. The research is aiming at recognizing the production possibilities of sorghum in Assiut Governorate via estimating the function of production and the cost, also, estimating the effect of Types Technology on the transmitting of the production function of the crop and also estimating the loss from the crop and the consequent effects. The study showed the following results:
\end{abstract}

By estimating the functions of the crops production of the three productive groups and the total of the research sample, the research shows the stability of the morality statistics of the complete pattern and the provisional pattern at level 0.01 .

For the first owners group, the stability of the morality statistics of the independent factors (numbers of labors S2, seeds quality S4, the quantity of fertilizers, number of nitrate fertilizers units S6) and the flexibility of the total productivity reached 1.07 it indicates the increase of the revenue on capacity. The results of the second owners group refers to the stability of the moral effect of the independent factors which is the cultivated land S1. The number of labors hands, number of automatic labor hours (S3) and the quantity of the fertilizers (S5). The total of research sample refers to the stability of the moral effect of the independent factors which are the cultivated land (S1), the number of the labor hands (S2), the quantity of the seed (S4), the number of the nitrate fertilizers (S6); the flexibility of the total production is 1.086 and it refers to the increase in the revenue capacity.

By evaluating the production cost functions of the summer sorghum, the research results indicate to the stability of the statistical morality of the three owners groups, and that the total research sample is at the level of 0.01 . According to the first owners group, the optimum volume of the production amounted 17.17 Ardeb/Feddan, the maximum volume of the profit is about 306.77 L.E./Ardeb, and the economical efficiency is about 0.96. Meanwhile, the previous economical derivatives of cost functions of the second owners group amounted 17.83 Ardeb, 18.75 Ardeb, 0.95, 276.04, respectively, and the third owners group amounted 18.28 Ardeb, 19.40 Ardeb, 262.64 L.E./Ardeb, 0.980 respectively. As regards the total research sample, the optimum volume of production amounted 19.56 Ardeb, about 20.68 Ardeb for the maximum volume, about 274.83 L.E. and 0.996 for both of the economical price and efficiency.

The study recommends the following:

* The necessity of replacing Horus products with the other products and generalizing it on the level of the governorate.

* Aiming at reducing the crop loss in the various marketing operations and this is for rationalizing the water consumption and reducing costs. 